

\section{Management of arthritis patients after functional deterioration}

Yvette Bulthuis 
Thesis, University of Twente, 2010

ISBN: 978-90-365-3107-8

(C) Yvette Bulthuis

Printed by: Ipskamp Drukkers

The studies described in this thesis were financially supported by the National Health Service RVVZ (Centraal Fonds Reserves Voormalige Vrijwillige Ziekenfondsverzekering) and St. Reuma onderzoek Twente.

Publication of this thesis was financially supported by the Dutch Arthritis Association (Reumafonds), Medisch Spectrum Twente and Stichting Residentiële en Ambulante Zorg. 


\title{
MANAGEMENT OF ARTHRITIS PATIENTS AFTER FUNCTIONAL DETERIORATION
}

\section{PROEFSCHRIFT}

\author{
Ter verkrijging van \\ de graad van doctor aan de Universiteit Twente, \\ op gezag van de rector magnificus, \\ Prof. dr. H. Brinksma, \\ volgens besluit van het College voor Promoties \\ in het openbaar te verdedigen \\ op donderdag 25 november 2010 om 16.45
}

door

Yvette Bulthuis

geboren op 11 mei 1974

te Losser 
Dit proefschrift is goedgekeurd door de promotor:

Prof. dr. M.A.F.J. van de Laar. 


\section{Promotiecommissie:}

\section{Promotor:}

Prof. dr. M.A.F.J. van de Laar

\section{Assistent-promotor:}

Dr. K.W. Drossaers-Bakker

\section{Leden:}

Prof. dr. J.M.J.P van der Linden, Universiteit Maastricht

Prof. dr. R.G.H.H. Nelissen, Universiteit Leiden

Prof. dr. M.W.G. Nijhuis-van der Sanden, Universiteit Nijmegen

Prof. dr. J.A.M. van der Palen, Universiteit Twente

Prof. dr. J.J. Rasker, Universiteit Twente

Prof. dr. J.S. Rietman, Universiteit Twente 



\section{CONTENTS}

Chapter 1 General Introduction 9

Chapter 2 Disease process, consequences and physical therapy for 21 arthritis patients

Chapter 3 Arm crank ergometer is reliable and valid for measuring aerobic capacity during sub-maximal exercise.

J Strength Cond Res 2010;24(10):2809-2815

Chapter 4 Arthritis patients show long-term benefits from 3 weeks intensive exercise training directly following hospital discharge. Results of the DAPPER (Disabled Arthritis Patients Post-hospitalization intensive Exercise Rehabilitation) study.

Rheumatology 2007;46:1712-1717

Chapter 5 Cost-effectiveness of intensive exercise therapy directly following hospital discharge in patients with arthritis: Results of a randomized controlled clinical trial. Arthritis Care \& Research 2008;59(2):247-254

Chapter 6 Patients with impairment of multiple joints after a total joint replacement benefit from three weeks' intensive exercise training directly following hospital discharge.

Submitted for publication

Chapter 7 Summary and general conclusion

Chapter 8 Samenvatting en algemene conclusie 



\section{Chapter 1}

General Introduction 
Rheumatoid arthritis (RA) is a chronic systemic inflammatory disorder of unknown etiology that primarily involves joints. This disabling disease is characterized by symmetric erosive polyarthritis; inflammation of joints and joint tissues. ${ }^{1}$ In many cases resulting in progressive disability. ${ }^{2}$ RA has an unpredictable course, often with periods of exacerbations and less frequently true remissions. ${ }^{3-7}$

Osteoarthritis $(\mathrm{OA})$ is a chronic degenerative disorder of multi-factorial etiology, which can affect multiple joints. ${ }^{8}$ The knees and hips are among the most commonly affected joints. In pathological terms, $\mathrm{OA}$ is described as a condition of cartilage degeneration, stiffening of the underlying subchondral bone (sclerosis), and active new bone formation (osteophytes).6,9-11

In later stages of RA and $\mathrm{OA}$, the pathological changes in bone and cartilage are followed by changes in other tissues of the joint itself and the surrounding ligaments and muscles. This may lead to instability of the joint, and muscle atrophy. ${ }^{12-15}$ These changes will often result in functional disability and decreased quality of life.

When daily activities are intensive and burdensome, and pain becomes unbearable, hospitalization may be necessary. In case of serious inflammation of joints, hospital admission may be necessary to reduce disease activity and prevent further damage to the joint. When a joint is severely damaged by OA or RA, the joint can be replaced with an artificial joint.

\section{MANAGEMENT OF ACTIVE RA PATIENTS}

Until the 1970s, therapeutic options were limited and hospitalization for rest and immobilization was viewed as a mainstay of medical treatment for rheumatic diseases. ${ }^{16-18}$ Centers for rheumatic diseases were developed in order to provide care. Parallel to the growth of these centers, treatment options of rheumatic diseases improved dramatically. The emphasis shifted from care (rehabilitation and physical modalities) to cure (pharmacotherapy), aimed at suppressing disease activity. As a result, the duration of intramural treatment decreased from an average of two to three months to approximately two weeks. ${ }^{19-21}$ Moreover, the number of admitted patients decreased dramatically.

At present, active RA is treated quickly and effectively with (multiple) drugs.22 Due to improved medication and tight control, joint damage and joint destruction may be prevented in a majority of patients.6,23 Beside pharmacotherapeutic 
developments, exercise therapy has been shown to offer a valuable contribution to preserving function, without negative effects on disease activity. ${ }^{24,25}$

With each hospital stay for an exacerbation of RA, deterioration of physical condition and function is inevitable. Obviously, it is mandatory to continue physical exercise both during and after hospitalization, to further facilitate fast and optimal recovery. Therefore, successful treatment of a disease flare in RA does not only depend on effective pharmacotherapy during hospitalization, but also on the revalidation afterwards. ${ }^{26}$

Several studies have shown that in-patient treatment is more efficient than outpatient treatment. ${ }^{25,27,28}$ Although some research has been reported on intensive training for RA patients during the in-patient period, little is known about intensive training immediately after hospitalization for a disease flare. Most studies have focused on early and stable RA, with training programs varying in exercise forms, intensity, frequency and duration.

Based on the positive results of in-patient treatment and the increasing demand for cost reduction in health care, intensive exercise therapy similar to the in-patient setting, but in an extramural resort seems an interesting option to reduce costs and improve physical function and quality of life of RA patients.

\section{MANAGEMENT OF TOTAL JOINT REPLACEMENTS}

In the early 1960s, after many years of developments of materials and techniques, surgeon Sir John Charnley was the first to perform a total hip arthroplasty (THA) with a prosthesis that would serve as the basis for modern prosthetic replacements. ${ }^{29,30}$ By the end of that decade, the modern total knee arthroplasty (TKA) was pioneered in Charnley's laboratory by Frank Gunston. ${ }^{29,30}$ Since then, many different shapes, sizes and designs of hip and knee prostheses have been developed. Because of these improvements, THA and TKA can now be performed in patients who previously would not have been considered as candidates for surgery, including younger individuals, the very elderly, and those with multiple comorbidities. $^{31}$

At present, the most commonly performed joint surgeries are THA and TKA. The 15-year survival rate for hip and knee prostheses are around 95\%.23 Total hip and knee arthroplasties have proven to be the most successful surgical interventions aiming to reduce pain and restoring physical function in people with arthritis. ${ }^{32}$ 
In the Netherlands, as in other Western countries, in the coming decades the numbers of elderly will increase both relatively and absolutely. As a result, an increase is predicted in the demand for THAs and TKAs. Effectiveness of these procedures is therefore warranted. The use of these clinical pathways have been shown to be successful in reducing costs and length of hospital stay, without compromising the outcome..$^{33-36}$

However, these clinical pathways are only appropriate for physically fit patients without comorbidities undergoing primary elective arthroplasty with minimal risk of complications or failure. ${ }^{37}$ Patients who are expected to have an extended hospital stay are not included. Examples of these patient categories are: 1) a revision, hip fracture or bi-articular surgery, 2) patients with various comorbidities, 3) psychological disorders and/or 4) reduced general functionality. In these patients recovery is slower and they have a higher risk of infections and other complications. ${ }^{38-40}$

Each joint surgery procedure is related to deterioration of physical condition and function. It is important to continue physical exercise whenever possible, during and after hospitalization, aiming at a fast and optimal recovery. Therefore, Ouellet et all ${ }^{41}$ emphasized the need for more careful follow up and intensive rehabilitation programs in the first month following TKA.

\section{INACTIVITY AND EXERCISE IN ARTHRITIS PATIENTS}

In case of total joint replacement and for some RA flares, hospital admission is inevitable. Immobility, preceding and during hospitalization, leads to loss of muscle strength and decrease in mobility of joints, resulting in limited physical functioning and condition. Classical post-operative physical therapy may not promote the patients' maximal recovery. The rather limited daily physical activities of patients after THA may lead to further deterioration of physical condition. ${ }^{42}$ This situation has a strong negative influence on the patients' health status and quality of life. A deterioration was seen among patients who underwent revision surgery. 40

Physical disability is a major adverse health outcome which is associated with aging. Older adults with preclinical functional changes, and hospitalized persons, are at particularly high risk of becoming disabled or experiencing progression of disability. ${ }^{43}$ 
An increasing number of studies show the positive effects of exercise therapy in patients with chronic musculoskeletal diseases. ${ }^{44}$ For both RA and OA it has been shown that training muscle strength and/or aerobic capacity reduces pain, ${ }^{45-50}$ increases bone density, 51 improves muscle strength 24,49,52,53 and improves physical condition. ${ }^{48,52,54-56}$ In some cases, an improvement in functionality was also observed. ${ }^{48-50,54,57,58}$

The necessity for rehabilitation increases parallel to the reduced length of hospital stay. The literature indicates that shortening the hospital stay will increase the number of visits to the general practitioner and physical therapist after hospitalization. ${ }^{59}$ Retarded functional recovery during hospitalization will threaten early discharge. In these cases, patients may go to a nursing home or comparable facilities. A fast recovery of function and physical condition is necessary for optimal functioning. We hypothesize that an intensive, dedicated, short training program in an extramural in-patient setting like a resort or hotel, immediately after hospitalization could lead to a fast and effective restoration of functional capacity in these patients.

Expected advantages are: a) full focus on improving mobility, strength, physical conditioning and functioning; b) minimize doubt and anxiety through opportunities for answering questions; c) minimize burden of care for the family; d) reduce length of hospitalization; e) therapy engagement guaranteed, due to in-patient stay; f) reduced costs.

Requisites for an extramural in-patients setting are: a) resort, residence or hotel function; b) full board service and resting facilities; c) trainings facilities, such as fitness room, swimming pool, stairs etc.; d) presence of a caretaker; e) 24-hour availability of a nurse and medical doctor; f) alarm system in bedroom and bathroom; g) daily exercise therapy by a physiotherapist; h) patient education facilities.

There is consistent evidence that regular graded therapeutic exercise provides at least a short-term benefit for patients with arthritis. ${ }^{44}$ However, the effectiveness of exercise training has been studied mainly in stable RA or OA patients. Obviously, there are differences between the exercise programs regarding intensity, contents, duration, focus, and treatment delivery. Most training programs have durations of at least three months with a trainings intensity of twice a week. Only a few studies describe the effects of training after hospitalization. For example, Vliet Vlieland 60 
focused on in-patient care for RA patients. There have been no studies specifically on RA patients starting an intensive training program directly after an exacerbation of their RA. In THA and TKA patients, the focus has been on the differences between group-based or at-home physiotherapy but not specifically on an intensive training following discharge from the hospital.

Most short-term studies on exercise therapies did not demonstrate the desired effect. Reasons for these results include insufficient intensity of therapy engagement.

Despite limited evidence for the effects of short-term exercise therapy in an outpatient setting for arthritis patients, we expect that an intensive intervention of maximal three weeks immediately following a hospital stay should be sufficient to demonstrate the effect of training. We assume that an intensive program of at least five times a week and twice daily with a training intensity of at least $60 \%$ of the maximal heart rate, should be sufficient to recover a patient's ability to perform their daily activities independently. Three weeks of intensive training in a resort directly following hospitalization should have a positive influence on the recovery of this target group for both short-term and long-term effects.

\section{SCOPE AND AIM OF THE THESIS}

This thesis presents the results of a randomized controlled trial. It concerns disabled patients with rheumatoid arthritis or severe osteoarthritis, leading to hospitalization for either a disease flare or for a total hip or knee arthroplasty. Usual care was compared with a short 'in-patient rehabilitation program' immediately after hospital discharge, carried out in a resort by physical therapists. This so-called DAPPER study was conducted between July 2002 and January 2004 (DAPPER: Disabled Arthritis Patients Post-hospitalization intensive Exercise Rehabilitation).

This thesis aims to provide insight into measuring physical improvement and to investigate the effects of three weeks of intensive exercise training in arthritis patients immediately following hospitalization. Study questions include: 'Does intensive training reduce pain and disability, improve mobility, functional ability, aerobic capacity and health related quality of life for the short and long-term?' 
Due to increasing number of elderly over the next decades and the need to reduce the general health costs, this thesis also focuses on the cost-effectiveness of extramural treatment following hospitalization.

\section{OUTLINE OF THE THESIS}

Chapter 2 provides a theoretical framework for, on the one hand, RA and OA, and on the other hand, their treatment. These include: the consequences of the disease for arthritis patients, the underlying mechanisms of improvement and deterioration of the disablement process, the influence of patient education in combination with self-efficacy and self-management, the management of rheumatic diseases, the physiological background of exercise therapy, the effects of training and recommendations for training with arthritis patients. Finally, we describe the optimal training program for arthritis patients with reduced function who have been hospitalized for an exacerbation of their RA or for an arthroplasty.

Measuring physical fitness becomes increasingly important to assess changes in physical function. Most sub-maximal tests depend upon the function of the lower extremities. For patients with limitations of the lower extremities a method of measuring the aerobic capacity using the upper extremities is warranted. In Chapter 3, we describe our investigations into the reliability of an adapted submaximal arm crank ergometer test. Different comparisons were made between adapted sub-maximal tests on an arm crank and a bicycle ergometer. We also compared the sub-maximal test for the arm crank ergometer to the more common bicycle ergometer.

Chapter 4 presents the results of the randomized clinical DAPPER trial. This study concerns the efficacy of three weeks intensive exercise training (IET) directly following hospital discharge. Patients with rheumatoid arthritis or osteoarthritis were eligible when hospitalized for either a disease flare or elective hip- or knee arthroplasty. As soon as the medical condition of the patient allowed discharge from the hospital, the IET patients went to a dedicated resort for three weeks of intensive exercise therapy. This resort offers hotel facilities and professional care for disabled people. The control group was treated with the usual care (UC). The outcomes were assessment of range of motion (ROM), disability, and healthrelated quality of life (HRQoL) on several moments in time with a total follow-up period of one year. 
There is limited information on costs and cost-effectiveness of care following hospitalization of arthritis patients. Chapter 5 describes the cost-effectiveness analyses, which were performed parallel to the DAPPER study. Cost as well as utilities and outcomes were collected over a period of one year. Analysis were performed using the societal perspective. We estimated the cost-utility and costeffectiveness of the three weeks intensive exercise training program directly following hospital discharge compared to usual care in arthritis patients.

Since rehabilitation after elective joint surgery is a frequent and important healthcare issue, in Chapter 6, we conducted an additional analysis of the DAPPER study data. The efficacy of the three weeks' intensive exercise training was examined in the subgroup of patients with elective hip or knee arthroplasty. The previously described intervention group was compared with the control group. Repeated measurement analyses were performed with outcomes (i.e. ROM, disability, pain and HRQoL) assessed at baseline during hospital stay and follow-up during a period of one year.

This thesis ends with a summary and general conclusion in Chapter 7. 


\section{REFERENCES}

1. Hochberg MC, Silman AJ, Smolen JS, Weinblatt ME, Weisman MH. Rheumatoid Arthritis. Philadelphia, Mosby Elsevier, 2009.

2. Firestein GS, Budd RC, Harris Jr. ED, McInnes IB, Ruddy S, Sergent JS. Kelly's Textbook of Rheumatology, volume II, 8th edition, Saunders Elsevier, 2009.

3. Hill J, Cairns E, Bell DA. The joy of citrulline: new insights into the diagnosis, pathogenesis, and treatment of rheumatoid arthritis [editorial]. J Rheumatol 2004;31:1471-3.

4. Jenkins JK, Hardy KJ, McMurray RW. The pathogenesis of rheumatoid arthritis: a guide to therapy. Am J Med Sci 2002;323:171-80.

5. Tak PP, Bresnihan B. The pathogenesis and prevention of joint damage in rheumatoid arthritis: advances from synovial biopsy and tissue analysis. Arthritis Rheum 2000;43:2619-33.

6. Bijlsma JWJ. EULAR compendium on Rheumatic Diseases, BMJ, 2009.

7. Minaur NJ, Jacoby RK, Cosh JA, Taylor G, Rasker JJ. Outcome after 40 years with rheumatoid arthritis: A prospective study of function, disease activity, and mortality. J Rheumatol 2004;31 Suppl 69:3-8.

8. Wieland HA, Michaelis M, Kirschbaum BJ, Rudolphi KA. Osteoarthritis an untreatable disease? Nat Rew Drug Dis 2005;4:331-44.

9. Felson DT, Lawrence RC, Dieppe PA, Hirsch R, Helmick CG, Jordan JM, et al. Osteoarthritis: new insights. Part 1: the disease and its risk factors. Ann Intern Med 2000;133:635-46.

10. Koopman WJ, Boulware DW, Heudebert GR. Clinical Primer of Rheumatology. first edition, Philadelphia, USA, Lippincott Williams \& Wilkins, 2003. pp. 3-8, 97-115, 245-61.

11. Bartlett SJ, Bingham CO, Maricic MJ, Iversen MD, Ruffing V. Clinical care in the rheumatic diseases, Association of Rheumatology health professionals, 3rd edition, Atlanta, 2006.

12. Hunter DJ, McDougall JJ, Keefe FJ. The Symptoms of Osteoarthritis and the Genesis of Pain. Medical Clinics of North America. 2009;93:83-100.

13. Dieppe P. The classification and diagnosis of osteoarthritis. In: Kuettner KE, Goldberg VM, editors. Osteoarthritis disorders. Rosemont IL: American Academy of Orthopaedic surgeons, 1995:5-12.

14. Threlkeld AJ, Currier DP. Osteoarthritis. Effects on synovial joint tissues. Phys Ther 1988;68:364-70.

15. Stokes M, Young A. The contribution of reflex inhibition to arthrogenous muscle weakness. Clin Sci (Colch) 1984;67:7-14.

16. Ropes MW. Conservative treatment in rheumatoid arthritis. Med Clin North Am 1961;45:1197-207.

17. Anonymous. Immobilisation of rheumatoid joints. Lancet 1963;1:1035. 
18. Smith RD, Polley HF. Rest therapy for rheumatoid arthritis. Mayo Clin Proc 1978;53:141-45.

19. Clarke AE, Esdaile JM, Hawkins D. Inpatients rheumatic disease units: Are they worth it? Arthritis Rheum 1993;36:1337-40.

20. Balandraud N, Meynard JB, Auger I, Sovran H, Mugnier B, Reviron D, Roudier J, Roudier C. Epstein-Barr virus load follow up in rheumatoid arthritis patients treated with TNF- $\alpha$ inhibitors. Arthritis Res Ther 2004;66:91.

21. Grigor C, Capell H, Stirling A, McMahon AD, Lock P, Vallance R, Kincaid W, Porter D. Effect of a treatment strategy of tight control for rheumatoid arthritis (the TICORA study): a single-blind randomised controlled trial. The Lancet 2004;364:263-9.

22. Breedveld FC, Kalden JR. Appropriate and effective management of rheumatoid arthritis (review) Ann Rheum Dis 2004;63:627-33.

23. Nederlandse vereniging voor reumatologie (NVR). De richtlijn 'Diagnostiek en behandeling van reumatoïde artritis'. Alphen aan den Rijn, The Netherlands, Van Zuiden Communications BV, 2009.

24. Van den Ende CHM, Breedveld FC, le Cessie S, Dijkmans BAC, de Mug AW, Hazes JMW. Effect of intensive exercise on patients with active rheumatoid arthritis: a randomized clinical trial. Ann Rheum Dis 2000;59:615-21.

25. Vliet Vlieland TPM, Breedveld FC and Hazes JMW. The two-year follow-up of a randomized comparison of in-patient multidisciplinary team care and routine outpatient care for active rheumatoid arthritis. Br J Rheumatol 1997;36:82-5.

26. Taal E, Bobietinska E, Lloyd J, Veehof M, Rasker WJM, Oosterveld FGJ, Rasker JJ. Successfully living with chronic arthritis. The role of the allied health professionals. Clin Rheumatol 2006;25:189-97.

27. Lee DM, Weinblatt ME. Rheumatoid arthritis. Lancet 2001;358:903-11.

28. Spiegel JS, Spiegel TM, Ward NB. Are rehabilitation programs for rheumatoid arthritis patients effective? Sem Arthr Rheum 1987;16:260-70.

29. Habermann ET. Total joint replacement: an overview. Semin Roentgenoly 1986;21:7-19.

30. Utah hip \& knee centre. History of Total joint replacement. http://www.utahhipandknee.com/history.htm, Jun 2010.

31. Ostendorf M, Johnell O, Malchau H, Dhert WJ, Schrijvers AJ, Verbout AJ. The epidemiology of total hip replacement in The Netherlands and Sweden: present status and future needs. Acta Orthop Scand 2000;73:282-6.

32. Jones DL, Westby MD, Greidanus N, Johanson NA, Krebs DE, Robbins L, Rooks DS, Brander V. Update on hip and knee arthroplasty: Current state of evidence. Arthritis Care Res 2005;53:772-80.

33. Kim S, Losina E, Solomon DH, Wright J, Katz JN. Effectiveness of clinical pathways for total knee and total hip arthroplasty. Literature review. J Arthroplasty 2003;18:69-74. 
34. Brunenberg DE, van Steyn MJ, Sluimer JC, Bekebrede LL, Bulstra SK, Joore MA. Joint recovery programme versus usual care. An economic evaluation of a clinical pathway for joint replacement surgery. Med Care 2005;43:1018-26.

35. Bogies R. Goede resultaten heup-knieprogramma. Medisch contact 2005;60:496-8.

36. Pilot P, Engelen M, Dreessen F, van Os JJ, Kuipers H. Critical pathway for hip and knee replacement; Faster home due to multidisciplinary cooperation. J Integr Care Pathways 2006;9:1-4.

37. Berend KR, Lombardi AV, Mallory TH. Rapid recovery protocol for peri-operative care of total hip and total knee arthroplasty patients. Surg Technol Int 2004;13:239-47.

38. Jain N, Guller U, Pietrobon R, Bond T, Higgins T. Comorbidities increase complication rates in patients having arthroplasty. Clin Orthop Related Res 2005;435:232-8.

39. Rubin GJ, Cleare A, Hotopf M. Psychological factor in postoperative fatigue. Psychosomatic Medicine 2004;66:959-64.

40. Espehaug B, Havelin LI, Engeseater LB, Langeland N, Vollset SE. Patient satisfaction and function after primary and revision total hip replacement. Clin Orthop Related Res 1998;351:135-48.

41. Ouellet D, Moffet H. Locomotor Deficits before and two months after knee arthroplasty Arthritis Care Res 2002;47:484-93.

42. Maire J, Tordi N, Parratte B, Lonsdorfer J, Rouillon JD. Cardiovascular deconditioning in elderly with hip osteoarthrosis and benefits of reconditioning program after total hip arthroplasty. Science Sport 2002;17:155-65.

43. Fried LP, Guralnik JM. Disability in older adults: Evidence regarding significance, etiology, and risk. J of the Am Geriatrics Society 1997;45:92-100.

44. Fransen M. When is physiotherapy appropriate? Best Practice \& Research Clinical Rheumatology 2004;18:477-89.

45. Ettinger WH, Burns R, Messier SP, Applegate W, Rejeski WJ, Morgan T, Shumaker S, Berry MJ, OToole M, Monu J, Craven T. A randomized trial comparing aerobic exercise and resistance exercise with a health education program in older adults with knee osteoarthritis - The Fitness Arthritis and Seniors Trial (FAST). JAMA 1997;277:25-31.

46. McCarthy CJ, Mills PM1, Pullen R, Roberts C, Silman A and Oldham JA. Supplementing a home exercise programme with a class-based exercise programme is more effective than home exercise alone in the treatment of knee osteoarthritis. Rheumatology 2004;43:880-6.

47. Komatireddy GR, Leitch RW, Cella K, Browning G, Minor M. Efficacy of load resistive muscle training in patients with rheumatoid arthritis functional class II and III. J Rheumatol 1997;24:1531-9.

48. Brosseau L, Pelland L, Wells G, et al. Efficacy of aerobic exercises for osteoarthritis (Part II): A meta-analysis. Phys Ther Rev 2004;9:125-45. 
49. Pelland L, Brosseau L, Well G, et al. Efficacy of strengthening exercise therapy for osteoarthritis (Part I): A meta-analysis. Phys Ther Rev 2004;9:77-108.

50. Roddy E, Zhang W, Doherty M. Aerobic walking or strengthening exercise for osteoarthritis of the knee? A systematic review. Ann Rheum Dis 2005;64:544-8.

51. de Jong Z, Munneke M, Lems WF, Zwinderman AH, Kroon HM, Pauwels EK, Jansen A, Ronday KH, Dijkmans BA, Breedveld FC, Vliet Vlieland TP, Hazes JM. Slowing of bone loss in patients with rheumatoid arthritis by long-term high-intensity exercise: results of a randomized, controlled trial. Arthritis Rheum 2004;50:1066-76.

52. Van den Ende CHM, Hazes JMW, le Cessie S, Mulder WJ, Belfor DG, Breedveld FC, et al. Comparison of high and low intensity training in well controlled rheumatoid arthritis: results of a randomised clinical trial. Ann Rheum Dis 1996;55:798-805.

53. Hakkinen A, Sokka T, Kautiainen H, Kotaniemi A, Hannonen P. Sustained maintenance of exercise induced muscle strength gains and normal bone mineral density in patients with early rheumatoid arthritis: a 5 year follow up. Ann Rheum Dis 2004;63:910-6.

54. Minor MA, Hewett JE, Webel RR, Anderson SK, Day DR. Efficacy of physical conditioning exercise in patients with rheumatoid arthritis and osteoarthritis. Arthritis Rheum 1989;32:1396-405.

55. Ekdahl C, Andersson SI, Moritz U, Svensson B. Dynamic versus static training in patients with rheumatoid arthritis. Scand J Rheumatol 1990;19:17-26.

56. Baslund B, Lyngberg K, Andersen V, Halkjaer Kristensen J, Hansen M, Klokker M, et al. Effect of $8 \mathrm{wk}$ of bicycle training on the immune system of patients with rheumatoid arthritis. J Appl Physiol 1993;75:1691-5.

57. de Jong Z, Munneke M, Zwinderman AH, Kroon HM, Jansen A, Ronday KH, van Schaardenburg D, Dijkmans BA, Van den Ende CH, Breedveld FC, Vliet Vlieland TP, Hazes JM. Is a long-term high-intensity exercise program effective and safe in patients with rheumatoid arthritis? Results of a randomized controlled trial. Arthritis Rheum 2003;48:2415-24.

58. McMeekin J, Stillman B, Story I, Kent P. The effects of knee extensor and flexor muscle training on the timed-up-and-go test in individuals with rheumatoid arthritis. Physiother Res Int 1999;4:55-67.

59. Stevens M, van den Akker-Scheek I, Spriensma A, Boss NAD, Diercks RL, van Horn JR. The Groningen Orthopedic Exit Strategy (GOES): a home-based support program for total hip and knee arthroplasty patients after shortened hospital stay. Patient Education and Counseling 2004;54:95-9.

60. Vliet Vlieland TPM, Zwinderman AH, Vandenbroucke JP, Breedveld FC, Hazes JMW. A randomized clinical trial of in-patient multidisciplinary treatment versus routine outpatient care in active rheumatoid arthritis. Br J Rheumatol 1996;35:475-82. 


\section{Chapter 2}

Disease process, consequences and physical therapy for arthritis patients 


\section{RHEUMATOID ARTHRITIS}

Rheumatoid Arthritis (RA) is a chronic disease characterized by systemic inflammation, especially of the synovial membrane of joints and related tissues. ${ }^{1} \mathrm{RA}$ is an erosive symmetric polyarthritis, primarily affecting the peripheral joints. ${ }^{2,3} \mathrm{At}$ later disease stages, other joints may also be involved. ${ }^{2}$ Up to present, the in 1987 revised criteria for the classification of RA have been used as guidelines for establishing the diagnosis. ${ }^{4,5}$ Recently, a combined effort of the European League Against Rheumatism (EULAR) and the American College for Rheumatology (ACR) have presented novel evidence based diagnostic criteria for RA. ${ }^{6}$

RA affects approximately $1 \%$ of the population. ${ }^{5}$ Women are affected two to three times more frequently than men.5,7 There is no clear association between the prevalence of RA and socioeconomic status. ${ }^{2}$ The disease can occur at any age, but onset is most common between the age of 40 and 70 . Obviously, the prevalence increases with age. ${ }^{1}$

The cause of the disease is unknown, hereditary characteristics as well as environment factors are thought to play an important role in the development of the disease. ${ }^{2}$ In RA, the defense systems of one's own immune system are directed against the synovial tissues, resulting in an inflammatory synovitis causing pain, swelling, stiffness, and increased temperature resulting in decreased range of motion, periarticular loss of bone density, bone erosions and muscle weakness. ${ }^{1}$ All leading to an immediate loss of function. ${ }^{8}$ In the long run with irreversible structural joint damage.

Obviously, the disease has a major impact on psychosocial function and quality of life.9,10 Although the cause of the disease is not known, pharmacotherapeutic innovations and intensive treatment strategies have caused revolutionary improvements for patients with RA. ${ }^{11}$

RA has an unpredictable course, often with periods of remissions and exacerbations and less frequently true remissions. ${ }^{1,12}$ 


\section{OSTEOARTHRITIS}

Osteoarthritis (OA) is the most frequent joint disorder, affecting over 135 million people worldwide. ${ }^{13,2} \mathrm{OA}$ is a degenerative joint disease, causing disability in many elderly patients. This rheumatic disease primarily affects the articular cartilage and subchondral bone of synovial joints and results in joint failure. ${ }^{14}$ Signs and symptoms of osteoarthritis are joint pain, decreased function, postural deformities, joint instability, periarticular muscle weakness, and fatigue. ${ }^{5,15,16}$

Radiographical changes such as loss of joint space narrowing, osteophytes and sclerosis are found in general. However, in early disease radiographic findings may be limited. Moreover, radiographic changes do not always relate to symptoms. Radiological damage may occur in any joint but occurs most commonly in the hands, spine, knees, feet, and hips.5,17 Osteoarthritis also has a major impact on psychosocial function and quality of life. ${ }^{5}$

OA can be defined radiologically using the criteria of Kellgren and Lawrence ${ }^{18}$ or clinically using patient reported outcomes of physical signs. The clinical criteria for the classification of $\mathrm{OA}$ of the hip and knee as defined by the American College of Rheumatology, are frequently used, also in primary care. ${ }^{19,20}$ It is not easy to clearly estimate the prevalence and incidence of $\mathrm{OA}$, because the symptoms of OA are not specific, and the radiological changes reflect a gradual pathological process for which no time of onset can be defined. The prevalence of OA is increasing, mainly due to increasing life spans. Using radiological criteria, 30\% of individuals between the age of 45 and 65 are affected ${ }^{2}$. Above the age of $50-75$, more than $80 \%$ of the population presents radiological signs of $\mathrm{OA}$, however the percentage with disease symptoms such as pain, loss of function or stiffness are considerably lower. ${ }^{5}$ It is unclear why only $40 \%$ of patients with severe radiographic OA have pain. ${ }^{21}$ There is an association between prevalence of $\mathrm{OA}$ and lower socioeconomic status. The incidence of hip and knee OA increases with age and all forms of OA seem to appear more frequently in women. ${ }^{5}$

The cause of $\mathrm{OA}$ is not completely understood. Biomechanical stress (such as trauma, obesity and anatomical abnormalities), biochemical change, race, gender, age, and genetic factors are all important in its pathogenesis.5,22,23 Evidence is growing for the role of systemic factors, such as genetics, diet, estrogen use, and bone density, and local biomechanical factors, such as muscle weakness, obesity, and joint laxity. These risk factors are particularly important in weight-bearing 
joints, and modifying these risk factors may help prevent $\mathrm{OA}$ related pain and disability. ${ }^{24}$ Prolonged heavy load bearing is not a cause of OA, however it can accelerate or trigger an early onset in someone with a predisposition for the disease.

Although there is no known cure for $\mathrm{OA}$, treatment tailored for the individual patient can reduce pain, maintain and/or improve joint mobility, and limit functional impairment. ${ }^{25}$

$\mathrm{OA}$ is characterized by a slow and variably progressive course. Due to the gradually declining quality of cartilage, forces on the bones of the joints increase which subsequently changes the bone structure. With the consequence that bone ends come into contact with each other. This friction causes inflammation resulting in joint swelling, warmth and more pain. Unlike with RA, the inflammation, if present, is usually mild. Physical examination findings are limited to the affected joints. There is tenderness on palpation, pain and limitation on active or passive range of motion, bone enlargement and crepitating are found during clinical examination. ${ }^{2,25}$ Joint pain is not related to the clinical and radiological classification of OA. Individual factors as well as ethnic, cultural, and personal circumstances all seem to play a role. ${ }^{26}$ Initially, pains occur during activity, relieved by rest and responsive to simple analgesia. ${ }^{2}$ As the disease progresses, joints may become unstable. ${ }^{2}$ Finally, pain becomes more prominent and patients may respond less optimally to medication. OA has a major impact on functioning in daily life and frequently leads to limitations of activities, especially in elderly patients. ${ }^{27}$ 


\section{SIMILARITIES AND DIFFERENCES BETWEEN RA AND OA}

Although the term arthritis is used in both OA and RA, there are similarities as well as differences between the diseases. The most important differences between RA and $O A$ are presented in the Table 1.

Table 1. Differences between RA and OA.

\begin{tabular}{|c|c|c|}
\hline & RA & $\mathrm{OA}$ \\
\hline Inflammation & $\begin{array}{l}\text { Primary synovitis } \\
\text { (auto-immune) }\end{array}$ & Secondary synovitis \\
\hline Process & $\begin{array}{l}\text { Primarily synovial inflammation } \\
\text { Secondary cartilage and bone } \\
\text { degradation }\end{array}$ & $\begin{array}{l}\text { Primarily cartilage degradation } \\
\text { Secondary inflammation and bone } \\
\text { and joint destruction. }\end{array}$ \\
\hline Course & $\begin{array}{l}\text { Spontaneous remissions and } \\
\text { exacerbations }\end{array}$ & $\begin{array}{l}\text { Progressive degenerative process, } \\
\text { with alternating signs and } \\
\text { symptoms }\end{array}$ \\
\hline Radiologic feature & Bone erosion & $\begin{array}{l}\text { Bone formation like osteophyte } \\
\text { formation }\end{array}$ \\
\hline Morning stiffness & More than one hour & Less than one hour \\
\hline Location & $\begin{array}{l}\text { Polyarticular; } \\
\text { symmetric peripheral joint } \\
\text { disease }\end{array}$ & $\begin{array}{l}\text { Also monoarticular; } \\
\text { axial as well as peripheral joint } \\
\text { disease }\end{array}$ \\
\hline
\end{tabular}

RA predominantly affects wrists, metacarpophalangeal (MCP), and proximal interphalangeal joints (PIP). Unlike OA, it rarely, if ever, involves the DIPs and the lumbosacral spine. $^{2}$ Laboratory findings in RA correlate with systemic inflammation. ${ }^{2}$

Despite these differences many similarities between OA and RA justify a combined clinical approach where applicable. The similarities between the rheumatic diseases RA and OA are: unknown or multi-factorial cause; no cure; women more frequently affected; destruction of joints; clinical signs include pain, muscle weakness, stiffness, reduced physical functioning; fatigue and tiredness reported in $80-90 \%$ of patients; loss of independence and a reduction in quality of life. 


\section{UNDERSTANDING OF THE FUNCTIONAL IMPAIRMENT IN OA AND RA}

Both RA and OA may result in impairments, functional limitations and disability. To optimize interventions aimed at reducing disability, a proper understanding of this process is needed. Joint pain, deformity, and inactivity are all involved with disability in rheumatic patients. ${ }^{28-30}$ However, the relationship between these characteristics and the occurrence of disability in individual patients is complex. People's ability to tolerate and adjust to rheumatic diseases teaches us that the level of disability is influenced by factors beyond the disease itself. ${ }^{31}$ In this section, some disease oriented models are described.

The theory of the arthrogenous reflex muscle inhibition is based on observations that muscle weakness is more pronounced in injured joints. ${ }^{32}$ The consequences and effects of joint damage are described in Figure 1. Joint damage causes immobilization and reflex inhibition resulting in muscle wasting. Muscle wasting will induce muscle weakness. Due to decreased muscle strength, the joint will be damaged even more. This vicious circle can be broken by either restoring mobility or physical activity or by restoring muscle strength.

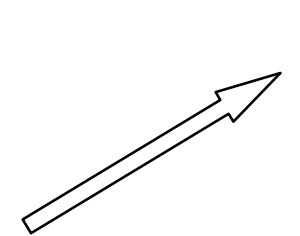

Muscle weakness

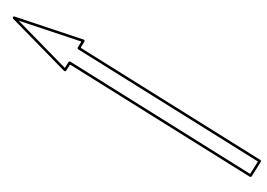

Joint Damage

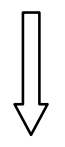

Reflex inhibition

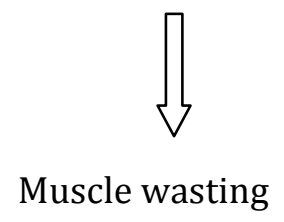

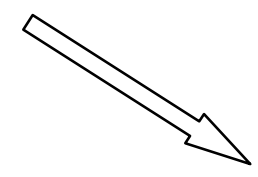

Immobilization

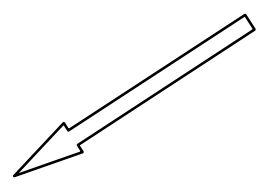

Figure 1: Vicious circles of arthrogenous muscle weakness. ${ }^{32}$ 
Not only the disease itself but also avoidance of physical activity can result in disability. The avoidance model is a framework which illustrates the vicious circle effect of avoidance of activity on muscle weakness, instability of joints and disability. ${ }^{33,34}$ The theory behind this model states that patients no longer perform certain activities because of increased pain and fear of pain. In the short-term, pain can be reduced by avoiding activities. However, in the long-term, avoidance will have physical (loss of mobility, muscle strength and fitness) and psychological consequences (lost of self-esteem, depression). These consequences may augment disability also.

During bed rest or inactivity, fewer motor units are activated resulting in decreased muscle force and coordination. In addition to muscle weakness, also cardio respiratory function $\left(\mathrm{VO}_{2} \max \right)$ will be reduced. When the oxygen availability is insufficient, biochemical changes in muscles cause fatigue and pain. The negative spiral from disease to deconditioning, inactivity and finally disability, as described by Painter in 1994, can be broken by increasing the physical fitness. ${ }^{35}$

A widely used framework for classifying the consequences of a disease is the World Health Organization International Classification of Functioning, Disability and Health (ICF). ${ }^{36}$ Within this model, the individual's experience of functioning is not considered as the consequence of the disease, but as the result of the interaction between a health condition and both personal attributes and environmental influences, ${ }^{37}$ see Figure 2. Dysfunction can occur at one or more of these levels. The different components of this framework recognize human functioning as a complex interaction of the different areas. ${ }^{38}$ 


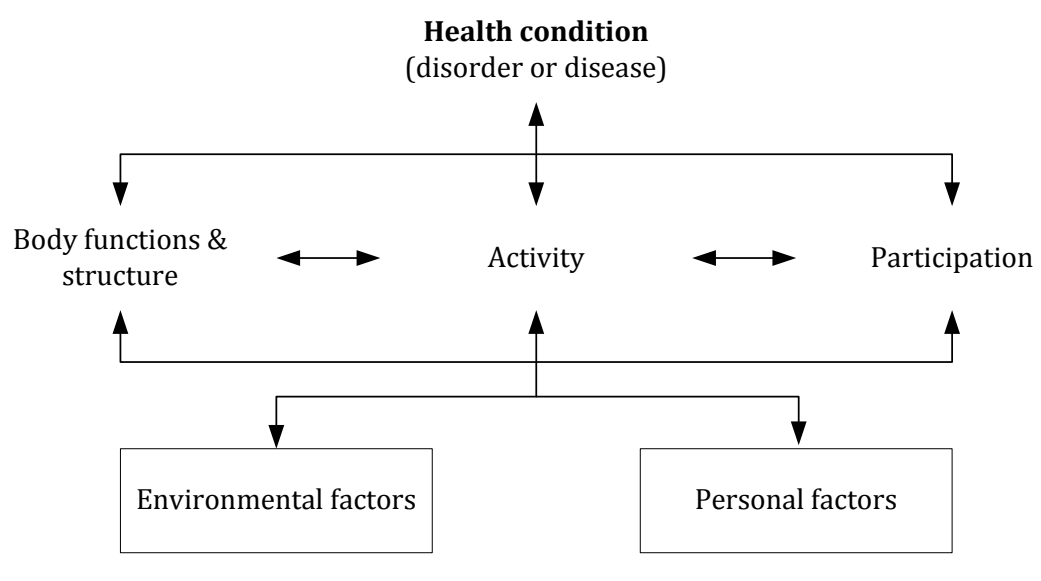

Contextual factors

Figure 2: Interactions between the components of the World Health Organization (WHO) International Classification of Functioning, Disability and Health (ICF). ${ }^{36}$

Part 1 of the ICF covers functioning and disability and includes (a) body function and body structure, and (b) activities and participation. Part 2 covers disease consequences modified by contextual factors, including (a) environmental factors and (b) personal factors. Each ICF component can be expressed in both positive and negative terms. Non-problematic aspects of health are summarized under the umbrella term "functioning," whereas "disability" serves as an umbrella term for impairment, activity limitation, or participation restriction.

'Impairment' is a problem with body structures or functions, including the signs and symptoms of a disease, such as pain, stiffness or fatigue. 'Activity limitation' describes the difficulties that a person may have in executing everyday tasks such as self care. 'Restriction in participation' relates to problems experienced by a person regarding societal participation and life situations such as employment or social activities.

The conceptual factors represent the complete background of an individual's life and living situation. 'Environmental factors' make up the physical, social and attitudinal environment in which people live and conduct their lives. 'Personal factors' are an individual's particular background and living situation, such as age, gender, fitness, lifestyle, habits, social and educational background. 
For $\mathrm{RA}^{39,40}$ and $\mathrm{OA}^{41}$ the most important and relevant disease-specific consequences have been listed and labeled in ICF Core Sets. They are fractions of the ICF relevant for specific health conditions. ICF Core Sets can be used in daily practice to set and evaluate treatment goals. ${ }^{42}$ Brief versions of these core sets serve as minimal standards for reporting on functioning and health in clinical studies and clinical encounters.

Escalante and del Rincon proposed a comprehensive model for the disablement process in RA patients, ${ }^{43}$ based on the model by Jette and Verbrugge ${ }^{44}$ as well as on the ICF. The model brings together the relative influence of psychosocial factors and disease manifestations in relation to disability of patients with RA. ${ }^{43}$

Within the main disability pathway (pathology - impairment - functional limitation - disability), two explicit pathways were identified by Escalante in 2002.30 The first is the pain pathway. Pain mediates the development of disability in RA. The second is the damage pathway. This pathway begins with inflammation in the joints and finally ends with damaged articular cartilage and underlying bone. Obviously, this interferes with joint function and anatomy, which is detected clinically by abnormal range of motion, and eventually, by joint deformity (Figure 3).

\section{PATHOLOGY $\longrightarrow$ IMPAIRMENT $\longrightarrow \begin{aligned} & \text { FUNCTIONAL } \\ & \text { LIMITATION }\end{aligned} \longrightarrow$ DISABILITY}

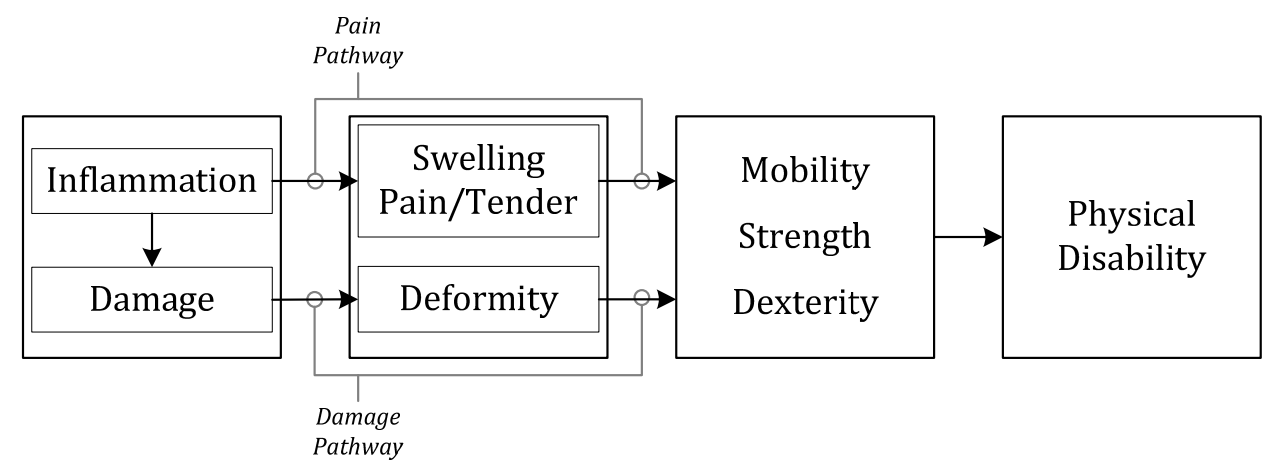

Figure 3: The main disease disability pathway, including the pain and damage pathway. Model of disablement process by Escalante. ${ }^{30}$ 
The 'psychosocial pathway', mediated by psychosocial factors and depression can lead to disability by affecting the different stages in the main disease-disability pathway. Figure 4 shows the influences of external factors that can influence the disablement process, including contextual variables, psychosocial modifiers, depression and co-morbid conditions. Psychological modifiers can also have a major influence on pain perception.

High levels of helplessness, passive coping strategies, and low-self efficacy in general are associated with higher depression-symptom scores in persons with RA. 45

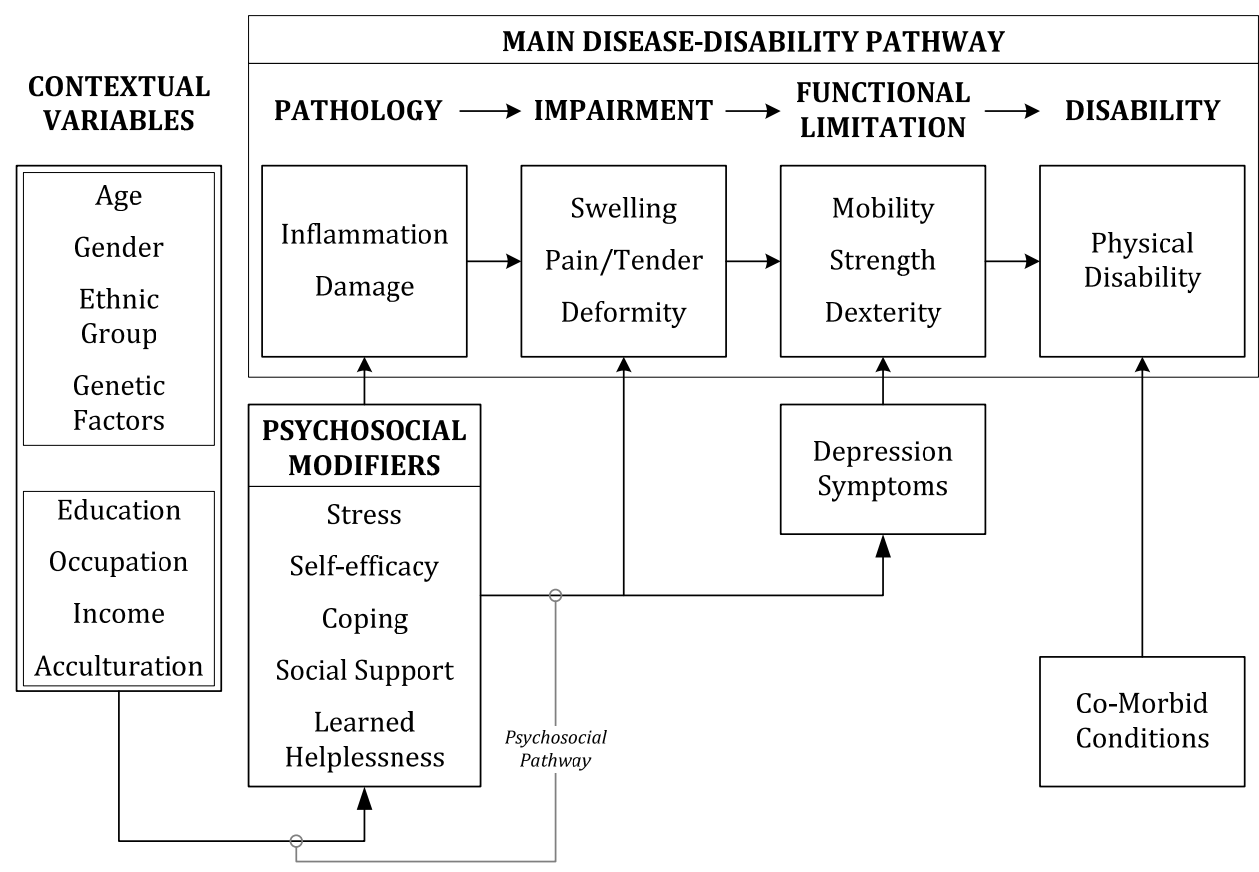

Figure 4: The influence of contextual variables, psychosocial modifiers, depression and comorbid conditions are described, including the psychosocial pathway. ${ }^{30}$ 
This model also permits hypotheses about the stages at which different treatment interventions exert their beneficial effect (Figure 5). Anti-rheumatic medications target inflammation at the stage of pathology and impairment. Surgery for RA remedies the structural consequences of joint damage, and therefore enters the model late, at the level of impairment or functional limitation, impacting primarily the pathway marked by mechanical damage to the joints. However, joint surgery also has a well recognized effect on pain. Thus, surgery positively influences the first two pathways to disability. Rehabilitation strategies in general are aimed at reducing the gap between a person's capabilities and the demands of the environment, i.e., at reducing disability.

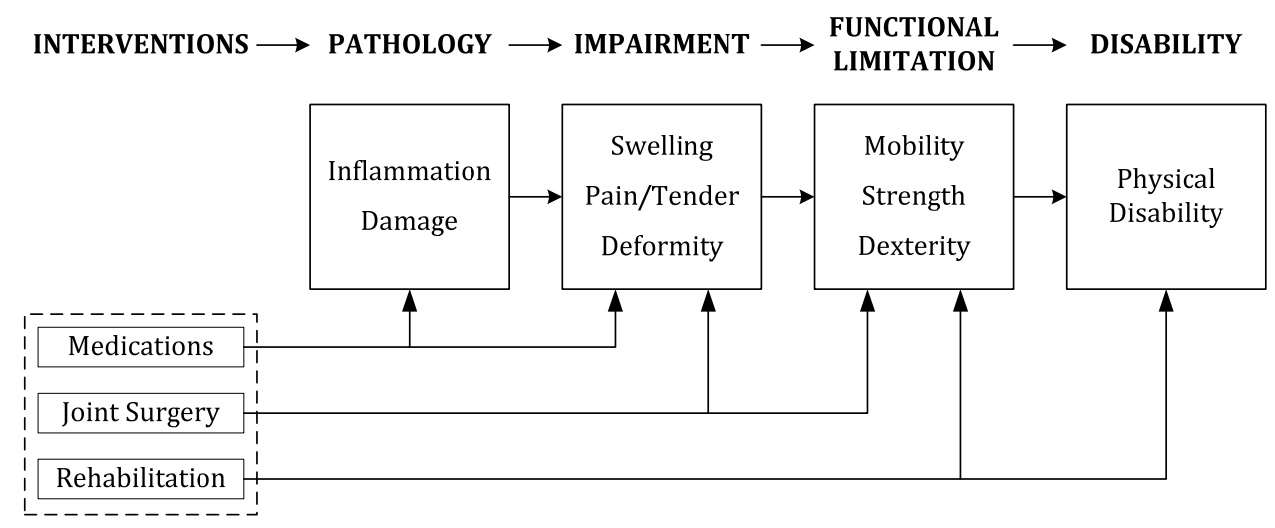

Figure 5: Different interventions influence the disablement process at different stages in RA. 30

Although the above presented model is focused on RA patients. There are many similarities with OA patients. 


\section{PSYCHOSOCIAL FACTORS AND PATIENT EDUCATION}

Pain due to arthritis has traditionally been evaluated from a biomedical perspective, but there is increasing evidence that psychological factors play an important role in the patients' adjustment to this pain. Factors, such as depression, social support, stress, self-efficacy, and helplessness, may influence pain, movement functions, and the level of disability experienced by arthritis patients. ${ }^{43,46,47}$ Psychological treatments may be useful in helping patients with arthritis to better adjust to pain. ${ }^{48}$ Those education programs for patients with arthritis are complementary to medical treatment ${ }^{49,50}$ and can give patients strategies and tools necessary to make daily decisions to cope with the disease and improve the patients' health. ${ }^{50-52}$ In addition, patients are instructed on how to approach situations and make adjustments that are appropriate for each individual and his or her own needs. ${ }^{53}$ General mental health is a modifiable component of health and may represent a new avenue for prevention of OA pain flares. ${ }^{54}$

Patient education is often based on the social cognitive theory by Bandura. ${ }^{55}$ This theory uses reciprocal determinism of human functioning: a continuous interaction between behavioural, cognitive and other personal factors, and environmental influences. ${ }^{56}$

An important concept of this theory is the self-efficacy expectation, which refers to a person's belief in his or her ability to accomplish a task or cope with a stressor. ${ }^{57,58}$ Arthritis patients, who have high self-efficacy enjoy better physical status and less pain. ${ }^{59,60}$ Self-efficacy enhancing techniques can be applied to induce changes in behavior.

Several studies have shown a large variety in patient education programmes with many disciplines involved. ${ }^{61}$ In general, positive short-term effects are found, though long-term effects are not convincing. ${ }^{53,61,62}$ Traditional patient education focuses primarily on transmitting knowledge or information. However, this has limited impact compared to forms of patient education that focus on helping patients to incorporate behavior change.53,63 Therefore, psychosocial interventions should aim at teaching self-management and coping skills that are useful for an adequate treatment of the consequences of the disease. A systematic review on patient education for RA patients, found positive effects on function, joint counts, patients' global assessment, psychological status and depression. ${ }^{53}$ 
Several studies have demonstrated the efficacy of the combination of patient education with exercise programs. ${ }^{53}$ Dutch investigators found that combining a peer-led Arthritis Self-Management Program (ASMP) course series with group exercises supervised by physical therapists resulted in improved self-efficacy and less pain in people with knee 0A. ${ }^{64}$ A positive effect is that interventions such as supervised or individualized exercise therapy and self-management techniques may also enhance exercise adherence. ${ }^{65}$ Behavioral Graded Activity (BGA) is another approach using education and exercise. BGA teaches the patient that it is safe to increase activity levels. It always starts with the determination of baseline values of the individually chosen activities. ${ }^{66}$ The patient and therapist then gradually increase the level of activities towards a present goal. ${ }^{67}$ The essential features of BGA are positive reinforcement of healthy behavior, and consequent withdrawal of attention towards pain behavior.68-70 Detailed action planning, perceived self-efficacy, and self-regulatory strategies (action control) may mediate between intentions and behaviour. Results confirmed that these three factors served to mediate between earlier exercise intentions and later physical activity, each of them making a unique contribution..$^{71}$

The American College of Rheumatology (ACR) guidelines consider patient education and self-management programs as first-line non-pharmacologic treatments for the management of hip and knee OA and RA.25,63,72 Self-management interventions are patient-centered and designed to foster active participation of patients in order to promote well-being and to manage symptoms. Over the past two decades, the role of self-management in chronic diseases has gained momentum. ${ }^{73}$ Self-management programs are now acknowledged as a key element of quality care. ${ }^{74}$ But the results of group self-management interventions with or without partners for patients with RA have been disappointing. ${ }^{75,76}$ Limited effects appear to be linked with low motivation to participate. Furthermore, a study by Elzen et al. ${ }^{77}$ found that the Chronic Disease Self-Management Program (CDSMP) is not beneficial for chronically ill elderly people in the Netherlands, despite their enthusiasm. 


\section{THE TREATMENT OF RHEUMATOID ARTHRITIS}

The management of RA involves a variety of medical and paramedical interventions. Rheumatologists and physical therapists are frequently involved in the care of RA patients together. If indicated, care can be extended to other disciplines. The overall treatment of RA focuses on suppressing inflammation and controlling symptoms, so joint destruction and disability are prevented and health related quality of life is improved. Treatment includes a rich spectrum of medication, surgery, and rehabilitation. ${ }^{9}$ The key aspects, besides the corner stone of pharmacotherapy, are patient education, physiotherapy, occupational therapy, podiatry and surgery. ${ }^{7}$

The pharmacological treatment is directed towards suppressing disease activity by means of disease-modifying anti-rheumatic drugs (DMARD's), including biological response modifiers. Moreover, symptoms, especially pain, is controlled by intraarticular corticosteroid injections and non steroidal anti-inflammatory drugs (NSAIDs). At present, remission of disease activity is the treatment goal. If necessary, destructed joints can be replaced by surgical therapy.

In addition, health professionals like occupational and physical therapists offer treatment modalities aiming to improve and facilitating daily functioning. ${ }^{78}$ The actions of these health professionals are directed at the consequences of the RA in terms of body functions, structures, activities, participation, and in the education of these patients.

The number of devices used by patients with RA appears to increase gradually with the duration of disease. ${ }^{79}$ Orthoses are externally applied devices aimed at supporting or immobilizing joints. In RA patients, orthoses are predominantly used to reduce local pain and inflammation by relieving strain or load on a joint or by decreasing motion. ${ }^{80}$ Exercise therapy, as a part of the total management of RA, has an important role in maintaining and improving physical functioning. Treatments such as exercise aim to relieve pain and stiffness and to improve the ability to move. $^{3}$ The objectives of exercise therapy in patients with RA are restoration, preservation or increase of joint range of motion, muscle strength or cardiovascular condition. ${ }^{81}$

Traditionally, patients with active RA were advised to rest from active exercise, particularly during exacerbations. ${ }^{82}$ Subsequently, most studies were performed on exercise therapy during episodes of low disease activity or remission. 
Over the last two decades, there has been increasing use of active exercise in patients with RA, with a number of studies looking at the effect of exercise on outcome measures as diverse as fitness, muscle strength, bone density, functional scores, disease activity and joint damage. 83

During hospitalization due to a flare of RA, the primary task of the rheumatologist is to prescribe medication and monitor the effects and prevent side effects. Patients with RA who are hospitalized for a flare and functional deterioration, improve significantly according to variables of disease activity, functional status and emotional status. Patients with long-standing, destructive disease and a high level of disease activity improve most during hospitalization. ${ }^{84}$ A short period of inpatient multidisciplinary treatment for active RA has a direct beneficial effect on disease activity and emotional status, with the favourable effect on disease activity remaining after 52 weeks. ${ }^{85}$ There is evidence that people with arthritis can safely exercise to improve health and function, and that certain types of exercise have positive effects on joint physiology and disease symptoms. ${ }^{80}$

Pain and functional impairment due to severe joint damage are the indications for total joint arthroplasty. In line with the epidemiology of RA, the majority of arthroplasties are performed in female patients. ${ }^{86}$ Many RA patients undergo multiple types of surgeries. In two cohort studies, the prevalence of joint arthroplasty among RA patients was estimated between $17 \%$ and $19 \% .87,88$ Presently, the life expectancies of THA and TKA are good, with more than $90 \%$ arthroplasty survival at the 5 th year and more than $84 \%$ at the 10 th year. ${ }^{89}$

Orthopedic procedures, including joint replacement surgeries, have substantially improved the overall function and quality of life of patients with RA. ${ }^{90}$ An early diagnosis, immediate treatment using tight control and per protocol treatment promise to result in fewer joint surgeries when compared with a delayed start. ${ }^{91,92}$

\section{THE TREATMENT OF OSTEOARTHRITIS PATIENTS}

The management of $\mathrm{OA}$ includes preventive as well as therapeutic components. After establishing the diagnosis of osteoarthritis, important first steps are to reassure the patient about the disease and the course of the disease, and to coach 
the patient on how to deal with pain and moving. The principle objectives of managing $\mathrm{OA}$ are to control pain, improve function and reduce disability. ${ }^{2}$

A combination of pharmacological and non-pharmacological interventions can be given to patients with $\mathrm{OA}$ of the hip and/or knee.16,93. Potential pharmacological therapies are analgesics, nonsteroidal anti-inflammatory drugs (NSAIDs), coxibs, and intra-articular steroids. Since the inflammation in $\mathrm{OA}$ is not immune mediated as it is in RA, DMARDs and biological response modifiers are not generally applied in OA. Patients with OA who take acetaminophen have less pain. ${ }^{94}$ Furthermore, evidence suggests that NSAIDs are superior to acetaminophen for improving knee and hip pain. However, the size of the treatment effect is modest, therefore, additional considerations need to be factored when choosing the decision between using acetaminophen or NSAIDs. ${ }^{93}$ The selective COX-2 inhibitors appeared promising. However, debate on the cardiovascular safety reduced the prescription of NSAIDs, and especially coxibs, worldwide. ${ }^{95,96}$ In case of secondary inflammation, intra articular corticosteroid injections are very effective. Rarely an arthroscopic lavage will be indicated. In addition to pharmacological therapy for pain, nonpharmacologic strategies are helpful, especially when combined together. ${ }^{92,97}$

The main non-pharmacologic strategies are exercise, bracing and footwear, weight loss, patient education, acupuncture, behavioral interventions and surgical treatment. ${ }^{16,92,98}$ Any therapeutic program for OA needs to take into account that OA is a heterogeneous condition, so every patient has his/her own symptoms, signs, and functional limitations. This implies that apart from generic strategies, individualized treatment components are needed. Moreover, the therapeutic program should include a combination of physical measures, medical measures, psychological approaches and surgical interventions. Despite all the possible treatment options, up to present, the majority of $\mathrm{OA}$ patients are managed in primary care 27,99 with analgesics and exercise. ${ }^{100,101}$

Primary prevention of osteoarthritis is limited to the early diagnosis and treatment of rare metabolic conditions like haemochromatosis and hypoparathyroidism. Obviously the prevention of (micro)trauma to joints also prevents the development of osteoarthritis. The secondary prevention of osteoarthritis is clinical relevant. The most important preventive measure is reduction of overweight. In both sexes, obesity is a major risk factor for both the hip and knee joints. ${ }^{102}$ Weight loss should be a goal in obese patients, as even modest weight loss has been shown to reduce 
signs and symptoms of osteoarthritis of knee and hip. ${ }^{103,104}$ Exercise therapy improves the individual's overall functioning and helps to meet the demands of daily living. ${ }^{105}$ Exercise plays a major role in the management of OA, effecting welldocumented physiological improvements on muscle function. Moreover, exercise also has lasting benefits on the complex psychosocial sequelae of osteoarthritis facilitating appropriate health beliefs, behaviors, pain coping, and self-management strategies - that are as important as its physiological effects. ${ }^{106}$ Although training appears to be sensible and effective, questions remain about the optimal type, timing and amount of exercise. A review of international guidelines concluded that the best non-pharmacological care for OA consists of education as well as exercise. ${ }^{107}$

As mentioned earlier, the primary reason for elective orthopedic surgery is intractable pain. A secondary reason for surgery is restoration of compromised function. ${ }^{2,97}$ In moderate to severe $\mathrm{OA}$, when the preventive treatments do not result in less pain and better functioning and pain becomes unbearable (especially at night), replacement of the osteoarthritic joint with an artificial one is necessary. The most common surgical interventions in OA are the total hip arthroplasty (THA) and the total knee arthroplasty (TKA). Total hip and knee arthroplasties have proven to be the most successful surgical interventions aimed at reducing pain and enhancing physical function in people with arthritis. ${ }^{108-111}$ Patients undergoing a Total Joint Arthroplasty (TJA) report good to excellent long-term results in more than $90 \%$ of cases. $62,112,113$ The functional improvements are not only a result of the arthroplasty itself, but depend largely on active participation in rehabilitation following surgery. Clinical evidence show that fit, strong patients generally rehabilitate more quickly after surgery compared with patients who are less fit.114117 THA and TKA have also improved the morbidity and probably also the indirect mortality of OA patients. ${ }^{2}$ Surgical interventions such as arthrotomies, osteotomies (redistribution of joint force) and nettoyages or lavages are less frequently applied due to lesser effectiveness. They are mostly used for specific indications (young patients or patients at high risk for complications of THA/TKA). ${ }^{5}$

Up to present, cartilage transplantation is considered a potential for the treatment of OA. However, harvesting or culturing cartilage remains complicated and procedures are considered experimental. 


\section{EXERCISE TREATMENT}

Different forms of exercise must be discussed in more detail. Exercise therapy, as part of the total management of arthritis patients, has an important role in maintaining and improving physical functioning. Physical activity and exercise are widely purported to enhance health and minimize or prevent functional loss and disability. Exercise therapy includes a variety of different exercise forms.

Joint diseases result in reduced ranges of motion (ROM) in peripheral as well as spinal joints. ${ }^{118}$ ROM exercise is intended to maintain or improve joint range of motion and flexibility. To improve joint mobility, passive, active-assisted and active exercises are recommended, in which all joint motions are exercised throughout the entire possible ROM. ${ }^{81}$

- Passive ROM exercises are fully undertaken by a physical therapist, and are indicated for joints that are incapable of moving and that are at risk for the development of contractures, with the aim of stretching peri-articular structures..$^{80}$ These passive exercises are considered to be useful in acutely inflamed joints to avoid contractures. ${ }^{119}$

- In active-assisted ROM exercise the patient himself performs the movement supported by the exercise therapist.

- Active ROM exercise refers to any angular movement of the joints by the patient himself. Obviously, active exercise is preferred whenever possible. ${ }^{118}$

Muscles have extremely important motor functions; they effect movement, bestow stability, protect against abnormal movement, and dissipate harmful forces generated during gait. Reduced muscle function is common in all kinds of rheumatic diseases. ${ }^{120,121}$ Causes of reduced muscle function are pain, reflex inhibition, changes in metabolism, reduced numbers of working fibers, poor biomechanical conditions due to damaged bone and cartilage, peripheral nerve injury and physical inactivity. ${ }^{118}$ The muscle is a physiologically "plastic" tissue that can be exercised to improve strength, endurance, and skill, even in very elderly people. ${ }^{122}$ It is important that muscle training is preceded by thorough analysis in order to be effective as possible.118 Muscle strength exercises have plausible longterm specific benefits like increased joint protection provided by improved musculoskeletal functioning and may slow down disease progression and disability. 
Exercises designed to increase muscle strength can be divided into three types, ${ }^{81}$ classified by the type of contraction:

- Isometric exercises (static); muscles are contracted while maintaining the joint in the same pose and in which the muscle maintains a constant length. The contraction is held for a specified time followed by a period of relaxation, and then repeated. These exercises are useful when joint motion is painful or otherwise contraindicated.

- Isotonic exercises involve moving a constant load through a full ROM with or without changing the velocity of the movement.

- Isokinetic exercises (dynamic); the joint moves through a range of motion while its rate of movement is held constant by a device such as a dynamometer. The speed of movement is constant, and resistance is variable, so that increased muscular force results in increased resistance rather than increased acceleration.

Isokinetic knee extensor strength training is safe and effective in patients with RA.123 There are no absolute contraindications towards muscle training in rheumatic diseases. Attention is needed for local inflammation, joint destruction, and long-term steroid intake. A large number of persons with RA live just above the muscle strength threshold needed for activities of daily life. In patients with serious RA, reductions of muscular strength of up to $70 \%$ have been reported. ${ }^{124}$ Reduced muscle function in patients with RA may also present itself as loss of functional balance and coordination. ${ }^{9}$ Numerous studies have demonstrated that quadriceps weakness occurs early in 0 A. ${ }^{125-128}$ Patients taking long-term corticosteroids have a more pronounced loss of muscle strength. ${ }^{129,130}$ To avoid unnecessary functional deficits in patients with RA, it is important to include and evaluate different types of muscular training in rehabilitation programs. ${ }^{131}$

Finally, muscle training consists of different components directed towards improved strength, endurance, or balance and coordination. Exercise strength and endurance may be static or dynamic. Strength training is performed with a relatively higher load and fewer repetitions compared to endurance training. ${ }^{118}$ The level of the exercise intensity is determined by the exercise load, the velocity of contraction and the number of repetitions. Furthermore, the amount of exercise can be varied by the duration of exercise sessions and the exercise frequency. 
Balance and coordination exercises are performed either to increase voluntary muscle control or to increase safety and avoid falls. Improving reaction time, balance, and coordination in patients with knee OA will improve functional joint stability and proprioception. ${ }^{132}$

Movement coordination is the capacity of the nervous system to pass motor stimuli with adjusted intensity to the proper muscle groups. These then follow with a custom, temporary and spatially precise, effective and economic movement. The coordination skills are also the basis and catalyst for learning, refined, stable, automate and economic use of conditional skills. The balance of power is one of coordination skills. This is the ability of the body to stay in balance (static equilibrium) or to restore the situation after a movement (dynamic equilibrium). A well-developed sense of balance is a prerequisite for all motor activities in daily life but also forms the basis for psycho-emotional balance and wellbeing.

The maximum aerobic (cardiovascular) capacity or $\mathrm{VO}_{2} \max$ is a combination of the efficiency of the lungs to oxygenize blood and the heart to circulate blood and the ability of the muscles to absorb oxygen from the blood. The $\mathrm{VO}_{2}$ max will be reduced in many medical conditions and also with prolonged bed rest. Exercise modes are commonly used to improve cardiovascular fitness. Cardiovascular fitness training can be performed in many ways and include elements of simultaneous ROM exercise and muscle training. ${ }^{133}$ Exercise can be performed in water or be landbased and can be carried out in a clinical environment with continuous supervision or in a community-based environment with professional support. Evidence exists for the efficacy of fitness training in the form of biking, brisk walking, aqua-aerobics and different types of circuit training. ${ }^{9,118}$ The most frequently used mode of aerobic exercise training in studies involving RA patients is cycling, followed by aquatic exercise, aerobic dance and walking/running. ${ }^{10}$ The exercise modes may vary depending on the patients' preferences. When we want to improve cardiovascular fitness effectively we have to take into account the patients' preference as well as accurate dosage, both are far more important than mode. Many patients with a rheumatic disease try to reduce pain and fatigue by resting. This leads to a physically inactive lifestyle that eventually results in reduced cardiovascular fitness (maximal oxygen uptake). Compared with healthy individuals of the same sex and age, patients with rheumatic diseases are less active, and (therefore) less physically 
fit. ${ }^{131,134}$ A lower aerobic capacity was found in the group with RA and OA as compared to normal subjects. ${ }^{131,135-137}$

Bathing in water (spa therapy, balneotherapy or 'passive' hydrotherapy) has been frequently used in patients with rheumatic diseases where disease activity is under control, to decrease muscle tension and pain. ${ }^{138,139}$ Spa therapy is best tolerated with temperatures of $34-35^{\circ} \mathrm{C}$ and duration of about 20 min. ${ }^{139}$ A systematic review on the effects of spa therapy in RA and OA concluded that a definite judgment about its efficacy is impossible because of methodological flaws in the available trials. ${ }^{140}$ Overall, the trials showed positive results, with the effects lasting for 3-9 months. With moderately intensive pool-based exercises, Bilberg et al. reported no significant differences in aerobic capacity. ${ }^{141}$ However, there were also some significant differences in favor of the intervention, although the benefits were less marked than in some of the more intensive programs. Most of the available evidence suggests that aquatic exercise does improve aerobic capacity, ${ }^{142-144}$ muscular strength ${ }^{145,146}$ and psychological status. ${ }^{143}$ A RCT with RA patients combining both warm water immersion and exercise revealed significant improvements. ${ }^{10}$

\section{EFFICACY OF EXERCISE THERAPY}

In adults with a chronic disease, reduced physical fitness is seen often. Factors linked to functional decline included pain, obesity, use of passive coping styles, muscle weakness, poor aerobic capacity and in some studies, radiographic disease severity. ${ }^{15,24,147,148}$ However, the literature indicates that adults with chronic musculoskeletal disease may benefit from intervention programs using exercise. ${ }^{149,150}$ In theory, exercise prevents the vicious cycle of joint pain leading to joint stiffness, soft tissue contracture, diminished muscle strength and endurance, and loss of independence. Although trials differ with respect to the duration and frequency of exercise, the types of patients studied, the specifics of the exercise regimen, and the end points used, some generalizations can still be made. Most exercise programs for patients with chronic musculoskeletal diseases are intended to increase muscle function (strength and co-ordination) and joint range of motion. Some studies also mention the intention of exercise to improve balance, 
coordination, aerobic capacity and training of activities of daily life. Exercise therapy, as an adjunct to pharmacological and surgical therapies, aims to minimize the consequences of the disease. ${ }^{80}$

Arthritis patients are often discouraged to participate in medium-high-intensity weight bearing exercise programs, aimed at the prevention of cardiovascular diseases, obesity and osteoporosis. This conservatism in exercise is prompted by the fear of damage to the joints and the exacerbation of inflammation by weightbearing exercise and the tenacious disbelief that RA patients are able to participate in these programs. ${ }^{151}$ There is evidence that people with arthritis can safely exercise to improve health and function and that certain types of exercise have positive effects on joint physiology and disease symptoms. ${ }^{152}$ Meta-analyses also support recommendations that exercise is important in OA management. ${ }^{153}$ Landbased therapeutic exercise was shown to reduce pain and improve physical function in people with OA of the knee. ${ }^{154}$ Van Baar et al. ${ }^{155}$ demonstrated the efficacy of an exercise program in improving muscle strength, mobility, and coordination in patients with $\mathrm{OA}$ of either knee or or hip. The effectiveness of this exercise program was similar in patients with hip or knee OA. There is strong evidence that exercise therapy has a short term benefit in patients with OA of hip and/or knee. Beneficial effects of exercise therapy on pain, physical function and patients global assessment have been demonstrated. ${ }^{105,154,156}$

THA or TKA can improve quality of life, but the benefits may be time limited. ${ }^{157}$ For the majority of patients, there are marked improvements after TKA in pain and physical function, with the maximum achievable benefit appearing around six months after surgery. ${ }^{158,159}$ However, the magnitude of improvement is smaller than demonstrated after total hip replacement surgery. ${ }^{111,159,160}$ Success of major joint arthroplasty is determined not just by an effective surgical procedure, but also by adequate post-surgical rehabilitation. ${ }^{161,162}$ Post-operative intensive physical exercise and continuous passive motion (CPM) offer remarkable benefits in terms of faster recovery, shorter hospital stay and increased range of motion. ${ }^{163}$ After elective primary total knee arthroplasty, interventions including functional exercise result in short-term benefit after discharge, with small to moderate effect size. ${ }^{164}$ Following primary hip replacement for $\mathrm{OA}$, insufficient evidence exists to establish the effectiveness of exercise. There is a need for well-designed trials to determine the value of post discharge exercise. ${ }^{165}$ There is little evidence supporting the use of 
any particular preoperative or postoperative interventions, and there is also a lack of guidelines for the appropriate amount and type of physical activity after surgery. ${ }^{166}$ The use of rehabilitation services is probably the most understudied aspect of joint replacement.

The effects of muscle-strengthening programs for RA patients were described in three review papers. ${ }^{133,167,168}$ Despite the fact that intensity and total duration of the exercise programs varied widely, a positive effect on muscle strength was seen in the majority of trials on the effect of muscle strengthening exercises alone. Häkkinen et al. and McMeekin et al. reported significant improvements with primarily strength training interventions, ${ }^{169-174}$ with a two years persisting improvement in knee extension and trunk extension in the exercise group. Moderate or high-intensity strength training programs have better training effects on muscle strength in RA than low-intensity programs. ${ }^{120}$ And dynamic training gives a greater increase in physical capacity than static training for RA patients. ${ }^{175}$ Numerous studies have demonstrated that quadriceps weakness in knee OA is a more important determinant of pain and disability than radiologic changes to bone and cartilage.128,155,176-178 With muscle strengthening, improvements in strength, pain, function and quality of life were noted for OA patients, however, there was no evidence that the type of strengthening exercise influence outcome.179 Findings suggest that the effectiveness of joint specific strengthening for RA patients is maximized when combined with general strength, flexibility and functional exercise.

While the benefits of exercise, in terms of cardiovascular health are clear for healthy individuals, there has been little study of the cardiovascular benefits of exercise for patients with RA, who already have an increased cardiovascular risk, and who have lower baseline levels of activity. ${ }^{180} \mathrm{~A}$ review by Westby ${ }^{133}$ showed that aerobic capacity improved in the majority of studies, but to the greatest extent in cycling interventions. Among patients with RA who were able to perform bicycle ergometer tests, the aerobic capacity was reduced by $20-30 \%{ }^{131,134,181,182}$ No evidence of any deleterious effects of dynamic exercise therapy on joint inflammation and disease activity has been found. ${ }^{133,167,168}$ Vliet Vlieland et al. ${ }^{80}$ reported that RA patients can safely benefit from aerobic activities. Baillet et al. ${ }^{183}$ reported that cardio respiratory aerobic conditioning in stable RA appears to be safe and improves some of the most important outcome measures, such as quality 
of life, HAQ score and VAS pain. Although individual studies vary in exercise frequency and overall duration of the intervention, cycling consistently appears to induce beneficial effects in aerobic capacity, functional ability and muscle strength. ${ }^{10,184}$ Results indicated that aerobic exercise in OA patients alleviates pain and joint tenderness, and promotes functional status and respiratory capacity. While strengthening appears superior to aerobic exercise for OA patients in the short-term for specific impairment-related outcomes, aerobic exercise appears more effective for functional outcomes over the longer term. ${ }^{153}$

Based on the available evidence, aerobic capacity training combined with muscle strength training is recommended in patients with RA.,184 The combination of intensive aerobic and strength training has been the most widely used exercise regimen in recent research in RA. Different studies used exercise programs with significant aerobic and strength training aspects. ${ }^{82,123,141,185-191}$ Most studies suggest that the aerobic capacity and strength improved $133,167,168$ without negative effects on pain and disease activity. ${ }^{9,152}$ According to Cairns et al., the majority of patients with RA should be encouraged to undertake aerobic and strength training exercise, ${ }^{180}$ because it produces an effective physical stimulus to achieve desirable physiological adaptations. Physiotherapy in combination with both aerobic and strength training exercise have shown positive effects in both the pre-operative and post-operative period in total knee and hip surgery. ${ }^{163}$ A number of studies reported improvement in muscle strength, physical function and aerobic capacity with dynamic exercise. No studies reported worse outcomes for function, disease activity or aerobic capacity with dynamic exercise. ${ }^{180}$ The results of a review from van de Ende et al. ${ }^{192,193}$ suggest that dynamic exercise lasting for three months or less is effective in improving aerobic capacity, muscle strength and joint mobility for RA patients, but less effective in improving functional ability. There is no indication of deleterious effects of dynamic exercise therapy on joint inflammation and disease activity. The American College of Rheumatology updated their treatment guidelines to introduce dynamic exercise as an effective means for the management of RA. ${ }^{72}$

A number of studies have been performed to investigate whether high intensive exercise programs are a valuable addition to the care for RA patients. ${ }^{151}$ In case of serious joint damage, it seems wise to limit extreme intensive training. ${ }^{194}$ However, (intensive) training is better than complete rest, both for stable and active RA. A 
short-term intensive exercise program in active RA is more effective in improving muscle strength than a conservative exercise program. ${ }^{83}$

The physical management of arthritis patients shows great variety. There are inpatients, out-patients, mono-disciplinary, multi-disciplinary, community-based, home-based, individual, and group approaches. A combination of these approaches is also possible. Physical therapy, either as an individually delivered treatment or in a small group format, is an effective intervention for patients with knee OA.195 Munin et al. ${ }^{196}$ demonstrated that early transfer from acute care to inpatient rehabilitation is associated with a more rapid attainment of goals. However, no studies have prospectively evaluated the benefits of inpatient rehabilitation after elective THA or TKA. The long-term impact of exercise and physical activity on implant longevity and patient quality of life is probably the least understood area of rehabilitation after joint replacement. It appears that supervised exercise sessions for OA patients are superior to home exercises for pain reduction. ${ }^{153} \mathrm{~A}$ short period (11 days) of care in an in-patient multidisciplinary team has a beneficial effect on disease activity over a period of two years and should be considered a useful treatment modality in patients with active RA. ${ }^{197}$ Most exercise programs in the study of Sternstorm and Minor, ${ }^{9}$ were performed in a clinical environment, but the results of those two studies suggest that individuals with arthritis may also benefit from professionally supported community based exercise or home-based exercise. ${ }^{170,175}$ Besides the clinical setting, public health initiatives in arthritis also recommend exercise and increased physical activity. ${ }^{152}$

The effects of exercise disappear soon after finishing an exercise program. ${ }^{64,195,198,199}$ This decline is thought to be related to the difficulties people have in maintaining adherence to prescribed exercise. ${ }^{154,156}$ The gains of exercise are likely to be lost over time ${ }^{200,201}$ unless patients are actively encouraged to continue exercising. ${ }^{64,202-205}$ 


\section{RECOMMENDATIONS FOR ARTHRITIS PATIENTS}

A successful muscular strength training program should incorporate at least two sessions per week, involve 8-10 exercises for different muscle groups and allow completion of one set of 10-15 repetitions per exercise. ${ }^{10}$ The provided load for strengthening exercises should be moderate to hard (i.e., $50-80 \%$ of a maximal voluntary contraction $)^{9}$ and performed dynamic instead of static. ${ }^{175}$ RCTs on these recommendations have revealed significant increases in functional ability123,169,187,206 and muscular strength,153,173 without exacerbating existing joint damage ${ }^{185,207}$ or deleterious effects on disease activity and pain ${ }^{153,173,206}$ in patients with RA as well as OA.

The intensity level of the aerobic exercise should be moderate to hard (i.e., $60-85 \%$ of the maximum heart rate), and aerobic exercise should be performed three times weekly for a duration of 30-60 minutes. However, in RA patients with structural joint damage, the patient's physical and cardiovascular limitations should be taken into account and the aerobic exercise should therefore usually be of a moderate intensity level. Adjustment of the intensity level is recommended. ${ }^{9}$

There is strong evidence that exercise therapy for patients with arthritis should at least consist of dynamic strength training and aerobic exercise.180,187,208 Moreover, exercise therapy can be extended with range of motion, balance or co-ordination exercises.

Although physical exercises are elementary for a fit body, it is important to involve the patient in the construction of the therapy to achieve a maximal results. The preferences and goals, but also the problems and fears of the patient, are important for the content of physical therapy. Clearly formulated goals for patient and clinician are necessary. If the patient is motivated, he will continue to exercise and will understand the relevance of exercise. It is also important to involve the patient in finding solutions for his everyday problems, in collaboration with his therapist. 


\section{REFERENCES}

1. Lee DM, Weinblatt ME. Rheumatoid arthritis. Lancet 2001;358:903-11.

2. Koopman WJ, Boulware DW, Heudebert GR. Clinical Primer of Rheumatology, first edition. Philadelphia, USA, Lippincott Williams \& Wilkins, 2003. pp. 3-8, 97-115, 245261.

3. Hurkmans E, van der Giesen FJ, Vliet Vlieland TPM, Schoones J, Van den Ende ECHM. Dynamic exercise programs (aerobic capacity and/or muscle strength training) in patients with rheumatoid arthritis. Cochrane Database of Systematic Reviews 2009, Issue 4. Art. No.: CD006853. DOI: 10.1002/14651858.CD006853.pub2.

4. Arnett FC, Edworthy SM, Bloch DA, McShane DJ, Fries JF, Cooper NS, et al. The American Rheumatism Association 1987 revised criteria for the classification of rheumatoid arthritis. Arthritis Rheum 1988;31:315-24.

5. Bijlsma JWJ, Voorn ThB. Praktische huisartsgeneeskunde: Reumatologie. Houten, Bohn Stafleu Van Loghum, 2000. pp. 17-18, 22-24, 166-169, 194-205, 314-324.

6. Aletaha D, Neogi T, Silman AJ, Funovits J, Felson DT, Bingham CO, et al 2010 Rheumatoid arthritis classification criteria: An American College of Rheumatology/European League Against Rheumatism collaborative initiative. Arthritis Rheum 2010;62:2569-81.

7. Heerick AL, Andrew JG, Funk L, Hutchinson C. Orthopaedic and Rheumatology in focus. by Churchill Livingstone Elsevier, 2010, ISBN 9780443100864.

8. Drossaers-Bakker KW, de Buck M, van Zeben D, Zwinderman AH, Breedveld FC, Hazes JM. Long-term course and outcome of functional capacity in rheumatoid arthritis: the effect of disease activity and radiologic damage over time. Arthritis Rheum 1999;42:1854-60.

9. Stenström $\mathrm{CH}$ and Minor MA. Evidence for the benefit of aerobic and strengthening exercise in rheumatoid arthritis 2003;49:428-34.

10. Metsios GS, Stravropoulos-Kalinoglou A, Veldhuijzen van Zamtem JJCS, Treharne GJ, Panoulas VF, Douglas KMJ, Koutedakis Y, Kitas GD. Rheumatoid arthritis, cardiovascular disease and physical exercise: a systematic review. Rheumatology 2008 47:239-48.

11. Kievit W, Adang EM, Fransen J, Kuper HH, van de Laar MA, Jansen TL, De Gendt CM, De Rooij DJ, Brus HL, Van Oijen PC, Van Riel PC. The effectiveness and medication costs of three anti-tumour necrosis factor alpha agents in the treatment of rheumatoid arthritis from prospective clinical practice data. Ann Rheum Dis 2008;67:1229-34.

12. Pinals RS, Masi AT, Larsen RA, et al. Preliminary criteria for clinical remission in rheumatoid arthritis. Arthritis Rheum 1981;24:1308-15.

13. Arden N, Nevitt MC. Osteoarthritis: epidemiology. Best Pract Res Clin Rheumatol 2006;20:3-25.

14. Fransen M, McConnell S and Bell M. Exercise for osteoarthritis of the hip or knee. The Cochrane Database of Systematic Reviews 2001, Issue 2. Art. No.: CD 004376. 
15. Dekker J, Boot B, van der Woude LH, Bijlsma JW. Pain and disability in osteoarthritis: a review of biobehavioral mechanisms. J Behav Med 1992;15:189-214.

16. Sarzi-Puttini P, Cimmino MA, Scarpa R, Caporali R, Parazzini F, Zaninelli A, et al. Osteoarthritis: an overview of the disease and its treatment strategies. Semin Arthritis Rheum 2005;35:1-10.

17. World Health Organization Technical Report Series 919. The burden of musculoskeletal conditions at the start of the new millennium. Geneva, Switzerland, WHO, 2003.

18. Kellgren JH, Lawrence RC. Radiological assessment of osteoarthrosis. Ann Rheum Dis 1957;16:494-501.

19. Altman R, Asch E, Bloch D, Bole G, Borenstein D, Brandt K, et al. Development of criteria for the classification of osteoarthritis. Classification of osteoarthritis of the knee. Arthritis Rheum 1986;29:1039-49.

20. Altman R, Alarcon G, Appelrouth D, Bloch D, Borenstein D, Brandt K, et al. The American College of Rheumatology criteria for the classification and reporting of osteoarthritis of the hip. Arthritis Rheum 1991;34:505-14.

21. Hochberg MC, Lawrence RC, Everett DF, et al. Epidemiologic associations of pain in osteoarthritis of the knee: data from the National Health and Nutrition Examination-I Epidemiologic follow-up survey. Semin Arthritis Rheum 1989;18:S4-9.

22. Mow VC, Setton LA, Fuilak F, Ratcliffe A. Mechanical factors in articular cartilage and their role in osteoarthritis. In: Kuettner KE, Goldberg VM, editors. Osteoarthritic disorders. Rosemont (IL): American Academy of Orthopaedic Surgeons, 1995. pp. 147172.

23. Holderbaum D, Haqqi TM, Moskowitz RW. Genetics and osteoarthritis: exposing the iceberg. Arthritis Rheum 1999;42:397-405.

24. Felson DT, Lawrence RC, Dieppe PA, Hirsch R, Helmick CG, Jordan JM et al. Osteoarthritis: new sights. Part 1: the disease and its risk factors. Ann Intern med 2000;133:635-46.

25. American College of Rheumatology (ACR) Subcommittee on Osteoarthritis Guidelines. Recommendations for the medical management of osteoarthritis of the hip and knee: 2000 update. Arthritis Rheum 2000;43:1905-15.

26. Vlaar AP, ten Klooster PM, Taal E, Gheith RE, El-Garf AK, Rasker JJ, van de Laar MAJ. A cross-cultural study of pain intensity in Egyptian and Dutch women with rheumatoid arthritis. Pain 2007 Sep;8:730-6.

27. Scott DL, Shipley M, Dawson A, Edwards S, Symmons DP, Woolf AD. The clinical management of rheumatoid arthritis and osteoarthritis: strategies for improving clinical effectiveness. Br J Rheumatol 1998;37:546-54.

28. Sherrer YS, Bloch DA, Mitchell DM, Young DY, Fries JF. The development of disability in rheumatoid arthritis. Arthritis Rheum 1986;29:494-500. 
29. Badley EM, Wagstaff S, Wood PHN. Measures of functional ability (disability) in arthritis in relation to impairment of range of joint movement. Ann Rheum Dis 1984;43:563-9.

30. Escalante A, Del Rincón I. The Disablement process in rheumatoid arthritis. Arthritis Rheum (Arthritis Care Res) 2002;47:333-42.

31. Holm MB, Rogers JC, Kwo CK. Predictors of functional disability in patients with rheumatoid arthritis. Arthritis Care Res 1998;11:346-55.

32. Stokes M, Young A. The contribution of reflex inhibition to arthrogenous muscle weakness. Clin Science 1984;67:7-14.

33. Dekker J, Tola P, Aufdemkampe G, Winckers M. Negative affect, pain and disability in osteoarthritis patients: the mediating role of muscle weakness. Behav Res Ther 1993;31:203-6.

34. Steultjens MP, Dekker J, Bijlsma JWJ. Avoidance of activity and disability in patients with osteoarthritis of the knee: the mediating role of muscle strength. Arthritis Rheum 2002;46:1784-8.

35. Painter P. The importance of exercise training in rehabilitation of patients with end stage renal disease. Am J Kidney Dis 1994;24:S2-S9.

36. World Health Organization, International Classification of Functioning, Disability and Health: ICF. Geneva, WHO, 2001.

37. Stucki G. International Classification of Functioning, Disability, and Health (ICF): a promising framework and classification for rehabilitation medicine. American Journal of Physical Medicine and Rehabilitation 2005;84:733-40.

38. Boonen A, Rasker JJ, Stucki G. The international classification for functioning, disability and health. A challenge and a need for rheumatology. Clin Rheumatol 2007;26:1803-8.

39. Stucki G, Cieze A, Geyh S, Battistella L, Lloyd J, Symmons D, et al. ICF Core Sets for rheumatoid arthritis. J Rehabil Med 2004;44:S87-S93.

40. Stucki G, Cieza A, The international Classification of Functioning, Disability and Health (ICF) Core Sets for rheumatoid arthritis: a way to specify functioning. Ann Rheum Dis 2004;63(Suppl II):ii40-ii45.

41. Dreinhofer K, Stucki G, Ewert T, Huber E, Ebenbichler G, Gutenbrunner C, et al. ICF Core Sets for osteoarthritis. J Rehabil Med 2004;44:S75-80.

42. Stucki G, Boonen A, Tugwell P, Cieza A, Boers M. The World Health Organisation International Classification of Functioning, Disability and Health: a conceptual model and interface for the OMERACT process. J Rheumatol 2007;34:600-6.

43. Escalante A, Del Rincón I. How much disability in rheumatoid arthritis is explained by rheumatoid arthritis? Arthritis Rheum 1999;42:1712-21.

44. Verbrugge LM, Jette AM. The disablement process. Soc Sci Med 1994;38:1-14.

45. Brown GK, Nicassio PM, Wallston KA. Pain coping strategies and depression in rheumatoid arthritis. J Consult Clin Psychol 1989;57:652-7. 
46. Parker JC, Wright GE. Assessment of psychological outcomes and quality of life in the rheumatic diseases. Arthritis Care Res 1997;10:406-12.

47. Lorish CD, Abraham N, Austin J, Bradley LA, Alarcon GS. Disease and psychosocial factors related to physical functioning in rheumatoid arthritis. J Rheumatol 1991;18:1150-7.

48. Keefe FJ, Somers TJ. Psychological approaches to understanding and treating arthritis pain. Nat Rev Rheumatol 2010;6:210-6.

49. Tucker M, Kirwan J. Does patient education in rheumatoid arthritis have therapeutic potential? Ann Rheum Dis 1991;50:422-8.

50. Riemsma RP, Taal E, Kirwan JR, Rasker JJ. Patient education programmes for adults with rheumatoid arthritis. BMJ 2002;325:558-9.

51. Hirano P, Laurent D, Lorig K. Arthritis patient-education studies, 1987-1991: a review of the literature. Patient Educ Couns 1994;24:9-54.

52. Taal E, Rasker J, Wiegman 0. Group education for rheumatoid arthritis patients. Semin Arthritis Rheum 1997;26:805-16.

53. Riemsma RP, Taal E, Kirwan JR, Rasker JJ. Systematic review of Rheumatoid Arthritis Patient education. Arthritis Rheum (Arthritis Care Res) 2004;51:1045-59.

54. Wise BL, Niu J, Zhang Y, Wang N, Jordan JM, Choy E, Hunter DJ. Psychological factors and their relation to osteoarthritis pain. Osteoarthritis and cartilage 2010;18:883-7.

55. Bandura A. Social foundations of thought and action: A social cognitive theory. Englewood Cliffs, NJ: Prentice Hall, 1986.

56. Bandura A. The self-system in reciprocal determinism. Am Psychol 1978;133:344-58.

57. Bandura A, Adams NE, Beyer J. Cognitive processes mediating behavioral change. J Pers Soc Psychology 1977;35:125-39.

58. O'Leary A. Self-efficacy and health. Behav Res Ther 1985;23:437-51.

59. Lorig K, Chastain RL, Ung E, Shoor S, Holman HR. Development and evaluation of a scale to measure perceived self-efficacy in people with arthritis. Arthritis Rheum 1989;32:3744.

60. Somers TJ, Shelby RA, Keefe FJ, Godiwala N, Lumley MA, Mosley-Williams A, Rice JR, Caldwell D. Disease severity and domain-specific arthritis self-efficacy: relationships to pain and functioning in patients with rheumatoid arthritis. Arthritis Care Res 2010;62:848-56.

61. Niederman KMPH, Fransen J, Knols R, et al. Gap between short- and long-term effects on patient education in rheumatoid arthritis patients: a systematic review. Arthritis Rheum (Arthritis Care Res) 2004;51:388-98.

62. Nederlandse vereniging voor reumatologie. De richtlijn 'Diagnostiek en behandeling van reumatoïde artritis'. Alphen aan den Rijn, The Netherlands, Van Zuiden Communications BV, 2009. 
63. Bartlett SJ, Bingham CO, Maricic MJ, Iversen MA, Ruffing V. Clinical Care in the Rheumatic Diseases. $3^{\text {rd }}$ edition, Atlanta, Published by the Association of Rheumatology Health Professionals a Division of the American College of Rheumatology, 2006. pp. 6771, pp. 79-87, pp. 127-134, pp. 157-166, pp. 230-311.

64. Hopman-Rock M, Westhoff MH. The effects of a health educational and exercise program for older adults with osteoarthritis for hip and knee. J Rheumatol 2000;27:1947-54.

65. Jordan JL, Holden MA, Mason EEJ, Foster NE. Interventions to improve adherence to exercise for chronic musculoskeletal pain in adults (Review). The Cochrane Library 2010; Issue 1:1-63.

66. Veenhof $\mathrm{C}$. The effectiveness of behavioral graded activity in patients with osteoarthritis of hip or knee [thesis]. Utrecht, Nivel, 2006.

67. Morley S, Eccleston C, Williams A. Systematic review and meta-analysis of randomized controlled trials of cognitive behaviour therapy and behaviour therapy for chronic pain in adults, excluding headache. Pain 1999;80:1-13.

68. Lindstrom I, Ohlund C, Eek C, Wallin L, Peterson LE, Fordyce WE et al. The effect of graded activity on patients with subacute low back pain: a randomized prospective clinical study with an operant-conditioning behavioral approach. Phys Ther 1992;72:279-90.

69. Fordyce WE. Behavioral methods for chronic pain and illness. St. Louis: Mosby, 1976.

70. Vlaeyen JW, Haazen IW, Schuerman JA, Kole Snijders AM, Eek van H. Behavioral rehabilitation of chronic low back pain: comparison of an operant treatment, and operant-cognitive treatment and an operant-respondent treatment. $\mathrm{Br}$ J Clin Psychol 1995;34:95-118.

71. Sniehotta FF, Scholz U, Schwarzer R. Bridging the intention-behaviour gap: Planning, self-efficacy, and action control in the adoption and maintenance of physical exercise. Psychology \& Health 2005;20:143-60.

72. American College of Rheumatology (ACR) Subcommittee on Rheumatoid Arthritis Guidelines. Guidelines for the management of rheumatoid arthritis: 2002 update. Arthritis Rheum 2002;46:328-46.

73. Iversen MD, Hammond A, Betteridge N. Self-management of rheumatic diseases: state of the art and future. Ann Rheum Dis 2010;69:955-63.

74. Newman S, Steed L, Mulligan K. Self-management interventions for chronic illness. Lancet 2004;364:1523-37.

75. Riemsma RP, Taal E, Rasker JJ. Group education for patients with rheumatoid arthritis and their partners. Arthritis Rheum (Arthritis Care Res) 2003;49:556-66.

76. Bode C, Taal E, Emons PAA, Galetzka M, Rasker JJ, Van de Laar MAFJ. Limited results of group self-management education for rheumatoid arthritis patients and their partners: explanations from the patient perspective. Clin Rheumatol 2008;27:1523-8. 
77. Elzen H, Slaets JPJ, Snijders TAB, Steverink N. Evaluation of the chronic disease selfmanagement program (CDSMP) among chronically ill older people in the Netherlands. Social Science \& Medicine 2007;64:1832-41.

78. Van den Ende CHM. Exercise Therapy in Rheumatoid Arthritis [thesis]. Leiden, the Netherland, University of Leiden; 1997.

79. Van der Heide A, Jacobs JWG, van Albada-Kuipers GA et al. Self report functional disability scores and the use of devices: two distinct aspects of physical function in rheumatoid arthritis. Ann Rheum Dis 1993; 52:497-502.

80. Vliet Vlieland TPM. Rehabilitation of people with Rheumatoid arthritis. Best Practice of Research Clinical Rheumatology 2003;17(5):847-61.

81. Ytterberg SR, Mahowald ML, Krug HE. Exercise for arthritis. Baillière's Clinical Rheumatology 1994; 8:161-89.

82. Iversen MD, Fossel AH, Daltroy LH. Rheumatologist patient communication about exercise and physical therapy in the management of rheumatoid arthritis. Arthritis Care Res 1999;12:180-92.

83. Van den Ende CHM, Breedveld FC, le Cessie S, Dijkmans BAC, de Mug AW, Hazes JMW. Effect of intensive exercise on patients with active rheumatoid arthritis: a randomized clinical trial. Ann Rheum Dis 2000;59:615-21.

84. Vliet Vlieland TPM, Zwinderman AH, Vandenbroucke JP, Breedveld FC, Hazes JMW. Inpatient treatment for active rheumatoid arthritis: clinical course and predictors of improvement. Br J Rheumatol 1995;34:847-53.

85. Vliet Vlieland TPM, Zwinderman AH, Vandenbroucke JP, Breedveld FC, Hazes JMW. A randomized clinical trial of in-patient multidisciplinary treatment versus routine outpatient care in active rheumatoid arthritis. Br J Rheumatol 1996;35:475-82.

86. Da Silva E, Doran MF, Crowson CS, O’Fallon WM, Matteson EL. Declining use of orthopedic surgery in patients with rheumatoid arthritis? Results of a long-term, population-based assessment. Arthritis Rheum (Arthritis Care Res) 2003;49:216-20.

87. James D, Young A, Kulinskaya E, Knight E, Thompson W, Ollier W, et al. Orthopaedic intervention in early rheumatoid arthritis. Occurrence and predictive factors in an inception cohort of 1064 patients followed for 5 years. Rheumatology (Oxford) 2004;43:369-76.

88. Gordon P, West J, Jones H, Gibson T. A 10 year prospective follow-up of patients with rheumatoid arthritis 1986-96. J Rheumatol 2001;28:2409-15.

89. Kaneko A, Eto Y, Tsukamoto M. Survival after total joint arthroplasty in patients with rheumatoid arthritis. Comparison of the postoperative life expectancies and survival by initial operative years: 1970s and 1980s group versus 1990s group. Mod Rheumatol 2004;14:466-9. 
90. Anderson R. The orthopedic management of rheumatoid arthritis. Arthritis Care Res 1996;9:23-8.

91. Verstappen SMM, Hoes JN, ter Borg EJ, Bijlsma JWJ, Blaauw AAM, van Albada-Kuipers GA, van Booma-Frankfort C, Jacobs JWG (on behalf of the Utrecht Rheumatoid Arthritis Cohort study Group). Joint surgery in the Utrecht Rheumatoid Arthritis Cohort: the effect of treatment strategy. Ann Rheum Dis 2006;65:1506-11.

92. Kuper HH, Hoekstra M, ten Klooster P, Vermeer M, Haagsma C, Zijlstra T, Laar M van der. Remission can be achieved in 50\% of early rheumatoid arthritis patients after 25 weeks in daily clinical practice. Ann Rheum Dis 2008,67:48.

93. Felson DT, Lawrence RC, Hochberg MC, McAlindon T, Dieppe PA, Minor MA, Blair SN, Berman BM, Fries JF, Weinberger M, Lorig KR, Jacobs JJ, Goldberg V. Osteoarthritis: New Insights Part 2: Treatment Approaches. Ann Intern Med 2000;133:726-37.

94. Towheed T, Maxwell L, Judd M, Catton M, Hochberg MC, Wells GA. Acetaminophen for osteoarthritis. Cochrane Database of Systematic Reviews 2006, Issue 1. Art. No.: CD004257.

95. Vonkeman HE, van de Laar MA. Non-steroidal anti-inflammatory drugs: adverse effects and their prevention. Semin Arthritis Rheum 2010;39:294-312

96. Vonkeman HE, Brouwers JR, van de Laar MA. Understanding the NSAID related risk of vascular events. BMJ. 2006;332:895-8.

97. Jordan KM, Arden NK, Doherty M, Bannwarth B, Bijlsma JW, Dieppe P, et al. EULAR recommendations 2003: an evidence based approach to the management of knee osteoarthritis: Ann Rheum Dis 2003;62:1145-55.

98. Sharma L. Non-pharmacologic management of osteoarthritis. Curr Opin Rheumatol 2002;14:603-7.

99. Creamer P, Flores R, Hochberg MC. Management of osteoarthritis in older adults. Clinics in Geriatric Medicine 1998;14:435-54.

100.Altman RD, Lozada CJ. Practice guidelines in the management of osteoarthritis. Osteoarthritis \& Cartilage 1998;6:22-4.

101. Lane NE, Thompson JM. Management of osteoarthritis in the primary-care setting: an evidence-based approach to treatment. Am J of Medicine 1997;103:S25-30.

102. Hochberg MC, Lethbridge-Cejku M, Scott WW Jr, et al. The association of body weight, body fatness and body fat distribution with osteoarthritis of the knee: data from the Baltimore Longitudinal Study of Aging. J Rheumtol 1995;22:488-493.

103. Felson DT, Zhang Y, Anthony JM, et al. Weight loss reduces the risk for symptomatic knee osteoarthritis in women. Ann Intern Med 1992;116:535-9.

104. Messier SP, Loeser RF, Mitchell MN, Valle G, Morgan TP, Rejeski WJ, et al. Exercise and weight loss in obese older adults with knee osteoarthritis: a preliminary study. J Am Geriatr Soc 2000;48:1062-72. 
105. Smidt N, de Vet HC, Bouter LM, Dekker J, Arendzen JH, de Bie RA, et al. Effectiveness of exercise therapy: a best-evidence summary of systematic reviews. Aust J Physiother 2005;51:71-85.

106. Hurley MV, Mitchell HL, Walshvol N. In osteoarthritis, the psychosocial benefits of exercise are as important as physiological improvements. Exerc Sport Sci Rev 2003;31:138-43.

107. Pencharz JN, Grigoriadis E, Jansz GF, Bombardier C. A critical appraisal of clinical practice guidelines for the treatment of lower-limb osteoarthritis. Arthritis Research 2002;4:36-43.

108. Jones DL, Westby MD, Greidanus N, Johanson NA, Krebs DE, Robbins L, Rooks DS, Brander V. Update on hip and knee arthroplasty: Current state of evidence. Arthritis Care Res 2005;53:772-80.

109. De Groot I. Functioning before and after total hip or knee arthroplasty [thesis]. Rotterdam, the Netherlands: Erasmus University; 2009.

110. Nilsdotter AK, Petersson IF, Roos EM, Lohmander LS. Predictors of patient relevant outcome after total hip replacement for osteoarthritis: a prospective study. Ann Rheum Dis 2003;62;923-30.

111. Ethgen O, Bruyere O, Richy F, Dardennes C, Reginster JY. Health-related quality of life in total hip and total knee arthroplasty. J Bone Joint Surg Am 2004;86:963-74.

112. Muller-Fabender H, Bach GL, Haase W, et al. Glucosamine sulfate compared to ibuprofen in osteoarthritis of the knee. Osteoarthritis Cartilage 1994;2:61-9.

113. Font-Rodriguez DE, Scuderi GR, Insall JN. Survivorship of cemented total knee arthroplasty. Clin Orthop Relat Res 1997;345:79-86.

114. Carswell S, Holman B, Thompson J, Walker W. Acceptable level of aerobic power for patients undergoing elective surgery. J Physiol 1978;285:13.

115. Shelbourne D, Klootwyk T, DeCarlo M: Update on accelerated rehabilitation after anterior cruciate ligament reconstruction. J Orthop Sports Phys Ther 1992;15:303-8.

116. Shilling JA, Molen MT: Physical fitness and its relationship to preoperative recovery in abdominal hysterectomy patients. Heart Lung 1984;13:639-44.

117. Wheatley W, Krome J, Martin D. Rehabilitation programmes following arthroscopic menisectomy in athletes. Sports Med 1996;21:447-56.

118. Weisman MH, Weinblatt ME, Louie JS, van Vollenhoven RF. Targeted Treatment of the rheumatic diseases. first edition, Philadelphia, Saunders Elsevier, 2010. pp. 408-419.

119. Hicks JE. Exercise in patients with inflammatory arthritis and connective tissue disease. Rheum Dis Clin North Am 1990;16:845-70.

120. Häkkinen A. Effectiveness and safety of strength training in rheumatoid arthritis. Curr Opin Rheumatol 2004;16:132-7.

121. Lohmander LS. Clinical Update treating OA. Lancet 2007;370:2082-4. 
122. Hurley MV. Muscle dysfunction and effective rehabilitation of knee osteoarthritis: What We Know and What We Need To Find Out. Arthritis Rheumatism (Arthritis Care Res) 2003;49:444-52.

123. Lyngberg K, Harreby M, Bentzen H, Frost B, Danneskiold- Samsoe B. Elderly rheumatoid arthritis patients on steroid treatment tolerate physical training without an increase in disease activity. Arch Phys Med Rehabil 1994;75:1189-95.

124. Nordesjö LO, Nordgren B, Wigren A, Kolstad K. Isometric strength and endurance in patients with severe rheumatoid arthritis or osteoarthrosis in the knee joints. Scand J Rheumatol 1983;12:152-6.

125. Fisher NM, White SC, Yack HJ, Smolinski RJ, Pendergast DR. Muscle function and gait in patients with knee osteoarthritis before and after muscle rehabilitation. Disabil Rehabil 1997;19:47-55.

126. Hurley MV, Newham DJ. The influence of arthrogenous muscle inhibition on quadriceps rehabilitation of patients with early, unilateral osteoarthritic knees. Br J Rheumatol 1993;32:127-31.

127. Madsen O, Bliddal H, Egsmore C, Sylvest J. Isometric and isokinetic quadriceps strength in gonarthrosis: inter-relations between quadriceps strength, walking ability, radiology, subchondral bone density and pain. Clin Rheumatol 1995;14: 308-14.

128. Slemenda C, Brandt KD, Heilman DK, Mazzuca S, Braunstein EM, Katz BP, et al. Quadriceps weakness and osteoarthritis of the knee. Ann Intern Med 1997;127:97-104.

129. Danneskiold-Samsoe B, Grimby G. Isokinetic and isometric muscle strength in patients with rheumatoid arthritis: the relationship to clinical parameters and the influence of corticosteroids. Clin Rheumatol 1986;5:459-67.

130. Danneskiold-Samsoe B, Grimby G. The relationship between leg muscle strength and physical capacity in patients with rheumatoid arthritis, with reference to the influence of corticosteroids. Clin Rheumatol 1986;5:468-74.

131. Ekdahl C, Broman G. Muscle strength, endurance, and aerobic capacity in rheumatoid arthritis: a comparative study with healthy subjects. Ann Rheum Dis 1992;51:35-40.

132. Hurley MV, Scott Dl. Improvements in quadriceps sensorimotor function and disability of patients with knee osteoarthritis following a clinically practicable exercise regime. $\mathrm{Br}$ J Rheumatol 1998;37:1181-7.

133. Westby MD. A health professional's guide to exercise prescription for people with arthritis: a review of aerobic fitness activities. Arthritis Rheum 2001;45:501-11.

134. Beals CA, Lampman RM, Banwell BF, Braunstein EM, Albers JW, Castor CW. Measurement of exercise tolerance in patients with rheumatoid arthritis and osteoarthritis. J Rheumatol 1985;12:458-61. 
135. Van den Ende CHM, Breedveld FC, Dijkmans BAC, Hazes JMW. The limited value of the Health Assessment Questionnaire as an outcome measure in short term exercise trials. J Rheumatol 1997;24:1972-77.

136. Çimen OB, Deviren SD, Yorgancioğlu ZR. Pulmonary function tests, aerobic capacity, respiratory muscle strength and endurance of patients with rheumatoid arthritis. Clin Rheumatol 2001;20:168-73.

137. Philbin EF, Ries MD, French TS. Feasibility of maximal cardiopulmonary exercise testing in patients with end-stage arthritis of the hip and knee prior to total joint arthroplasty. Chest 1995;108;174-81.

138. Van Tubergen A, van der Linden S. A brief history of spa therapy. Annals of the Rheumatic Diseases 2002; 61:273-5.

139. Stucki G, Sangha O. Principles of rehabilitation. In Klippel JH \& Dieppe PA (eds) Rheumatology, 2nd edn. London: Mosby, 1998, pp. 3.11.1-3.11.14.

140.Verhagen AP, de Vet HCW, de Bie RA, et al. Balneotherapy for Rheumatoid Arthritis and Osteoarthritis (Cochrane Review). The Cochrane Library, Oxford: Update Software, 2002. Issue 4.

141. Bilberg A, Ahlmen M, Mannerkorpi K. Moderately intensive exercise in a temperate pool for patients with rheumatoid arthritis: a randomized controlled study. Rheumatology (Oxford) 2005;44:502-8.

142. Minor MA, Hewett JE, Webel RR, Anderson SK, Day DR. Efficacy of physical conditioning exercise in patients with rheumatoid arthritis and osteoarthritis. Arthritis Rheum 1989;32:1396-1405.

143. Hall J, Skevington SM, Maddison PJ, Chapman K. A randomized and controlled trial of hydrotherapy in rheumatoid arthritis. Arthritis Care Res 1996;9:206-15.

144. Suomi R, Collier D. Effects of arthritis exercise programs on functional fitness and perceived activities of daily living measures in older adults with arthritis. Arch Phys Med Rehabil 2003;84:1589-94.

145. Stenström CH, Lindell B, Swanberg E, Swanberg P, Harms-Ringdahl K, Nordemar R. Intensive dynamic training in water for rheumatoid arthritis functional class II-a longterm study of effects. Scand J Rheumatol 1991;20:358-65.

146. Sanford-Smith S, Mackay-Lyons M, Nunes-Clement S. Therapeutic benefit of aqua aerobics for individuals with Rheumatoid Arthritis. Physiother Canada 1998;50:40-6.

147. Creamer P, Lethbridge-Cejku M, Hochberg MC. Determinants of pain severity in knee osteoarthritis: effect of demographic and psychosocial variables using 3 pain measures. J Rheumatol 1999;26:1785-92.

148. Keefe FJ, Caldwell DS, Queen K, Gil KM, Martinez S, Crisson JE et al. Osteoarthritic knee pain: a behavioral analysis. Pain 1987;28:309-21. 
149. Fransen M. When is physiotherapy appropriate? Best Practice \& Research Clinical Rheumatology 2004;18:477-89.

150. De Vreede PL, Samson MM, van Meeteren NL, Duursma SA, Verhaar HJ. Functional-task exercise versus resistance strength exercise to improve daily function in older women: a randomized, controlled trial. J Am Geriatr Soc 2005;53:2-10.

151. De Jong Z, Munneke M. Rheumatoid Arthritis patients in training. Long-term highintensity exercise in patients with rheumatoid arthritis (the RAPIT study) [thesis]. Leiden, the Netherlands: University of Leiden; 2004.

152. Minor MA. 2002 Exercise and Physical Activity Conference, St. Louis, Missouri: Exercise and Arthritis "We Know a Little Bit About a Lot of Things ..." Arthritis Rheum (Arthritis Care Res) 2003;49:1-2.

153. Bennell K, Hinman R. Exercise as a treatment for osteoarthritis. Curr Opin Rheumatol 2005;17:634-40.

154.Fransen M, McConnell S, Bell M. Therapeutic exercise for people with osteoarthritis of the hip or knee. A systematic review. J Rheumatol 2002;29:1737-45.

155.Van Baar ME, Dekker J, Lemmens JAM, Oostendorp RAB, Bijlsma JWJ. Pain and disability in patients with osteoarthritis of hip or knee: the relationship with articular, kinesiological, and psychological characteristics. J Rheumatol 1998;25:125-33.

156.Van Baar ME, Assendelft WJ, Dekker J, Oostendorp RA, Bijlsma JW. Effectiveness of exercise therapy in patients with osteoarthritis of the hip or knee: a systematic review of randomized clinical trials. Arthritis Rheum 1999;42:1361-9.

157. Rat AC, Guillemin F, Osnowycz G, Delagoutte JP, Cuny C, Mainard D, Baumann C. Total hip or knee replacement for osteoarthritis: Mid- and long-term quality of life. Arthritis Care Res 2010;62:54-62.

158. Fortin PR, Penrod JR, Clarke AE, St-Pierre Y, Joseph L, Belisle P, Liang MH, Ferland D, Phillips CB, Mahomed N, et al. Timing of total joint replacement affects clinical outcomes among patients with osteoarthritis of the hip or knee. Arthritis Rheum 2002;46:332730.

159. Bachmeier CJ, March LM, Cross MJ, Lapsley HM, Tribe KL, Courtenay BG, Brooks PM. A comparison of outcomes in osteoarthritis patients undergoing total hip and knee replacement surgery. Osteoarthritis Cartilage 2001;9:137-46.

160.Salmon P, Hall GM, Peerbhoy D, Shenkin A, Parker C. Recovery from hip and knee arthroplasty: patients' perspective on pain, function, quality of life, and well-being up to 6 months postoperatively. Arch Phys Med Rehabil 2001;82:360-6.

161. Stevens M, van den Akker-Scheek I, Spriensma A, Boss NAD, Diercks RL, van Horn JR. The Groningen Orthopedic Exit Strategy (GOES): a home-based support program for total hip and knee arthroplasty patients after shortened hospital stay. Patient Education and Counseling 2004;54:95-9. 
162. Peerbhoy D, Keane P, Maciver K, Shenkin A, Hall GM, Salmon P. The systematic assessment of short-term functional recovery after major joint arthroplasty. J Qual Clin Pract 1999;19:165-71.

163. Lenssen AF, de Bie RA. Role of physiotherapy in peri-operative management in Total knee and hip surgery. Injury Int J Care Injured 2006;37:S41-3.

164. Minns Lowe CJM, Barker KL, Dewey ME, Sackley CM. Effectiveness of physiotherapy exercise after knee arthroplasty for osteoarthritis: systematic review and meta-analysis of randomised controlled trials. BMJ 2007;335:812;doi:10.1136/bmj.39311.460093.BE.

165. Minns Lowe CJM, Barker KL, Dewey ME, Sackley CM. Effectiveness of physiotherapy exercise following hip arthroplasty for osteoarthritis: a systematic review of clinical trials. BMC Musculoskeletal Disorders 2009, 10:98 (doi:10.1186/1471-2474-10-98).

166. National Institutes of Health. National Institutes of Health consensus statement on total knee replacement. Bethesda (MD): US Department of Health and Human Services; 2004, pp. 1-18.

167. Van den Ende CHM, Vliet Vlieland TPM, Munneke M, Hazes JMW. Dynamic Exercise Therapy for Treating Rheumatoid Arthritis (Cochrane Review). The Cochrane Library, Oxford: Update Software, 2002. Issue 4.

168. Munneke M, de Jong $\mathrm{Z}$. The role of exercise programs in the rehabilitation of patients with rheumatoid arthritis. International Journal of Sports Medicine 2001;1:1-12.

169. Häkkinen A, Sokka T, Kotaniemi A, Kautiainen H, Jäppinen I, Laitinen L, et al. Dynamic strength training in patients with early rheumatoid arthritis increases muscle strength but not bone mineral density. J Rheumatol 1999;26:1257-63.

170. Häkkinen A, Sokka T, Kotaniemi A, Hannonen P. A randomized two-year study of the effects of dynamic strength training on muscle strength, disease activity, functional capacity, and bone mineral density in early rheumatoid arthritis. Arthritis Rheum 2001;44:515-22.

171. Häkkinen A, Sokka T, Lietsalmi AM, Kautiainen H, Hannonen P. Effects of dynamic strength training on physical function, Valpar 9 work sample test, and working capacity in patients with recent-onset rheumatoid arthritis. Arthritis Rheum 2003;49:71-7.

172. Häkkinen A, Sokka T, Hannonen P. A home-based two year strength training period in early rheumatoid arthritis led to good long-term compliance: a five-year follow up. Arthritis Rheum 2004;51:56-62.

173. Häkkinen A, Sokka T, Kautiainen H, Kotaniemi A, Hannonen P. Sustained maintenance of exercise induced muscle strength gains and normal bone mineral density in patients with early rheumatoid arthritis: a 5 year follow up. Ann Rheum Dis 2004;63:910-6.

174. McMeekin J, Stillman B, Story I, Kent P. The effects of knee extensor and flexor muscle training on the timed-up-and-go test in individuals with rheumatoid arthritis. Physiother Res Int 1999;4:55-67. 
175. Ekdahl C, Andersson SI, Moritz U, Svensson B. Dynamic versus static training in patients with rheumatoid arthritis. Scand J Rheumatol 1990;19:17-26.

176. Brandt KD, Heilman DK, Slemenda C, Katz BP, Mazzuca S, Braunstein EM, et al. A comparison of lower extremity muscle strength, obesity, and depression scores in elderly subjects with knee pain with and without radiographic evidence of knee osteoarthritis. J Rheumatol 2000;27:1937-46.

177. Hurley MV, Scott DL, Rees J, Newham DJ. Sensorimotor changes and functional performance in patients with knee osteoarthritis. Ann Rheum Dis 1997;56:641-8.

178. Steultjens MPM, Dekker J, van Baar ME, Oostendorp RAB, Bijlsman JWJ. Muscle strength, pain and disability in patients with osteoarthritis. Clin Rehabil 2001;15:331-41.

179. Pelland L, Brosseau L, Well G, et al. Efficacy of strengthening exercise therapy for osteoarthritis (Part I): A meta-analysis. Phys Ther Rev 2004;9:77-108.

180. Cairns AP, McVeigh JG. A Systematic review of the effects of dynamic exercise in rheumatoid arthritis. Rheumatol Int 2009;30:147-58.

181. Ekblom B, Lövgren O, Alderin M, Fridström M, Sätterström G. Physical performance in patients with rheumatoid arthritis. Scand J Rheumatol 1974;3:121-5.

182. Minor MA, Hewett JE, Webel RR, Dreisinger TE, Kay DR. Exercise tolerance and disease related measures in patients with rheumatoid arthritis and osteoarthritis. J Rheumatol 1988;15:905-11.

183. Baillet A, Zeboulon N, Gossec L, Combescure C, Bodin LA, Juvin R, Dougados M, Gaudin P. Efficacy of cardiorespiratory aerobic exercise in rheumatoid arthritis: Meta-analysis of Randomized Controlled Trials. Arthritis Care Res 2010;62:984-92.

184. Kettunen JA, Kujala UM. Exercise therapy for people with rheumatoid arthritis and osteoarthritis. Scand J Med Sci Sports 2004;14:138-142.

185. De Jong Z, Munneke M, Zwinderman AH, Kroon HM, Jansen A, Ronday KH, van Schaardenburg D, Dijkmans BA, Van den Ende CH, Breedveld FC, Vliet Vlieland TP, Hazes JM. Is a long-term high-intensity exercise program effective and safe in patients with rheumatoid arthritis? Results of a randomized controlled trial. Arthritis Rheum 2003;48:2415-24.

186. De Jong Z, Munneke M, Lems WF, Zwinderman AH, Kroon HM, Pauwels EK, Jansen A, Ronday KH, Dijkmans BA, Breedveld FC, Vliet Vlieland TP, Hazes JM. Slowing of bone loss in patients with rheumatoid arthritis by long-term high intensity exercise: results of a randomized, controlled trial. Arthritis Rheum 2004;50:1066-76.

187. De Jong Z, Munneke M, Zwinderman AH, Kroon HM, Ronday KH, Lems WF, Dijkmans BA, Breedveld FC, Vliet Vlieland TP, Hazes JM, Huizinga TW. Long-term high intensity exercise and damage of small joints in rheumatoid arthritis. Ann Rheum Dis 2004; 63(11):1399-405. 
188. Munneke M, de Jong Z, Zwinderman AH, Ronday HK, van Schaardenburg D, Dijkmans BA, Kroon HM, Vliet Vlieland TP, Hazes JM. Effect of a high-intensity weight-bearing exercise program on radiologic damage progression of the large joints in subgroups of patients with rheumatoid arthritis. Arthritis Rheum 2005;53:410-7.

189. Komatireddy GR, Leitch RW, Cella K, Browning G, Minor M. Efficacy of load resistive muscle training in patients with rheumatoid arthritis functional class II and III. J Rheumatol 1997;24:1531-9.

190. Van den Ende CHM, Hazes JMW, le Cessie S, Mulder WJ, Belfor DG, Breedveld FC, et al. Comparison of high and low intensity training in well controlled rheumatoid arthritis: results of a randomised clinical trial. Ann Rheum Dis 1996;55:798-805.

191. Westby MD, Wade JP, Rangno KK, Berkowitz J. A randomized controlled trial to evaluate the effectiveness of an exercise program in women with rheumatoid arthritis taking low dose prednisone. J Rheumatol 2000;27:1674-80.

192. Van den Ende CHM, Vliet Vlieland TPM, Munneke M, Hazes JMW. Dynamic exercise therapy in rheumatoid arthritis: a systematic review. Br J Rheumatol 1998;37:677-87.

193. Van den Ende CH, Vliet Vlieland TP, Munneke M, Hazes JM. Dynamic exercise therapy for rheumatoid arthritis. Cochrane Database Syst Rev 2000;2(2):CD000322.

194. Finckh A, Iversen M, Liang MH. The exercise prescription in rheumatoid arthritis: primum non nocere. Arthritis Rheum 2003;48:2393-5.

195. Fransen M, Crosbie J, Edmonds J. Physical therapy is effective for patients with osteoarthritis of the knee: a randomised controlled trial. J Rheumatol 2001;28:156-64.

196. Munin MC, Rudy TE, Glynn NW, Crossett LS, Rubash HE. Early inpatient rehabilitation after elective hip and knee arthroplasty. JAMA 1998;279:847-52.

197. Vliet Vlieland TPM, Breedveld PC, Hazes JMW. The two-year follow-up of a randomized comparison of in-patient multidisciplinary team care and routine out-patient care for active rheumatoid arthritis. Br J Rheumatol 1997;36:82-5.

198. Häkkinen A, Malkia E, Häkkinen K, Jäppinen I, Laitinen L, Hannonen P. Effects of detraining subsequent to strength training on neuromuscular function in patients with inflammatory arthritis. Br J Rheumatol 1997;36:1075-81.

199. Takken T, van Brussel M, Engelbert RH, Van der Net J, Kuis W, Helders PJ. Exercise therapy in juvenile idiopathic arthritis: a Cochrane Review. Eur J Phys Rehabil Med 2008 Sep;44(3):287-97

200. Sullivan T, Allegrante JP, Peterson MGE, Kovar PA, McKenzie CR. One-year follow up of patients with osteoarthritis of the knee who participated in a program of supervised fitness walking and supportive patient education. Arthritis Care Res 1998;11:228-33.

201. Van Baar ME, Dekker J, Oostendorp RAB, Bijl D, Voorn TB, Lemmins JAM, et al. Effectiveness of exercise therapy in patients with osteoarthritis of knee and hip: nine month follow-up. Ann Rheum Dis 2002;60:1123-30. 
202. Chamberlain MA, Care G, Harfeild B. Physiotherapy in osteoarthritis of the knee: a controlled trial of hospital versus home exercises. Int J Rehabil Med 1982;4:101-6.

203. O'Reilly S, Muir K, Doherty M. Effectiveness of home exercises on pain and disability from osteoarthritis of the knee: a randomised controlled trial. Ann Rheum Dis 1999;58:15-9.

204.Ettinger WH, Burns R, Messier SP, Applegate W, Rejeski WJ, Morgan T, et al. A randomised control trial comparing aerobic exercise and resistance exercise with a health education program in older adults with knee osteoarthritis. JAMA 1997;277:2531.

205. Thomas KS, Muir KR, Docherty M, Jones AC, O’Reilly SC, Bassey EJ. Home based exercise programme for knee pain and knee osteoarthritis: randomised controlled trial. BMJ 2002;325:752-6.

206. Roddy E, Zhang W, Doherty M. Aerobic walking or strengthening exercise for osteoarthritis of the knee? A systematic review. Ann Rheum Dis 2005;64: 544-48.

207. Häkkinen A, Häkkinen K, Hannonen P. Effects of strength training on neuromuscular function and disease activity in patients with recent-onset inflammatory arthritis. Scand J Rheumatol 1994;23:237-42.

208. Roddy E, Zhang W, Doherty M, et al. Evidence-based recommendations for the role of exercise in the management of osteoarthritis of the hip or knee - the MOVE consensus. Rheumatol 2005; 44:67-73. 



\section{Chapter 3}

\section{Arm crank ergometer is reliable and valid for measuring aerobic capacity during submaximal exercise}

Y. Bulthuis, K.W. Drossaers-Bakker, F. Oosterveld, J. van der Palen and M.A.F.J. van de Laar

J Strength Cond Res 2010;24(10):2809-2815 


\begin{abstract}
Objective. Measuring physical fitness becomes more important. Yet most instruments depend upon the function of the lower extremities. Hence, we investigated whether an adapted submaximal arm crank test on an ergometer for the upper body is reliable to use, and if the submaximal test for the arm crank ergometer is valid compared to the test on the bicycle ergometer.

Methods. Different types of reliability measures of the adapted submaximal test on an arm crank ergometer were assessed in healthy volunteers, such as test-retest, inter-observer, inter-ergometer and between arm crank and bicycle ergometer. $\mathrm{A}$ cross-over design was used.
\end{abstract}

Results. The measurements were proportionally distributed over 30 volunteers. Based on the intraclass correlation coefficient (ICC) and the magnitude of withinperson differences, we revealed a good reliability of the submaximal test. For the test-retest reliability the ICC was 0.76 , the inter-observer reliability was 0.82 and the inter-ergometer reliability 0.63 . In addition, the criterion validity was also tested by comparing the calculated $\mathrm{VO}_{2}$ max during the submaximal test on the arm crank ergometer and on the bicycle ergometer. Between $\mathrm{VO}_{2}$ max on the arm crankand bicycle ergometer, an ICC of 0.64 was found. The results of the submaximal test on the arm crank ergometer are reliable and valid as compared with the bicycle crank ergometer.

Conclusion. We showed that the submaximal test on the arm crank ergometer is suitable for measuring physical fitness in healthy people. We expect that disabled people can use this submaximal test on the arm crank ergometer for measuring their physical fitness, also. 


\section{INTRODUCTION}

Beyond any doubt, exercise has physical and psychological benefits to health. ${ }^{21}$ In healthy people but especially in disabled persons, attention for exercise is warranted. 4,9,15,18,25,26 In recent years, there is an increasing use of physical training programs. Although in healthy people assessment of physical fitness is generally performed on the lower extremities, in many patients, the lower extremities are impaired. Examples are patients with surgery on the lower extremity, paraplegia, and patients with amputations. To assess physical fitness in these patients, development of valid measurements for the upper extremities is mandatory to evaluate their improvement because of exercise.

The best and most accurate way to determine the aerobic capacity is direct measurement of the maximum oxygen uptake $\left(\mathrm{VO}_{2}\right.$ max $)$ during a maximal test. ${ }^{16,22}$ However, this method is expensive, time-consuming and often difficult to perform. To assess physical fitness more easily, there are several alternative submaximal field tests for the lower extremities. Examples are the Harvard step test, ${ }^{20} \mathrm{Craft}$ step test, ${ }^{19}$ 6-minute walking test ${ }^{10}$ and the Åstrand-Ryhming test on a bicycle ergometer. ${ }^{3}$ The latter is validated and the most widely used submaximal exercise test. $1,2,8,19,27$

Although impairment of the lower extremities is prevalent, submaximal test generally depend upon normal function of the lower extremities. Nowadays, individuals who suffer from lower extremity injuries often use arm crank exercise as a training mode to improve their cardiorespiratory fitness during the rehabilitation process. To the best of our knowledge, no standard submaximal arm crank test is available to measure aerobic capacity in these patients and thus the effectiveness of training. Therefore, a specially adapted submaximal test have been used in this study.

We anticipated differences between submaximal tests performed with the arms and with the legs. Previous investigations have demonstrated differences in physiological responses between leg and arm exercise.4,7,12-14 Explanations for these differences are the relatively smaller muscle mass in the upper body and differences in training status between the arm and leg muscles. ${ }^{23}$ The use of a smaller muscle mass means that only approximately $60 \%$ of the maximal leg load can be achieved using the arm crank ergometer. ${ }^{16}$ Therefore, it is needed that the 
workload during the submaximal arm crank ergometer field test is titrated upon the individual and started with a minimal workload.

The goal of this study is to determine whether a submaximal arm crank test can be used for the assessment of the physical fitness in an individual. Moreover, we try to establish the reliability and validity of this method in predicting the $\mathrm{VO}_{2}$ max.

\section{METHODS}

\section{Experimental approach to the problem}

To test the validity of the adapted submaximal arm crank ergometer test, we used two arm crank ergometers and one bicycle ergometer. In healthy subjects, an adapted submaximal test was used, comparable to the Åstrand-Ryhming test. Between both arm crank ergometer tests, we compared the results of the average heart rate during the fifth and sixth minutes. Between the arm crank ergometer and bicycle ergometer, we compared the predicted $\mathrm{VO}_{2}$ max.

\section{Subjects}

Healthy volunteers were selected among students of the Saxion Hogeschool and employees of the Medisch Spectrum Twente hospital, Enschede, the Netherlands. The Ethical Committee approved the study and subjects were included after giving written informed consent.

For 30 healthy volunteers, a crossover design has been used for reliability and validity of the tests. Each subject performed a maximum of three tests. The selection and sequence of the different assessments in each person was random. Fifteen volunteers were asked to perform the test on the arm crank ergometer twice (test-retest reliability). Eight volunteers were selected to do a test on an arm crank ergometer twice observed by two different persons (inter-observer reliability). Fifteen volunteers performed a test on two different arm crank ergometers (inter ergometer reliability) and an additional test on a bicycle ergometer (criterion validity). Only one volunteer was not able to perform the last test (arm crank ergometer) because of unrelated injury.

The demographics and baseline characteristics are shown in Table 1 . The ergometer test was completed within 6 minutes by $94 \%$ of the volunteers. 


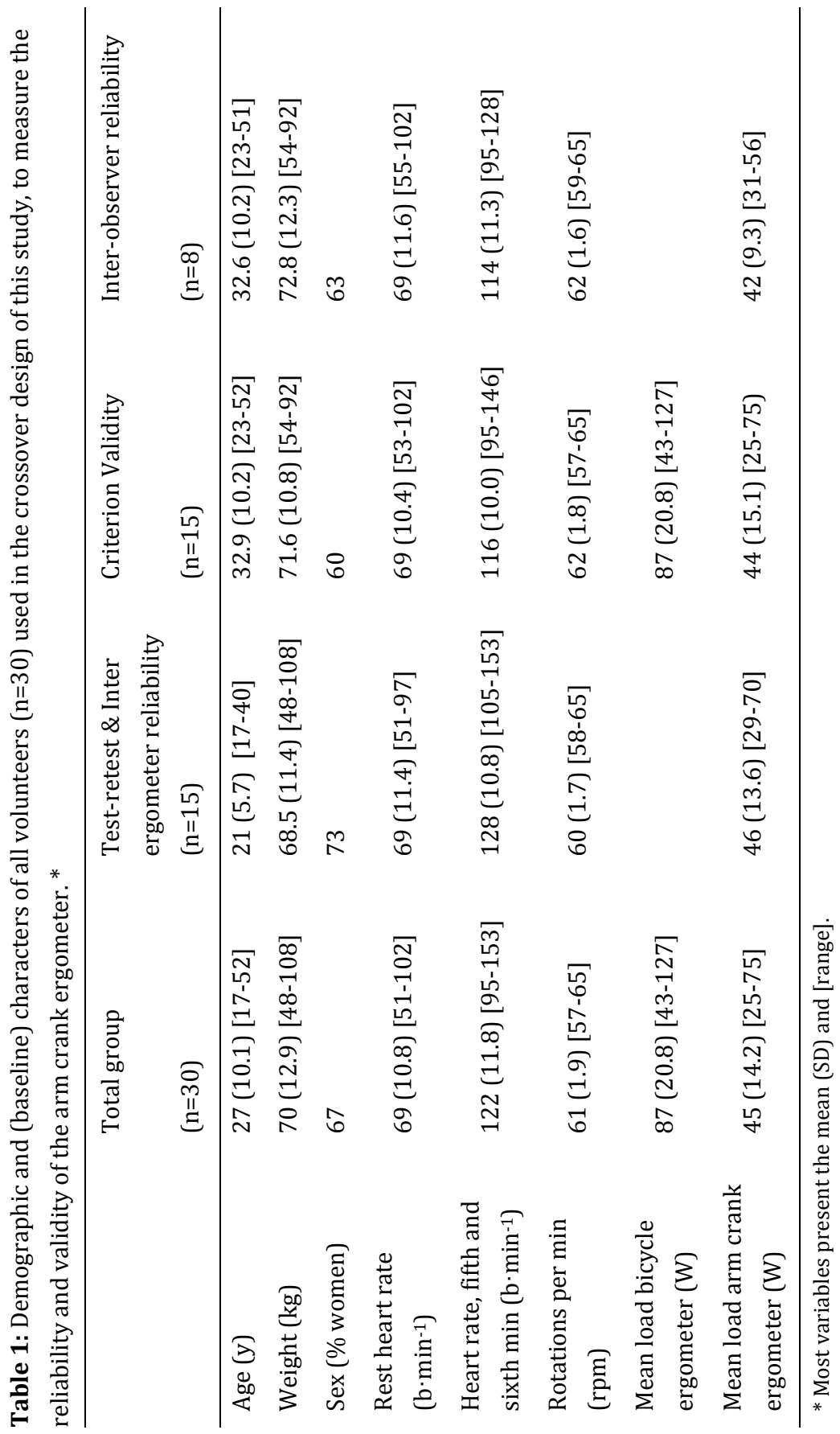




\section{Procedures}

In this study, we used the comparable arm crank- and bicycle ergometer, Ergocircle $1200^{\mathrm{TM}}$ and Ergo-cycle $1500^{\mathrm{TM}}$, respectively (see Figure 1).

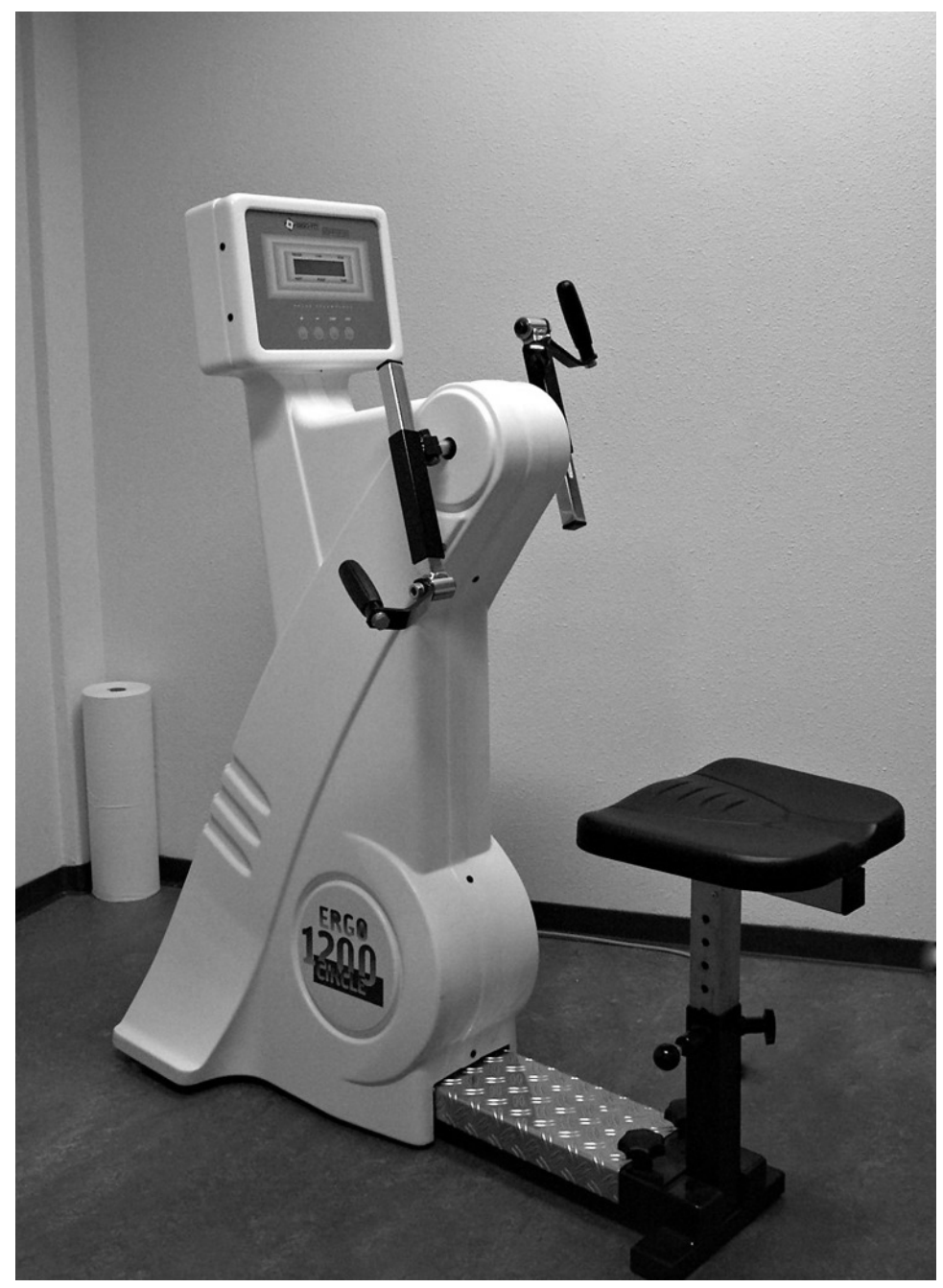

Figure 1: The arm crank ergometer (model Ergo-circle 1200) used in this study, from the company ERGO-FIT. 
During the arm cranking test, the elbows were at no time fully extended, and the individual was sitting. During the different arm crank tests, for each subject, the same increase of load was used. During the bicycle ergometer test, the knees were at no time fully extended. The resting heart rate and body weight (kilograms) were recorded before to the test. The resting heart rate was measured with a heart rate monitor after relaxation of two minutes. To create a constant rhythm of frequency rotations during the test, people practice before the submaximal test with a load of $25 \mathrm{~W}$.

The submaximal test was performed as follows. The exercise tests lasted six minutes while the frequency of rotations (55-65 per minute) was kept constant. We used a starting load of $25 \mathrm{~W}$ instead of the standard $50 \mathrm{~W}$ as used in the ÅstrandRyhming test. During the first three minutes of each test, the resistance was increased with steps of $5 \mathrm{~W}$ instead of $25 \mathrm{~W}$. The aim was to reach a heart rate between 60 and $85 \%$ of the expected maximum heart rate (HRmax=220-age), instead of $70 \%$ of the age-related HRmax in the Åstrand-Ryhming test. After the first three minutes, the resistance was kept constant. During the fifth and sixth minute, the aim was to establish a steady heart rate, allowing a maximum fluctuation of $5 \mathrm{~b} \cdot \mathrm{min}^{-1}$. When this steady state had not yet been reached, the test was extended up to a maximum of ten minutes.

The subjects refrained from smoking or taking coffee, heavy meals, or alcohol for at least two hours before the test. To ensure stable assessments, intensively physical exercise before or between the tests was not allowed, and the tests had at least a 24 hours' interval. Each individual completed all tests within a fortnight. The variables, heart rate $\left(\mathrm{b} \cdot \mathrm{min}^{-1}\right)$, used energy $(\mathrm{kcal})$, load $(\mathrm{W})$ and rotations per minute (rpm) were measured each minute.

\section{Statistical analysis}

The maximal oxygen uptake $\left(\mathrm{VO}_{2}\right.$ max $)$ was calculated using the equation of the Åstrand-Ryhming nomogram:

Estimated $\max \mathrm{VO}_{2}\left(\mathrm{ml} \cdot \mathrm{kg}^{-1} \cdot \mathrm{min}^{-1}\right)=$ Estimated $\mathrm{O}_{2}\left(\mathrm{ml} \cdot \mathrm{min}^{-1}\right) *$ Age Correction Factor/Weight (kg).3,12,17 
The equation for men is as follows:

Estimated $\mathrm{O}_{2}\left(\mathrm{ml} \cdot \mathrm{min}^{-1}\right)=1000 * \frac{174.2 * \mathrm{~W}+4020}{103.5 * \mathrm{~b} \cdot \mathrm{min}^{-1}-6298}$

The Equation for women is as follows:

Estimated $\mathrm{O}_{2}\left(\mathrm{ml} \cdot \min ^{-1}\right)=1000 * \frac{163.8 * \mathrm{~W}+3780}{104.4 * \mathrm{~b} \cdot \mathrm{min}^{-1}-7514}$

Where $b \cdot \min ^{-1}=$ mean exercise heart rate between the fifth and sixth minute and $\mathrm{W}=$ mean wattage during 6 minutes.

After analyzing the distribution of the data, and where applicable normalization of the data, comparability was tested by using the intraclass correlation coefficient (ICC). Interclass correlation coefficients were considered excellent when $>0.75$, fair to good when $\geq 0.40$ to $\leq 0.75$, and poor when $<0.40 .{ }^{11}$ Because the ICC does not provide information on the magnitude of within-person differences, a BlandAltman plot was constructed. ${ }^{5}$ The relation between $\mathrm{VO}_{2 \text { max }}$ arm and $\mathrm{VO}_{2 \text { max }}$ leg was tested with a univariate linear regression analysis.

The limit of statistical significance was set at $\mathrm{p} \leq 0.05$ (2-sided). Power analyses were performed to find the subject sample sizes for all tests. For test-retest, interergometer and validity tests, a sample size of at least 13 persons was calculated to find a correlation of 0.70 (alpha $=0.05$, beta $=0.20$ ). The inter-observer reliability correlation was set higher at 0.8 (alpha $=0.05$ ) because of rigidity of the protocol. Moreover, it was expected that the observer had a minimal effect on the outcome of the tests. This resulted in a sample size of nine subjects. Analyses were performed using the statistical package SPSS (version 12.0.1 SPSS for Windows). 


\section{RESULTS}

\section{Reliability}

The test-retest differences $(n=14)$ in heart rate during the fifth and sixth minute were on average $2.25 \mathrm{~b} \cdot \mathrm{min}^{-1}(\mathrm{SD}=7.74)$. During the retest, the average heart rate was usually lower. Figure 2 presents the Bland and Altman plot, which shows the intra-individual heart rate difference against the individual average heart rate during the fifth and sixth minute measured with the submaximal arm crank ergometer tests. The $95 \%$ limits of agreement are 17.42 and $-12.92 \mathrm{~b} \cdot \mathrm{min}^{-1}$. For the test-retest on the arm crank ergometer, an ICC of 0.76 was found $(95 \% \mathrm{CI}$; 0.41 $0.92, \mathrm{p}<.001)$

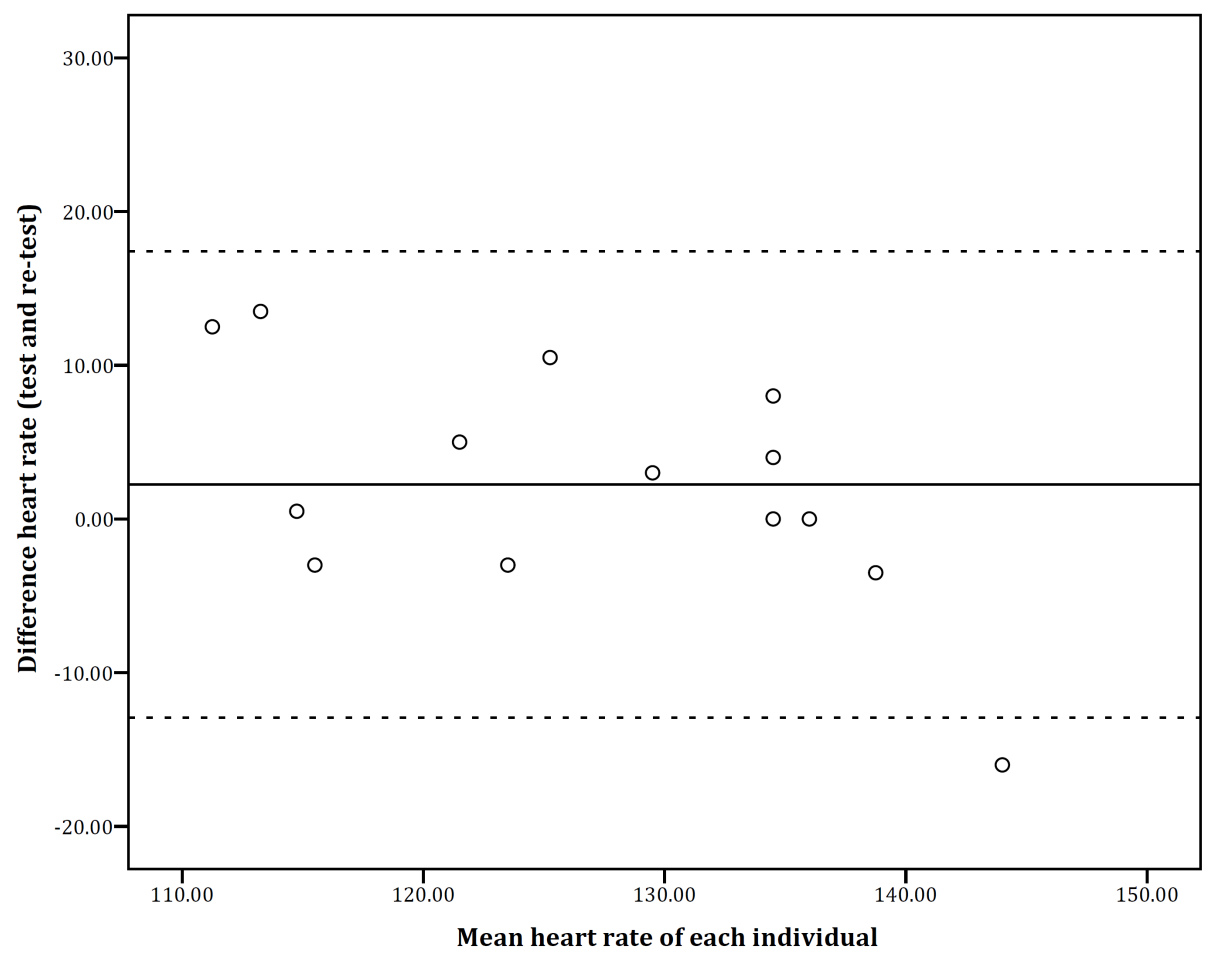

Figure 2: Test-retest differences of a submaximal test on an arm crank ergometer ( $n=14)$. It shows the intra-individual difference of the heart rate against the individual average heart rate during the fifth and sixth minute between two tests. It also presents the $95 \%$ limits of agreement (dashed lines 17.42 and $-12.92 \mathrm{~b} \cdot \mathrm{min}^{-1}$ ) and the horizontal solid line represents the mean difference of both change scores $\left(2.25 \mathrm{~b} \cdot \mathrm{min}^{-1}\right)$. 
An ICC of 0.82 was found when 2 different observers evaluated the same test (95\%CI; 0.35-0.96, p=.003). Figure 3 illustrates the inter-observer differences $(n=8)$ of each individual. It shows the intra-individual difference of heart rate against the average individual heart rate during the fifth and sixth minute on the submaximal arm crank ergometer tested by 2 observers. The mean difference between both heart rates was $-3.81 \mathrm{~b} \cdot \mathrm{min}^{-1}(\mathrm{SD}=6.71)$. The $95 \%$ limits of agreement are 9.34 and $-16.96 \mathrm{~b} \cdot \mathrm{min}^{-1}$.

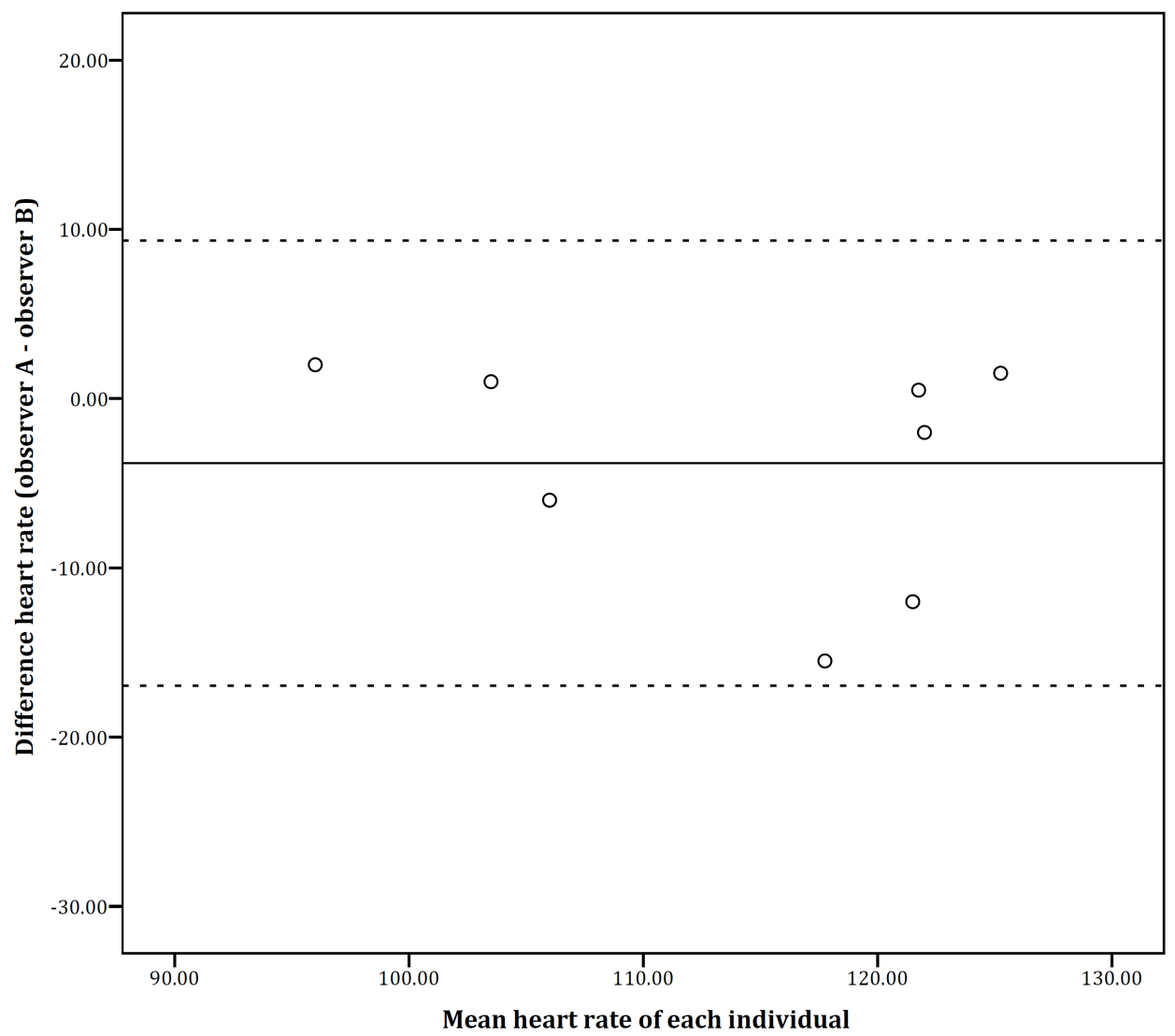

Figure 3: Inter-observer differences of a submaximal test on an arm crank ergometer $(n=8)$. It shows the intra-individual difference of the heart rate against the individual average heart rate during the fifth and sixth minute tested by two different observers. It also presents the 95\% limits of agreement (dashed lines 9.34 and $-16.96 \mathrm{~b} \cdot \mathrm{min}^{-1}$ ) and the horizontal solid line represents the mean difference of both change scores $\left(-3.81 \mathrm{~b} \cdot \mathrm{min}^{-1}\right)$. 
When subjects performed the same test on 2 crank ergometers of the same model, the ICC was fair to good (ICC $=0.63,95 \%$ CI; 0.19-0.86, $\mathrm{p}=.004$ ).

Inter arm crank ergometer differences $(n=15)$ of each individual are shown in Figure 4: It shows the intra-individual difference of the heart rate against mean individual average heart rate during the fifth and sixth minute with a submaximal test on 2 different crank ergometers. The mean difference of heart rate of all individuals is $-0.50 \mathrm{~b} \cdot \mathrm{min}^{-1}$. The $95 \%$ limits of agreement are 15.98 and -16.98 $\mathrm{b} \cdot \mathrm{min}^{-1}$.

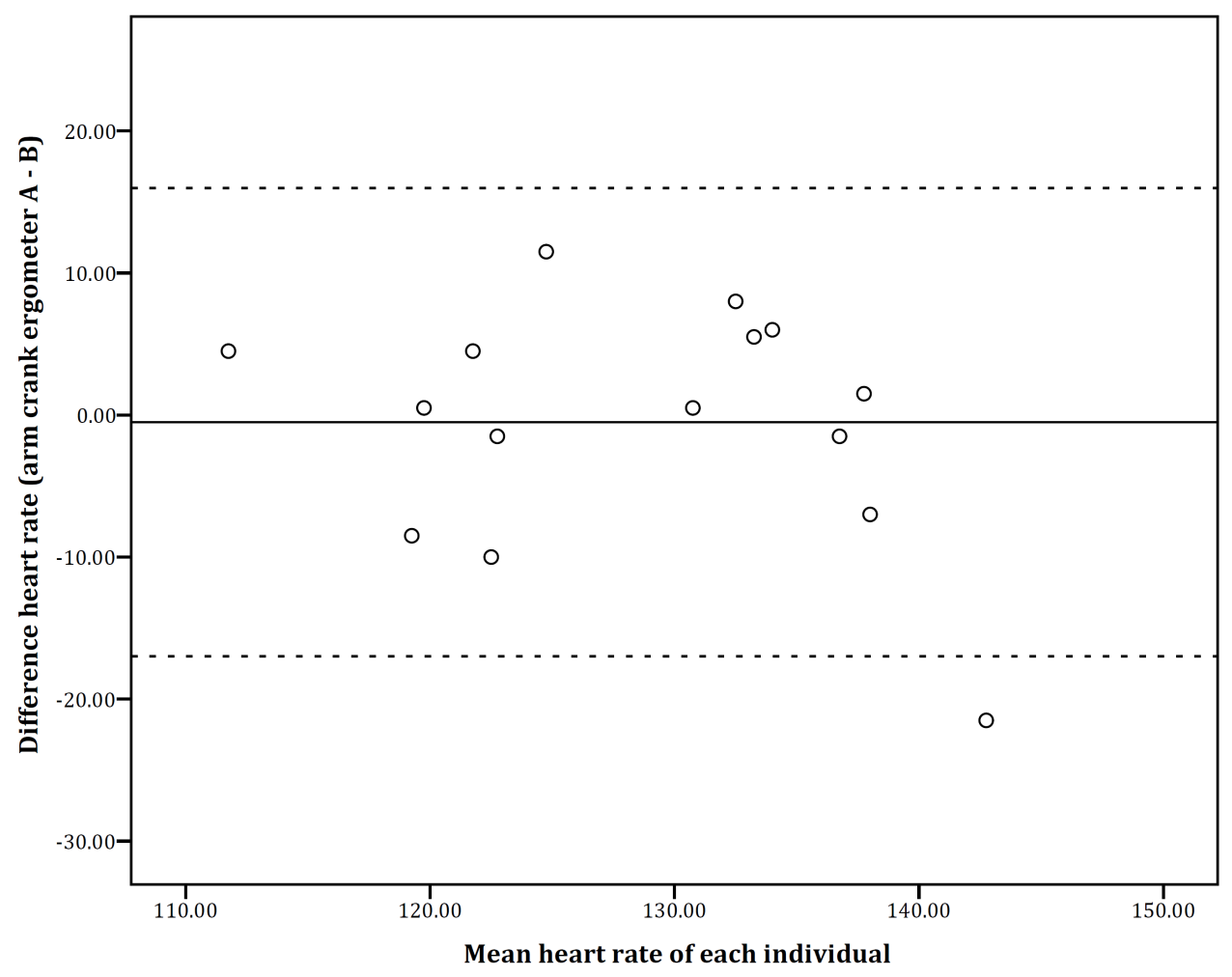

Figure 4: Inter ergometer differences during a submaximal test $(n=15)$. It shows the intraindividual difference of the heart rate against the individual average heart rate during the fifth and sixth minute, measured on two different arm crank ergometers. It also presents the 95\% limits of agreement (dashed lines, 15.98 and-16.98 b $\cdot \mathrm{min}^{-1}$ ) and the horizontal solid line represents the mean difference of both change scores $\left(-0.5 \mathrm{~b} \cdot \mathrm{min}^{-1}\right)$. 


\section{Criterion Validity}

The external validity of the arm crank ergometer was assessed by comparing the estimated $\mathrm{VO}_{2}$ max obtained with the arm crank ergometer and the results obtained with the bicycle ergometer. Although the heart rate during the submaximal tests was relative low (minimal $60 \%$ of the age related maximum heart rate), an ICC of 0.64 was found $(95 \% \mathrm{CI} ; 0.21-0.86, \mathrm{p}=.004)$.

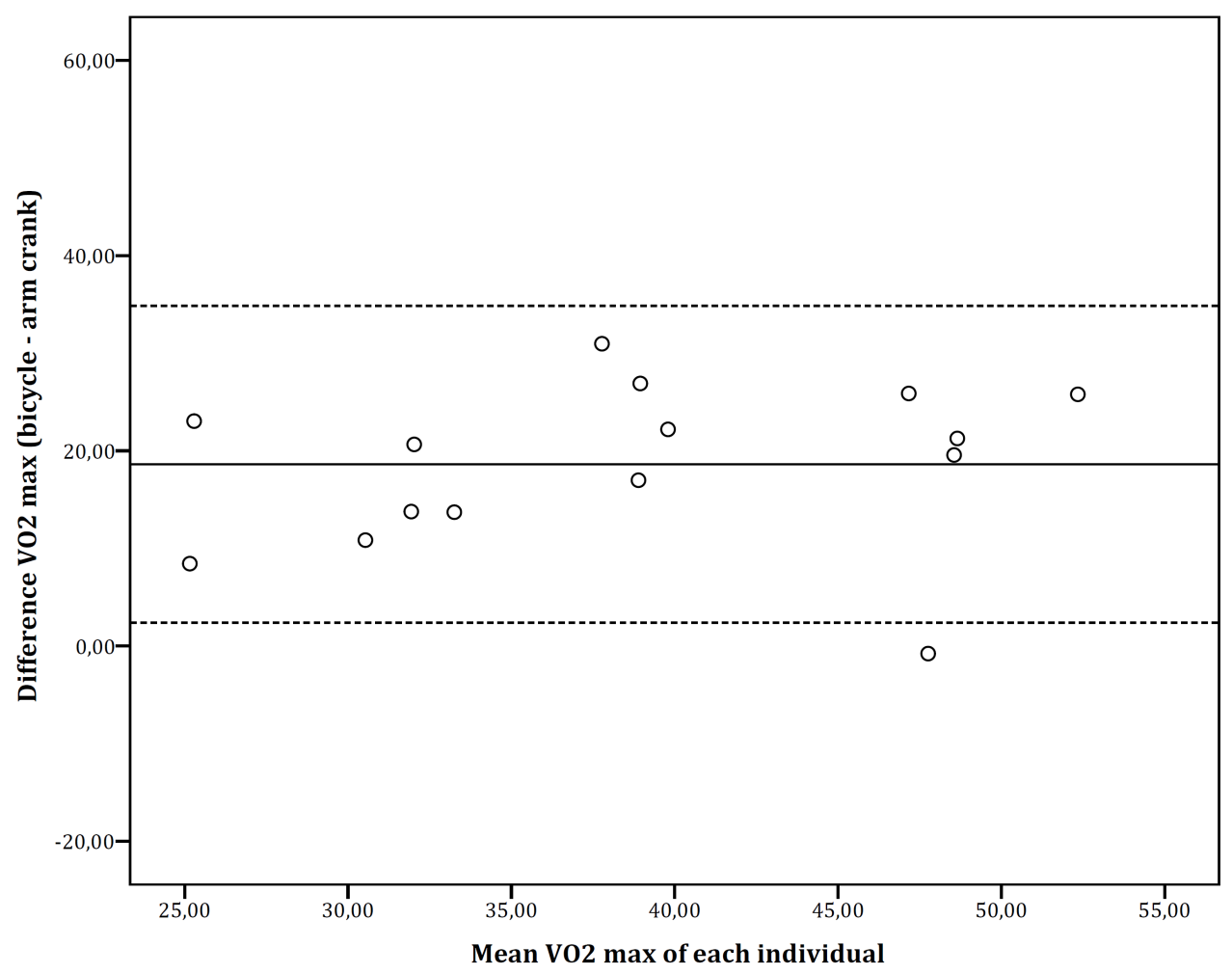

Figure 5: Agreement between the VO2 max of the arm crank and bicycle ergometer $(n=15)$. It shows the intra-individual difference of the VO2 max against the individual average VO2 max during the fifth and sixth minute on an submaximal test. The dashed lines represent the $95 \%$ limits of agreement ( 2.4 and $\left.34.8 \mathrm{ml} \cdot \mathrm{kg}^{-1} \cdot \mathrm{min}^{-1}\right)$. The horizontal solid line represents the mean difference between both change scores $\left(18.6 \mathrm{ml} \cdot \mathrm{kg}^{-1} \cdot \mathrm{min}^{-1}\right)$. 
Because the ICC does not provide information on the magnitude of within-person differences, a Bland-Altman plot was constructed to show the individual differences between observations with the mean difference between observations. ${ }^{5}$ The BlandAltman plot in Figure 5 illustrates the individual differences between arm crank and bicycle ergometer against the mean $\mathrm{VO}_{2}$ max of the arm crank and bicycle ergometer. A mean difference between bicycle ergometer and arm crank ergometer of $18.6 \mathrm{ml} \cdot \mathrm{kg}^{-1} \cdot \mathrm{min}^{-1}$ was found, with a $95 \%$ limit of agreement between 2.4 and 34.8. The residuals were distributed normally and no coherence was found $(r=.197$, $\mathrm{p}=.482$ ).

Although it is important to have a valid and reliable test, an algorithm is necessary to convert the results of an arm crank ergometer to $\mathrm{VO}_{2}$ max obtained from the Åstrand-Ryhming bicycle ergometer. The linear regression analysis revealed the next equation: $\mathrm{VO}_{2 \text { max }}$ bicycle ergometer $=25.85+0.75 * \mathrm{VO}_{2 \max }$ arm crank ergometer (95\% CI: 0.22-1.29).

\section{DISCUSSION}

Up to present, there has been very limited submaximal method for assessing the aerobic capacity using the upper extremities only. In this study, we have investigated the reliability and validity of the adapted submaximal test on the arm crank ergometer. The test-retest reliability is good. The test results are equal by repeated measurements within one individual. Therefore, this submaximal test using an arm crank ergometer is suitable for evaluating the improvements of training. In addition, an excellent inter-observer reliability was found, which indicates that the tester has minimal influence on the test. The reliability between two arm crank ergometers is fairly good (0.63). Obviously, it is preferable to use the same arm crank ergometer for successive tests in the evaluation of the physical fitness of one person. The within-person differences are small in this test, except for one subject who had a higher heart rate during one test due to hastiness. The ICC between the arm crank and bicycle ergometer is fairly good (0.64). Based on the ICC and the Bland and Altman plot, the submaximal test on the arm crank ergometer is a valid instrument for measuring physical fitness. This is important for evaluation of training programs in patients with impairment of their lower extremities. 
One drawback of the present study might be the use of a surrogate assessment of the $\mathrm{VO}_{2}$ max instead of the maximal exercise test. However, local fatigue in the arms is the main limiting factor to complete a maximal arm crank test with oxygen intake. ${ }^{16}$ The Åstrand-Ryhming method is one of the submaximal exercise tests that is robust, valid and generally accepted for assessing $\mathrm{V} 0_{2}$ max. ${ }^{24}$ Moreover, a minimum heart rate of $130 \mathrm{~b} \cdot \mathrm{min}^{-1}$ (as required by original Åstrand protocol) proved not to be feasible on the arm crank ergometer. Therefore, we choose to use the ÅstrandRyhming test as described before. This guarantied the core requirements of the test, namely a steady heart rate at an appropriate submaximal work rate.

The crossover design is a very powerful methodology and statistically efficient for this study in which four different types of tests were used. This justifies the used number of 30 subjects.

Although the arm crank ergometer proved to be valid and reliable, a formula is necessary to convert the results of an arm crank ergometer to $\mathrm{VO}_{2}$ max values that are comparable with the Åstrand-Rhyming bicycle ergometer. This is important in case where comparisons with nomograms are desired. The linear regression analysis revealed the equation: $\mathrm{VO}_{2 \text { max }}$ bicycle ergometer $=25.85+0.75 * \mathrm{VO}_{2}$ max arm crank ergometer [95\% CI: 0.22-1.29]. We note that this linear analysis is performed in a small selected population. Generalization is therefore not obvious. Moreover, in this study, we used healthy volunteers. The validity of the test has not been formaly proven for disabled persons.

However, in another study, the Disabled Arthritis Patients Post-hospitalization intensive Exercise Rehabilitation (DAPPER) study, we used this test in elderly patients with arthritis. ${ }^{6}$. About $80 \%$ of the patients were able to perfom this arm crank test. About $10 \%$ break off the test due to pain, tiredness or dizziness. About $5 \%$ were not able to keep a constant rhythm of at least $55 \mathrm{rpm}$. During hosipital stay the submaximal test is too hard to endure for at least $45 \%$ of the patients.

Because of the limited muscle mass of the arms, the oxygen uptake and the load during arm exercise is lower compared to leg exercise. Previous studies showed that the workload appropriate for leg training needs to be reduced by $50-60 \%$ for arm training. ${ }^{4,13}$ Our findings with respect to workload in legs and arms are in line with those of preceding studies. 
In conclusion, our data show that the arm crank ergometer can be used to measure physical fitness. Moreover, the test on the arm crank ergometer is reliable and valid. We showed that the calculated $\mathrm{VO}_{2}$ max using an adapted submaximal ÅstrandRhyming test is a reliable and valid test.

\section{PRACTICAL APPLICATIONS}

Physical fitness is an important outcome parameter. Especially if the physical fitness is moderate, the standard maximal or submaximal leg tests may be difficult to perform. The proposed adapted submaximal Åstrand-Ryhming test using an arm crank ergometer is a useful reliable and valid alternative test. Examples of people who can use the test are patients with surgery on the lower extremity, paraplegia and patients with amputations.

\section{ACKNOWLEDGMENT}

The authors wish to express their appreciation for the collaboration of all participating volunteers. Moreover, we are very grateful for the fruitful collaboration with European Care Residence \& Resort 'Groot Stokkert' and the Dutch Arthritis Foundation. A grant from RVVZ (Reserves van de Voormalige Vrijwillige Voormalige Ziekenfondsverzekering, today: Inovatiefonds Zorgverzekeraars) supported this study. 


\section{REFERENCES}

1. Åstrand I. Aerobic work capacity in man and woman with special reference to age. Acta Physiol Scand 1960;49:1-92.

2. Åstrand PO, Rodahl K, Dahl HA, Sigmund B. Textbook of Work Physiology: Physiological Bases of exercise (4th ed.) Champaign, IL: Human Kinetics, 2003.

3. Åstrand PO, Ryhming I. A nomogram for calculation of aerobic capacity (physical fitness) from pulse rate during submaximal work. J Appl Physiol 1954;7:218-21.

4. Birkett WA, Edwards DF. The use of on-arm crank ergometry in the prediction of upper body aerobic capacity. Clin Rehabil 1998;12:319-27.

5. Bland JM, Altman DG. Statistical methods for assessing agreement between two methods of clinical measurements. Lancet 1986;1:307-10.

6. Bulthuis Y, Drossaers-Bakker KW, Taal E, Rasker J, Oostveen J, Van 't Pad Bosch P, Oosterveld F, van de Laar MA. Arthritis patients show long-term benefits from 3 weeks intensive exercise training directly following hospital discharge. Rheumatology 2007;46:1712-17.

7. Calbet JA, Holmberg HC, Rosdahl H, Van Hall G, Jensen-Urstad M, Saltin B. Why do the arm extract less oxygen than the legs during exercise? Am J Physiol Reg Int Comp Physiol 2005;289:R1448-58.

8. Cink RE, Thomas TR. Validity of the Åstrand-Rhyming nomogram for predicting maximal oxygen intake. Br J Sports Med 1981;15:182-5.

9. Durstine JL, Painter P, Franklin BA, Morgan D, Pitetti KH, Roberts SO. Physical activity for the chronically ill and disabled. Sports Med 2000;30:207-19.

10. Enright PL. The six-minute walk test. Respir Care 2003;48:783-5.

11. Fleiss JL. The design and analysis of clinical experiments. New York, NY: Wiley, 1986.

12. Fox EL, Bowers RW, FOSS ML. Fysiologie voor lichamelijke opvoeding, sport en revalidatie (5 ${ }^{\text {th }}$ ed.). Maarssen, Nederlands: De Tijdstroom Elsevier, 1999. pp. 263-301 and pp. 593-595.

13. Franklin BA. Aerobic exercise training programs for the upper body. Med Sci Sports Exerc 1989;21:S141-8.

14. Hopman M. Paraplegia and exercise, a study of cardiovascular behaviour during arm exercise in persons with paraplegia. Master's thesis, University of Nijmegen, Department of Physiology; 2e druk, 1997.

15. Kell RT, Belle G, Quinney A. Musculoskeletal fitness, health outcomes and quality of life. Sport Med 2001;31:863-73.

16. Kofsky PR, Davis GM, Shephard RJ, Jackson RW, Keene GCR. Field testing: assessment of physical fitness of disabled adults. Eur J Appl Physiol 1983;51:109-20.

17. Legge BJ, Banister EW. The Åstrand-Ryhming nomogram revisited. J Appl Physiol 1986;61:1203-9. 
18. Lynberg K, Danneskiold-Samsoe B, Halskov O. The effect of physical training on patients with rheumatoid arthritis: changes in disease activity, muscle strength and aerobic capacity. A clinically controlled minimized cross-over study. Clin Exp Rheumatol 1988;6:253-60.

19. Noonan V, Dean E. Submaximal exercise testing: clinical application and interpretation. Phys Ther 2000;80:782-807.

20. Ryhming I. A modified Harvard step test for the evaluation of physical fitness. Arbeitsphysiologie 1953;15:235-50.

21. Santiago MC, Coyle CP, Kinney WB. Aerobic exercise effect on individuals with physical disabilities. Arch Phys Med Rehabil 1993;74:1192-8.

22. Sawka MN, Foley ME, Pimental NA, Toner MM, Pandolf KB. Arm crank protocols for determination of maximal aerobic power. Med Sci Sports Exerc 1982;14:168.

23. Shephard RJ, Bouhlel E, Vandewalle H, Monod H. Muscle mass as a factor limiting physical work. J Appl Physiol 1988;64:1472-9.

24. Siconolfi SF, Cullinane EM, Carleton RA, Thompson PD. Assessing $\mathrm{VO}_{2}$ max in epidemiologic studies: modification of the Åstrand-Rhyming test. Med Sci Sports Exerc 1982;14:335-8.

25. Steptoe A, Butler N. Sport participation and emotional wellbeing in adolescents. Lancet 1996;347:1789-92.

26. Wilder RP, Greene JA, Winters KL, Long WB3rd, Gubler K, Edlich RF. Physical fitness assessment: an update. J Long Term Eff Med Implants 2006;16:193-204.

27. Williams L. Reliability of predicting maximal oxygen intake using the Åstrand-Ryhming nomogram. Res Q 1975;46:12-6. 



\section{Chapter 4}

\section{Arthritis patients show long-term benefits from 3 weeks intensive exercise training directly following hospital discharge.}

Results of the DAPPER (Disabled Arthritis Patients Posthospitalization intensive Exercise Rehabilitation) study

Y. Bulthuis, K.W. Drossaers-Bakker, E. Taal, J.J. Rasker, J. Oostveen, P.J. van 't Pad Bosch, F.G.J. Oosterveld and M.A.F.J. van de Laar

Rheumatology 2007;46:1712-1717 


\section{ABSTRACT}

Objective. To examine the efficacy of short-term intensive exercise training (IET) directly following hospital discharge.

Methods. In the Disabled Arthritis Patients Post-hospitalization Intensive Exercise Rehabilitation (DAPPER) study, patients with rheumatoid arthritis or osteoarthritis were eligible when they needed hospitalization for either a flare-up in disease, elective hip or knee arthroplasty. The intervention group received IET for three weeks immediately after discharge; the control group was treated with the usual care (UC). The intensive exercise was provided in a resort. Outcomes were assessed at baseline, after 3, 13, 26 and 52 weeks. Range of motion was measured using the Escola Paulista de Medicina-Range of Motion scale (EPM-ROM), disability was measured using the HAQ and the McMaster Toronto Arthritis Patient Preference Disability Questionnaire (MACTAR), and for health-related quality of life (HRQoL), the Research and Development 36-Item Health Survey (RAND-36) was used.

Results. The IET showed a better and faster improvement than UC on all outcome measures except for HRQoL. Up to 52 weeks after baseline, the EPM-ROM and the MACTAR remained favourable in IET compared with UC. At three weeks, the MACTAR improved significantly more in the IET compared with the UC: mean difference -5.5 (95\% CI -8.4 to -2.2). At 26 weeks the mean difference remained significant $(-5.2 ; 95 \% \mathrm{CI}-10.0$ to -0.34$)$. At 52 weeks the effect was not significant; however, the mean difference in improvement between the groups can be considered clinically relevant. At three weeks, the IET had improved significantly more on the HAQ walking and rising subscales.

Conclusion. Intensive short-term exercise training of arthritis patients, immediately after hospital discharge results in improved regain of function. The DAPPER programme has a direct effect, which lasts up to 52 weeks. 


\section{INTRODUCTION}

Despite different pathophysiological processes, patients suffering from either rheumatoid arthritis (RA) or osteoarthritis (OA) experience pain and a gradual decline in muscle strength, eventually resulting in loss of function and quality of life. Hospitalization is required for arthritis patients who have a flare-up in disease activity or those requiring elective joint replacement. Especially during hospitalization, a rapid decline of function is observed. ${ }^{1}$ Increasing evidence shows that physical exercise improves function and prevents loss of function in both RA and $\mathrm{OA} .^{2-6}$

In hospitalized patients suffering from arthritis (OA as well as RA), the ability to regain function is retarded.7,8 Although, inpatient exercise is shown to be beneficial, the effects of intensive training directly following discharge has never been studied in these patients. Since risk factors for arthritis such as senescence and obesity in the population will increase, more arthritis patients will require hospitalization for joint replacement. Therefore, research into an optimal strategy to regain function and quality of life is warranted.

In RA patients, several exercise programmes have been investigated. Long-term high-impact exercise has been proven to be beneficial regarding function and muscle strength in patients with low disease activity in an outpatient setting. In contrast to earlier belief, exercise did not increase disease activity. ${ }^{6,9,10}$ In RA patients with active disease, an inpatient programme with frequent exercise therapy was found to be superior to usual care (UC) regarding disease activity as well as muscle strength. ${ }^{9}$ However, inpatient interventions are costly. Physical exercise in a resort might be more acceptable to patients, and might be as effective as an inpatient hospital programme at lower costs.

Exercise was also found to have beneficial effects in OA patients. Positive effects were found in function, pain and muscle strength. ${ }^{11-18}$ In patients with moderate functional limitations, early mobilization after arthroplasty resulted in improved functional ability. ${ }^{19,20}$ Even elderly, frail patients admitted for joint replacement were able to tolerate early intensive inpatient exercise therapy resulting in faster attainment of functional ability. ${ }^{21}$ However, studies reporting the long-term effects of exercise following joint replacement are lacking. ${ }^{22}$

We hypothesise that recovery of function in arthritis patients improves with a short-term intensive exercise program in a resort following hospital discharge. To 
test this hypothesis, the Disabled Arthritis Patients Post-hospitalization Intensive Exercise Rehabilitation (DAPPER) study was designed to investigate the short- and long-term effects of an intensive short-term exercise programme on function and health-related quality of life (HRQoL) in arthritis patients directly following hospital discharge.

\section{METHODS}

\section{Patients}

Patients were recruited from four hospitals (Medisch Spectrum Twente, Enschede; Twenteborg ziekenhuis, Almelo; Sint Maartenskliniek, Nijmegen and Isala Klinieken, Zwolle). Patients were eligible when they were admitted either due to a flare-up of their disease or for elective knee or hip replacement. Additional inclusion criteria were: (i) age over 18 yrs, and (ii) RA (according to American College of Rheumatology criteria 1987) ${ }^{23}$ or polyarticular OA.

Exclusion criteria were: (i) presence of serious cardiac disease (NYHA class III and IV), ${ }^{24}$ (ii) Incapacitating pulmonary disease Gold stage IV, ${ }^{25}$ (iii) serious hypertension (diastolic blood pressure > $110 \mathrm{~mm} \mathrm{Hg}$ (during treatment), (iv) pregnancy, (v) insufficient understanding of the Dutch language and (vi) functional incapacity (Steinbrocker functional class 4). ${ }^{26}$ A signed consent form was obtained from all participants. Ethical approval was given before the start of the study by the medical ethical revision board of the Medical Spectrum Twente.

In the power calculation, we used the equation for sample size required per group using the $t$-test to compare means of continuous variables. In order to have an $80 \%$ chance of detecting a significant (at one-sided 5\% level) 0.3 point difference in mean HAQ score between the two groups, assuming an S.D. of 0.57, 45 patients were needed per arm.

\section{Design}

The DAPPER study is a randomized controlled, clinical trial. In all participating centres, consecutive eligible patients were informed of the study by their treating physician. Those who agreed to participate were randomized. We performed a permutated blocked (blocks of four) randomization with stratification for centre and reason for admission (flare/ joint replacement), made up by random digit 
generator to allocate the patient to either intensive exercise therapy (IET) or UC to prevent unbalanced distribution. The allocation was only disclosed to physician and patient after inclusion into the study.

During hospitalization, all patients were treated at the discretion of the attending physician. Directly following discharge patients in the IET group were sent to a dedicated resort, to receive a 3-week IET. Thereafter, the IET group received regular care only. In contrast, after discharge the patients in the control group (UC) received UC at the discretion of their attending physician only. UC consists of either physical therapy by a local physical therapist or temporary admission to a nursing home, when applicable. Outcome assessments were done at baseline (the moment the patient was found to be well enough to be discharged from hospital by the treating physician) and after 3, 13, 26 and 52 weeks all by one experienced physiotherapist.

\section{Intervention programme}

Directly following discharge IET patients were sent to a dedicated 'resort', European Care Residence \& Resort 'Groot Stokkert', which offers hotel facilities and professional care for disabled people. These include exercise facilities and physical therapy dedicated to rheumatic patients. During their 3-week stay, patients were trained two to four times a day by physiotherapists, for $\sim 30$ minutes per session, depending on the capabilities of the individual patient. The goals of the training were improvement of range of motion, muscle strength, aerobic capacity and activities of daily live. The therapy sessions were given individually as well as in groups. In the first two weeks, treatment focused on individual limitations (range of motion of affected joints, strength, and aerobic capacity). Range of motion in restricted joints was treated by means of mobilizing techniques and angular movements. The principles of graded activity ${ }^{27}$ were used especially for improvement of strength. Aerobic capacity was trained daily on a heart rate level of $60 \%$ of the individually predicted maximum (220 minus age of the patient). Patients received at least three hydrotherapy sessions a week after sufficient wound healing. In some patients, a daily session was offered, depending on the individual goals, the loadability of the patient and the other content of the program. This enabled the physiotherapists for instance to do functional walking exercises although full weight basing on lower limbs was still not possible. During the third 
week, the training was focused on the functional capacities as prioritized by the patient, such as walking, climbing stairs, standing up from a chair or cycling. These activities of daily life were practiced under supervision of the physiotherapist.

A group education program was given twice a week. This program was based on the self-management training for arthritis patients by K. Lorig et al $^{28}$ modified for The Netherlands by E. Taal et al. ${ }^{29}$ During the $1 \frac{1}{2}-2 \mathrm{~h}$ period, all patients who were present at that time would participate. The number of patients obviously varied. The maximum number of patients was six and a minimum of two.

\section{Assessments}

The primary outcome was recovery of function as measured by the HAQ. The secondary outcomes were range of motion as measured by the Escola Paulista de Medicina-Range of Motion scales (EPM-ROM) for the recovery of function from the patients' perspective as measured by the McMaster Toronto Arthritis Patient Preference Disability Questionnaire (MACTAR). The Research and Developmet 36item Health Survey (RAND-36) was used as a quality of life measurement.

Function ability. This was measured with both the HAQ and the MACTAR. The HAQ is an independent patient-reported outcome questionnaire containing 20 questions, regarding eight domains of daily living activities. The total score as well as each sub-score range from 0 (no disability) to 3 (severe disability). The Dutch version of the HAQ has been validated. ${ }^{30}$ To assess functional disability of the lower extremities, the subcategories 'walking' and 'rising' (items 6-8 and 12) were used. ${ }^{31}$ An improvement of 0.26 is considered to be clinically relevant. ${ }^{32}$ For the MACTAR, ${ }^{33}$ an interviewer assesses at baseline which activities are most impaired and which are considered most important by the individual patient (maximum 5). The followup assessments focus on change in ability to perform this set of impaired activities. The second part of the MACTAR evaluates the patient's health status by asking questions on general health; quality of life; and physical, social and emotional wellbeing. The baseline score ranges from 39 to 59. The weighted MACTAR at follow-up assessments ranges from 21 to 77 points. Lower scores reflect better functional ability. The MACTAR has been validated in Dutch patients. ${ }^{34}$ An improvement of 3 points can be argued to be clinically significant. ${ }^{35}$ 
Range of motion. This was measured with the EPM-ROM scale. This scale evaluates 10 distinct movements of small and large joints and is based on movements and degrees of motion that are important in the performance of basic activities of daily living (ADL). The score for each movement can vary from 0 (no limitation) to 3 (severe limitation). The sum of the left and right side is divided by 2 . The total score varies from 0 to $30 .{ }^{36}$

Health-related quality of life. This was measured using the RAND 36-Item Health Survey 1.0 (RAND-36). The RAND-36 uses the same health-status assessment questionnaire as the Short Form 36 (SF-36). ${ }^{37}$ Scores from the eight subscales of the RAND-36 are aggregated into two summary scores: Physical Component Summary (PCS) and Mental Component Summary (MCS). ${ }^{38}$ Raw scale score of the RAND-36 were transformed into z-scores, using Dutch means and S.D. which were multiplied with the US factor score coefficients and summed over all eight subscales. US factor scores were used to facilitate international comparisons. Finally, $t$-scores were calculated by multiplying the obtained PCS and MCS sums by 10 and adding 50 to the product to obtain transformed summary scores that are normally distributed with a mean of 50 and an S.D. of $10 .^{39}$ This generic instrument has been translated and validated for use in Dutch patients. ${ }^{40}$

\section{Statistical analysis}

Comparison of the baseline scores was done using either the Mann-Whitney test or the independent Student's T-test, where appropriate. Evaluations were done according to the intention-to-treat method.

Between both groups, the changes of the follow-up scores compared to baseline were analysed. To control for baseline differences, analyses of covariance were performed with the change scores as dependent variables, the group as independent variable and the baseline scores of each outcome measure as covariates. In addition, to adjust for confounding, diagnosis, age and disease duration were included as covariates. To test if the assumption of homogeneity of regression slopes for ANCOVA was satisfied, we tested whether there was an interaction between the independent variable and the covariates for each outcome measure. To evaluate the importance of the differences between the groups the effect size was calculated. An effect size of 0.10 is considered a small effect, 0.30 
represents a moderate effect and 0.50 a large affect. ${ }^{41}$ All statistical analyses were performed using the statistical package SPSS and utilizing 2-tailed tests with a significance level of alpha $=.05$.

The institutional review boards of the hospitals approved the study.

\section{RESULTS}

Between July 2002 and January 2004114 patients gave signed consent and were randomized (60 IET; 54 UC; Fig. 1). Sixteen patients were lost during follow-up (16.3\%). Within the first three weeks, four patients withdrew consent (1 IET; 3 UC) and two UC patients stopped due to unexpected, non-related medical conditions. Ten patients (1 IET; 9 UC) withdrew consent during the course of the follow-up. Ninety-eight patients completed the study (58 IET, 40 UC). No significant differences were found at baseline between the completers and the non-completers or between the IET and UC groups.

The demographic and baseline characteristics of the evaluable patients are presented in Table 1. The mean age of the patients was 68 years (S.D.=11), with a mean disease duration of 12.4 years (S.D.=11.5). Fifty-two patients were admitted for total hip arthroplasty (53\%, 13 RA/39 OA). Thirty-five patients were admitted for total knee arthroplasty (36\%, $9 \mathrm{RA} / 26 \mathrm{OA})$ and only 11 patients were admitted because of flare $(11 \%, 11 \mathrm{RA} / 0 \mathrm{OA})$. Comorbidities beside the diagnose RA or OA were present in $81 \%$ of the patients. The most frequent comorbidities were hypertension (45\%) and heart failure (30\%), and 33\% of all patients have had a joint replacement in the past.

The assumption for ANCOVA of homogeneity of regression slopes was met for all outcome measures [i.e. ANCOVAs showed no significant interactions $(p>0.05)$ between the groups (IET/UC) and all covariates]. 


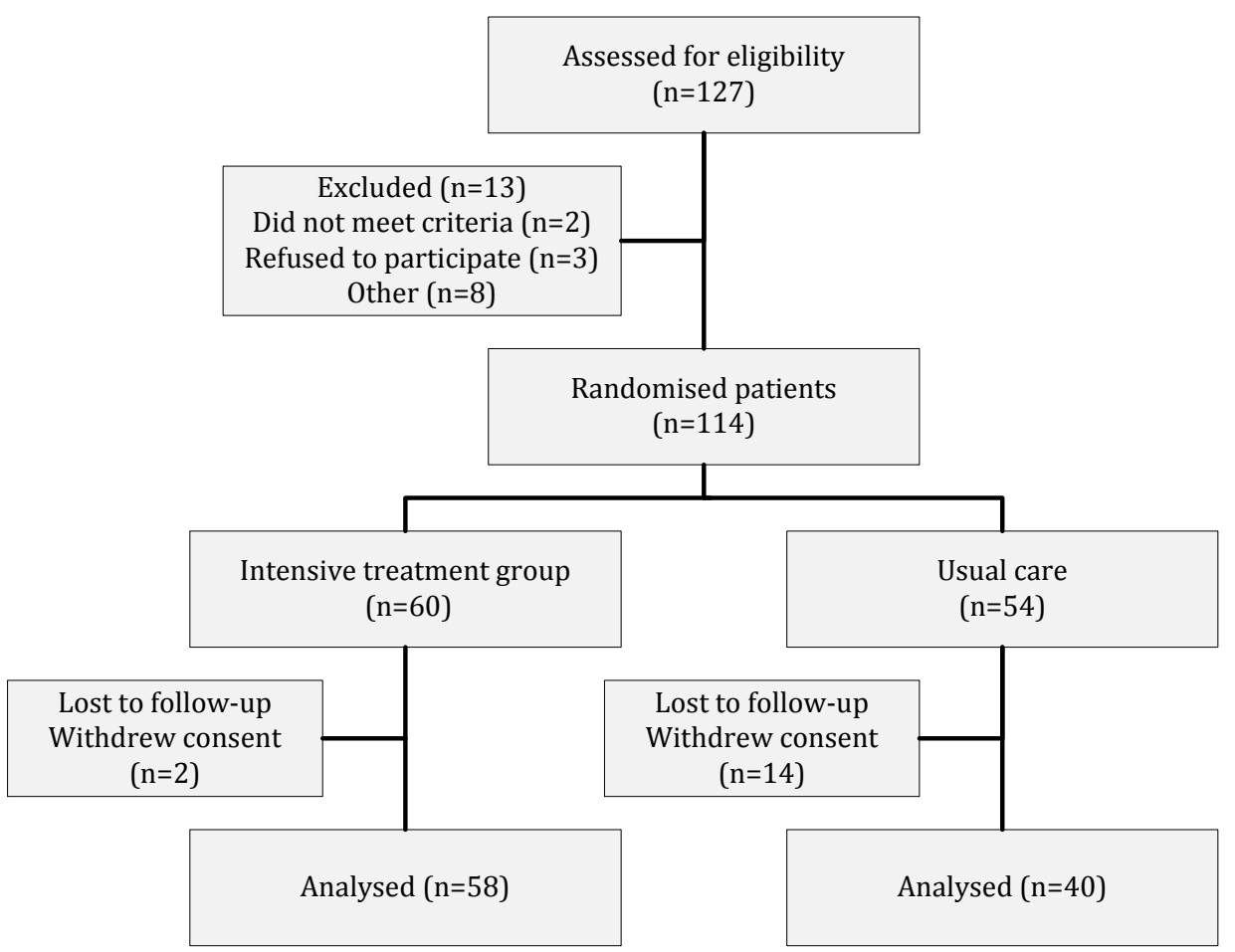

Figure 1. Flow chart of participants in the DAPPER trail, in which arthritis patients were treated with either IET or UC directly following hospital discharge. 
Table 1. Baseline characteristics of the 98 evaluable patients in the DAPPER trial, in which arthritis patients were treated with either IET or UC directly following hospital discharge.

\begin{tabular}{|c|c|c|}
\hline & $\mathrm{UC}(\mathrm{n}=40)$ & IET $(n=58)$ \\
\hline Age in years, mean (S.D.) & $67(11)$ & $69(12)$ \\
\hline Women, n (\%) & 31 (78) & $46(79)$ \\
\hline Disease duration in years, mean (S.D.) & $13.6(11.5)$ & $11.6(11.4)$ \\
\hline Co-morbidities a, n (\%) & $31(78)$ & $48(83)$ \\
\hline - none & 9 & 10 \\
\hline - one & 11 & 27 \\
\hline - two or more & 20 & 21 \\
\hline \multicolumn{3}{|l|}{ Reason of admission } \\
\hline - Flare n (\%) & $4(10)$ & $7(12)$ \\
\hline - Total knee arthroplasty, $n(\%)$ & $15(37)$ & $20(34)$ \\
\hline$(R A / O A), n$ & $(5 / 10)$ & $(4 / 16)$ \\
\hline - Total hip arthroplasty, $n(\%)$ & $21(53)$ & $31(54)$ \\
\hline$(R A / O A), n$ & $(8 / 13)$ & $(5 / 26)$ \\
\hline Previous joint replacement, $n(\mathrm{RA} / \mathrm{OA})$ & $10(5 / 5)$ & $22(4 / 18)$ \\
\hline \multicolumn{3}{|l|}{ Hospital location } \\
\hline - Enschede \& Almelo ${ }^{b}, n(\%)$ & $20(50)$ & $25(43)$ \\
\hline - Nijmegen, $n(\%)$ & $8(20)$ & $9(16)$ \\
\hline - Zwolle, $n(\%)$ & $12(30)$ & $24(41)$ \\
\hline
\end{tabular}

a Comorbidities besides the diagnose RA or OA.

b In Enschede \& Almelo, the same medical staff has included and treated the patients. 


\section{Functional Ability}

Compared to baseline the IET group improved more than the UC group on the HAQ subscales for walking and rising. At three weeks this difference was statistically significant (Table 2 and Figure 2A and B).

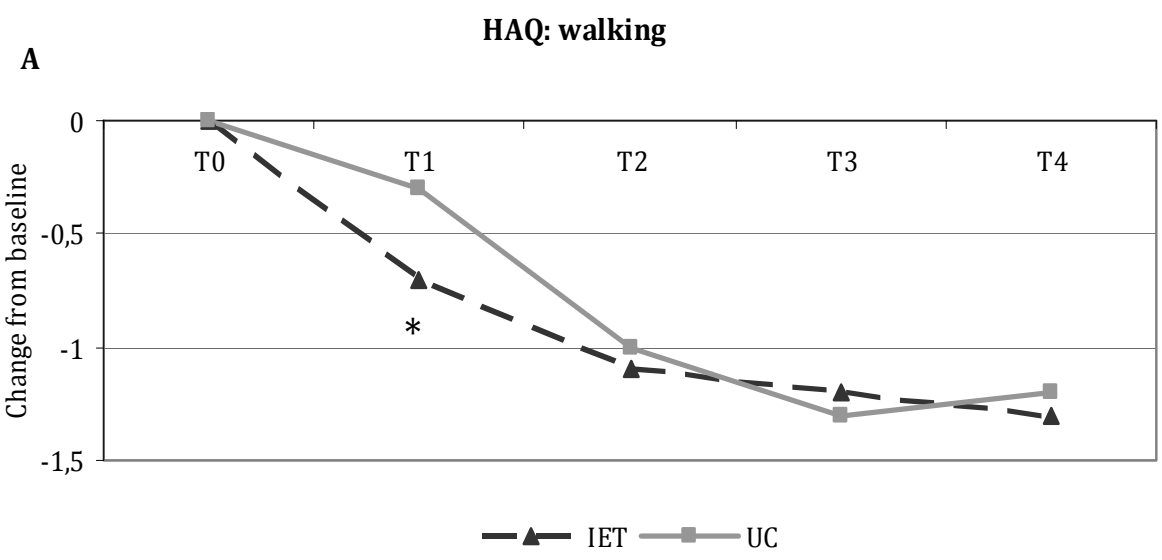

B

HAQ; rising

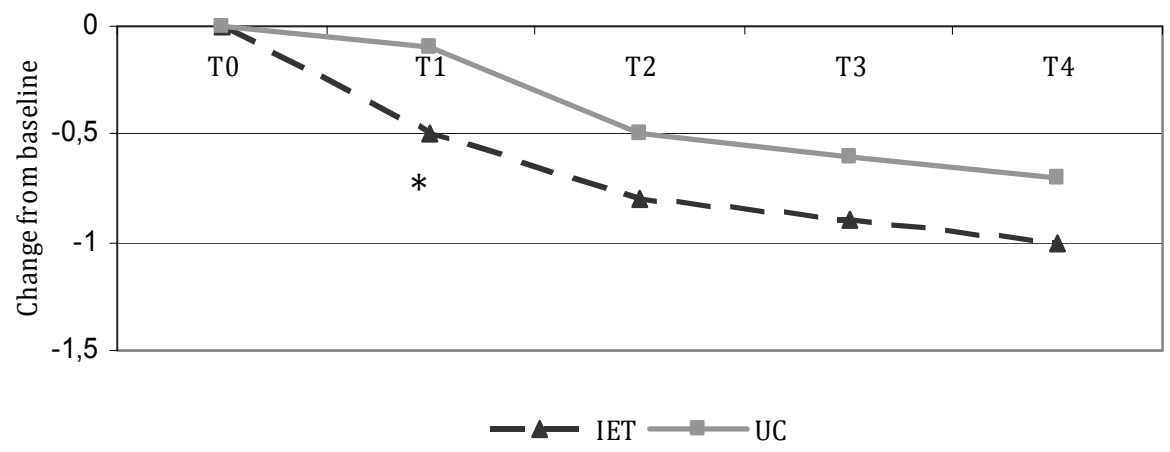

Figure 2A en 2B. The changes from baseline as measured with the HAQ subscales walking and rising in the DAPPER trial in which arthritis patients were treated with either a 3-week IET or UC directly following hospital discharge. HAQ, Health Assessment Questionnaire. Negative score stands for an improvement. ${ }^{*} P<0.05,{ }^{* *} P<0.01$. The $P$-value reflects the difference between groups. $\mathrm{T} 0=$ baseline, $\mathrm{T} 1=3$ weeks, $\mathrm{T} 2=13$ weeks, $\mathrm{T} 3=26$ weeks, $\mathrm{T} 4=$ 52 weeks. 


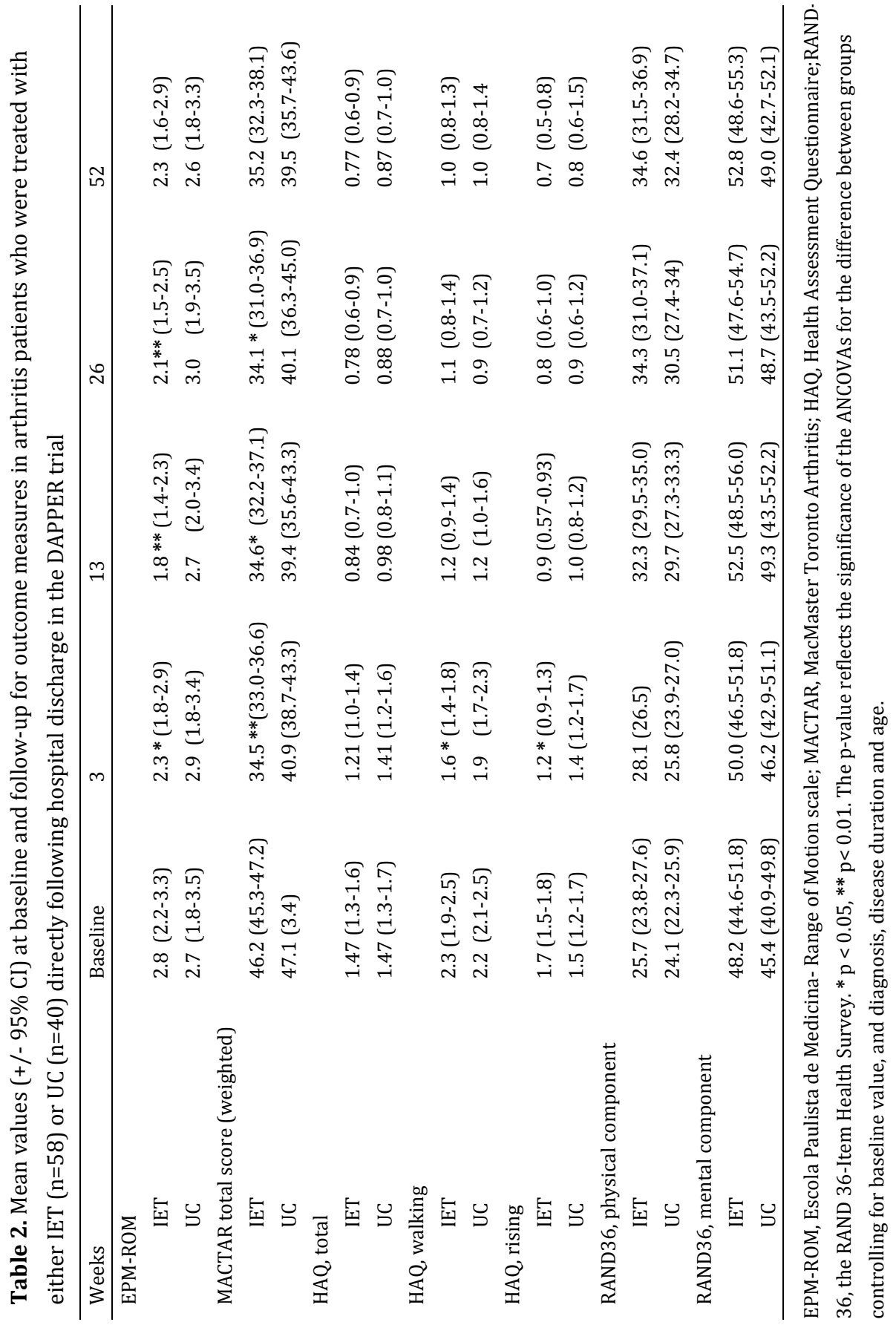


Compared with baseline the IET group showed better improvement in functional ability than the UC group, as measured with the MACTAR (Table 2 and Figure 2C). The difference was significant at 3,13 and 26 weeks with an effect size of 0.82, 0.46 and 0.50 respectively. At 52 weeks, the effect was not significant [-11 (S.D. 11) vs. 8.6 (S.D. 12.7)]. However, the mean difference in improvement between the groups of 4.3 can be considered clinically relevant. The effect was moderate (effect size $0.36)$.

C MACTAR, weighted

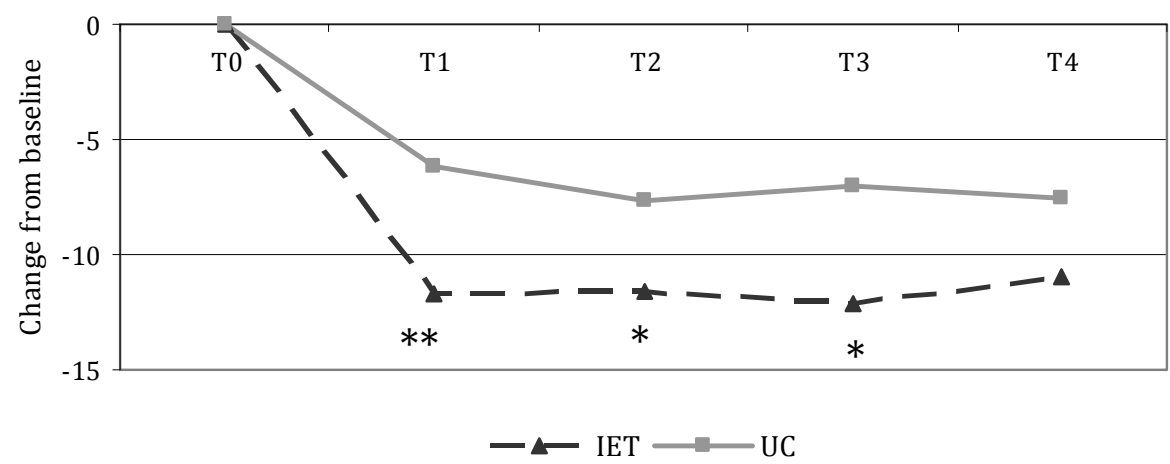

Figure 2C. The changes from baseline for function as measured with the MACTAR in the DAPPER trial where arthritis patients were treated with either a 3 week IET or UC directly after hospitalisation. MACTAR: McMaster Toronto Arthritis Patients Preference Disability Questionnaire. Negative score stands for an improvement. ${ }^{*} P<0.05$, ${ }^{* *} P<0.01$. The $P$-value reflects the difference between groups. $\mathrm{T} 0=$ baseline, $\mathrm{T} 1=3$ weeks, $\mathrm{T} 2=13$ weeks, $\mathrm{T} 3=26$ weeks, $\mathrm{T} 4=52$ weeks. 


\section{Range of Motion}

Compared with baseline the improvement of range of motion (EPM-ROM) in the IET group exceeded the improvement in the UC group. The difference was significant at 3, 13 and 26 weeks (Table 2 and Figure 3). The effect size was $0.46,0.6$, and 0.6 respectively.

\section{EPM-ROM}

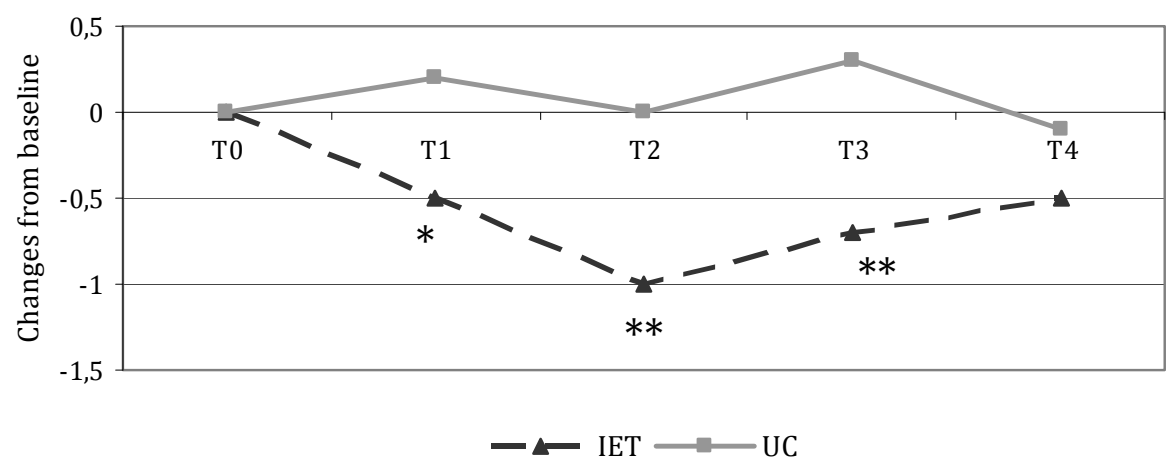

Figure 3: The changes from baseline for range of motion as measured with the with the EPM-ROM in the DAPPER trial in which arthritis patients were treated with either a 3-week IET or UC directly after hospitalization. T0 = baseline, T1 $=3$ weeks, $\mathrm{T} 2=13$ weeks, T3 = 26 weeks, T4 = 52 weeks. Negative score stands for an improvement. EPM-ROM: Escola Paulista de Medicina- Range of Motion scale, ${ }^{*} \mathrm{p}<0.05,{ }^{* *} \mathrm{p}<0.01$. The $\mathrm{p}$-value reflects the difference between groups. 


\section{Health Related Quality of Life}

The effects on the Rand-36 physical component were not different between the groups. (Table 2 and Figure $4 \mathrm{~A}$ and B).

A

RAND-36; PCS

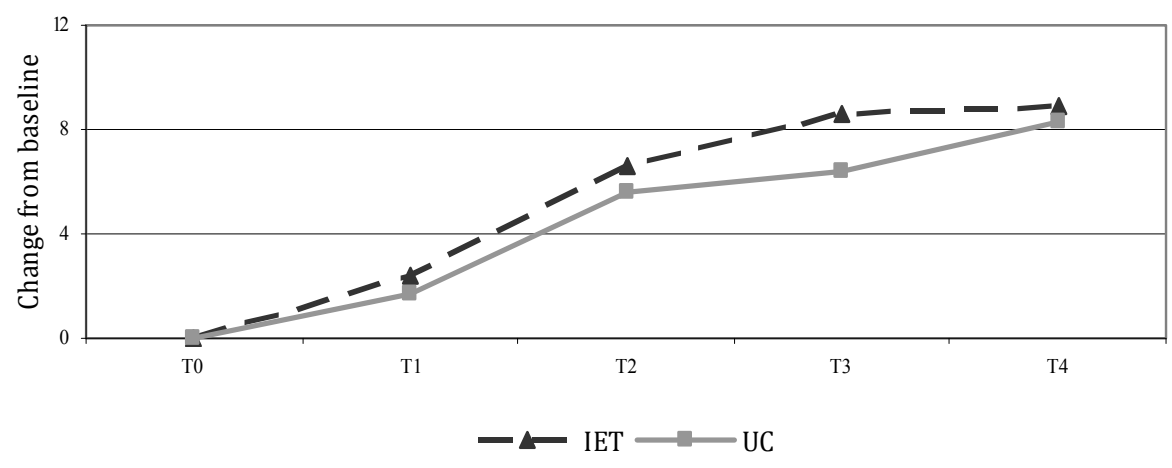

B

RAND-36; MCS

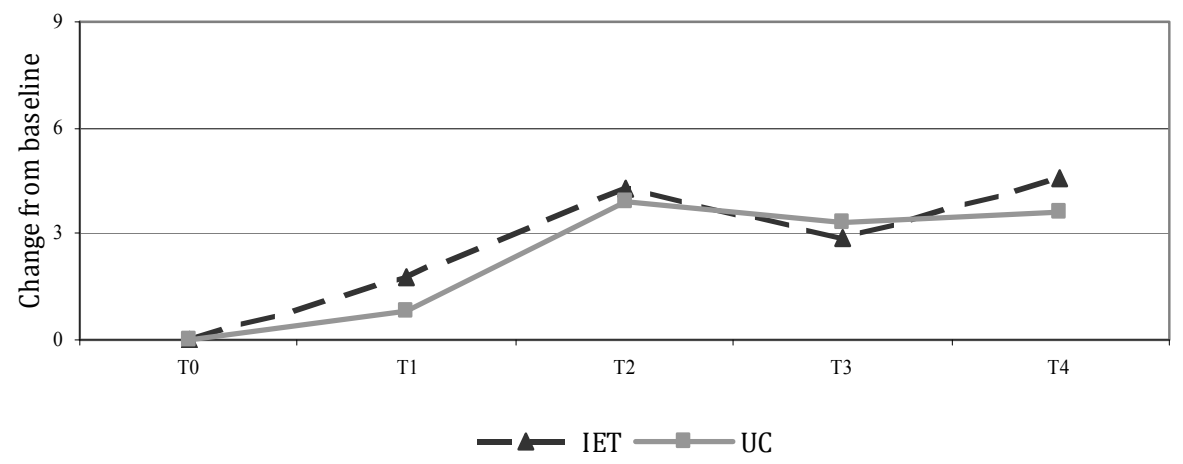

Figure 4A and B: The changes from baseline of health-related quality of health as measured with the RAND-36 subscales for physical function (PCS) and mental health (MCS) in the DAPPER trial in which arthritis patients were treated with either IET or UC directly following hospital discharge. $\mathrm{T} 0=$ baseline, $\mathrm{T} 1=3$ weeks, $\mathrm{T} 2=13$ weeks, $\mathrm{T} 3=26$ weeks, $\mathrm{T} 4=52$. RAND-36: the RAND 36-Item Health Survey. Positive score stands for an improvement, no significant improvement between the groups, ${ }^{*} \mathrm{p}<0.05$, ${ }^{* *} \mathrm{p}<0.01$. The $\mathrm{p}$-value reflects the difference between groups. 


\section{DISCUSSION}

The DAPPER study shows improved recovery of function in arthritis patients due to a 3-week IET program directly following hospital discharge. The patients in the IET group showed a quicker and significantly better recovery in all physical measures (HAQ, MACTAR and EPM-ROM). HRQoL (RAND-36) did not show a beneficial effect with the IET compared with UC. The improvements observed in the IET group lasted up to 12 months.

Before the DAPPER study, superiority of such a brief intensive exercise program has never been demonstrated in an outpatient setting. Moreover the DAPPER study encompassed RA patients among OA patients. The DAPPER study used a 3-week intensive exercise programme compared with other outpatient programmes lasting from 6 weeks up to 24 months. ${ }^{42,43}$ Despite the short duration of the DAPPER programme, the immediate effects were long-lasting. Due to the limited number of patients in each arm, the differences did not reach significance at 52 weeks, however, the difference between the groups could still be considered clinically relevant.

The DAPPER study used an intensive exercise programme in an outpatient setting in contrast to comparable programmes on an inpatient basis. The effects are comparable but the friendly resort dedicated to arthritis patients costs considerable less compared with hospital care. The DAPPER programme was not limited to exercise only. The beneficial effects might be explained by the combination of intensive exercise, excellent arthritis-dedicated facilities, the presence of care givers and group-based patient education.

Although the differences between the groups with respect to change in mobility and functional capacity as measured with the MACTAR were significant, the question whether the differences are relevant remains to be solved. To the best of our knowledge the minimal clinically important change on the EPM-ROM and MACTAR still have to be established. However, since the weighted MACTAR score on average assigns 3 points to an individually selected impaired activity, the mean difference between the intervention and control group range from four to six. This outcome could be interpreted as at least one less relevant problem and thus clinically relevant.

A limitation of the current study was that the assessments were not blinded. Obviously, taking the informed consent obligation seriously, blinding is nearly 
impossible in clinical trials other than drug trials. Therefore, in this type of study, assessor bias is almost impossible to prevent. Disproportionately, UC patients were lost for follow-up due to withdrawal of informed consent. However, statistically there is no indication for bias by selective dropout.

Although the intervention took place in a resort dedicated to arthritis patients, we feel that the main finding of our study that intensive training directly following discharge quickly improved function, can be generalized. The setting in which the study took place is unique; however, the facilities of rehabilitation centres and nursing homes could be used for the implementation of this programme. The primary study question of the DAPPER study was to study the effects of intensive short- term exercise therapy on function as measured with the HAQ. We operationalized this by choosing the clinical problem of deterioration of function in hospitalized patients. Both patients with RA and OA who suffered deterioration in function were included in this study representing daily rheumatology practice. The results of the DAPPER study have implications for the care of arthritis patients. In many studies, intensive training has been found to improve function in arthritis patients and also after arthroplasty. It is expected that increasing numbers of patients will need arthroplasty whereas at the same time the availability of inpatient facilities will decline, so effective recovery strategies on an outpatient basis are needed. The DAPPER study indicates that intensive training in a resort with arthritis-dedicated facilities and trained staff might be a very good alternative. In conclusion, The DAPPER study supports the hypothesis that recovery of function in arthritis patients benefits from a 3-week intensive exercise program directly following discharge from hospital. In accordance with earlier research on intensive exercise training on an inpatient basis, the importance of intensive exercise in arthritis patients has gained strength. Moreover, we consider it likely that the gained benefits of the DAPPER protocol outweigh the costs compared to UC. Obviously this has to be demonstrated by a health economical analysis.

\section{Rheumatology key message:}

Recovery of function of arthritis patients benefits from a three week intensive exercise program directly following discharge from the hospital. 


\section{ACKNOWLEDGEMENT}

The authors wish to express their appreciation for the collaboration of all participating patients, nurses, physiotherapists and physicians. Moreover, we are very grateful for the fruitful collaboration with European Care Residence \& Resort 'Groot Stokkert', and the Dutch Arthritis Foundation. 


\section{REFERENCES}

1. Convertino VA, Bloomfield SA, Greenleaf JE. An overview of the issues: physiological effects of bed rest and restricted physical activity. Med Sci Sports Exerc 1997;29:187-90.

2. Minor MA. 2002 Exercise and physical activity conference, St. Louis, Missouri: Exercise and arthritis "We know a little bit about a lot of things.... Arthritis \& Rheumatism 2003;49:1-2. (editorial)

3. Keysor JJ, Jette AM. Have we oversold the benefit of late-life exercise? Gerontol A Biol Sci Med Sci 2001;56:412-23.

4. Fentem PH. Exercise in prevention of disease. Br Med Bull 1992;48:630-50.

5. Semble EL, Loeser RF, Wise CM. Therapeutic exercise for rheumatoid arthritis and osteoarthritis. Semin Arthritis Rheum 1990;20:32-40.

6. De Jong Z, Vliet Vlieland TPM. Safety of exercise in patients with rheumatoid arthritis. Curr Opin Rheumatol 2005;17:177-82.

7. Creditor MC. Hazards of hospitalization of the elderly Review. Ann Intern Med 1993;118:219-23.

8. Gilbey HJ, Ackland TR, Wang AW, Morton AR, Trouchet T, Tapper J. Exercise Improves Early Functional Recovery after total hip arthroplasty. Clinical orthopaedics and related research 2003;408:193-220.

9. Vliet Vlieland TPM, Zwinderman AH, van den Broucke JP, Breedvled FC, Hazes JMW. A randomized clinical trial of in-patient multidisciplinary treatment versus routine outpatient care in active rheumatoid arthritis. Br J of Rheum 1996;35:475-82.

10. van den Ende CHM, Breedveld FC, le Cessie S, Dijkmans BAC, de Mug AW, Hazes JMW. Effect of intensive exercise on patients with active rheumatoid arthritis: a randomised clinical trial. Ann Rheum Dis 2000;59:615-21.

11. Foley A, Halbert J, Hewitt T, Crotty M. Does hydrotherapy improve strength and physical function in patients with osteoarthritis - a randomised controlled trial comparing a gym based and a hydrotherapy based strengthening programme. Ann Rheum Dis 2003;62:1162-7.

12. van Baar ME, Dekker J, Oostendorp RAB, Bijl D, Voorn Th B, Bijlsma JWJ. Effectiveness of exercise in patients with osteoarthritis of hip or knee: nine months' follow up. Ann Rheum Dis 2001;60:1123-30.

13. Bennell K, Hinman R. Exercise as a treatment for osteoarthritis. Curr Opin Rheumatol 2005;17:634-40.

14. Jordan KM, Arden NK, Doherty M, Bannwarth B, Bijlsma JWJ, Dieppe P et all. EULAR recommendations 2003: an evidence based approach to the management of knee osteoarthritis: Report of a task force of the standing committee for international clinical studies including therapeutic trials (ESCISIT). Ann Rheum Dis 2003;62:1145-55. 
15. Kettunen JA, Kujala UM. Exercise therapy for people with rheumatoid arthritis and osteoarthritis. Scand J Med Sci Sports 2004;14:138-42.

16. Fransen M, McConnell S, Bell M. Exercise for osteoarthritis of the hip or knee (Cochrane Review). In: The Cochrane Library, Issue 4. Chichester, UK: John Wiley \& Sons, Ltd, 2005.

17. McCarthy CJ, Mills PM, Pullen R, Roberts C, Silman A, Oldham JA. Supplementing a home base exercise programme with a class-based exercise programme is more effective than home exercise alone in the treatment of knee osteoarthritis. Rheumatology 2004;43:880-86.

18. Jones CA, Voaklander DC, Johnston DWC, Suarez-Almazor ME. Health related quality of life outcomes after total hip and knee Arthroplasties in a community based population. J Rheumatol 2000;27:1745-52.

19. Berend KR, Lombardi AV jr, Mallory TH. Rapid recovery protocol for peri-operative care of total hip and total knee arthroplasty patients. Surg Technol Int 2004;13:239-47.

20. Isaac D, Falode T, Liu P, l' Anson H, Dillow K, Gill P. Accelerated rehabilitation after total knee replacement. The Knee 2005;12:346-50.

21. Munin MC, Rudy TE, Glynn NW, Crossett LS, Rubash HE. Early inpatient rehabilitation after elective hip and knee arthroplasty. Jama 1998;279:847-52.

22. Roos EM. Effectiveness and practice variation of rehabilitation after joint replacement. Curr Opin Rheumatol 2003;15:160-2.

23. Arnett FC, Edworthy SM, Bloch DA, McShane DJ, Fries JF, Cooper NS et al. The American Rheumatism Association 1987 revised criteria for the classification of rheumatoid arthritis. Arthritis Rheum 1988;31:315-24.

24. The Criteria Committee of the New York Heart Association. Nomenclature and Criteria for Diagnosis of Diseases of the Heart and Great Vessels, 9th ed. New York, NY: Little, Brown and Company; 1994:253-56.

25. Fabbri LM, Hurd SS. GOLD scientific committee. Global strategy for the Diagnosis, management and prevention of COPD 2003 Update. Eur Resp J 2003;22:1-2.

26. Steinbrocker 0 , Traeger $\mathrm{CH}$, Batterman RC. Therapeutic criteria in rheumatoid arthritis. J Am Med Ass 1949;140:659-662.

27. Fordyce WE, Fowler RS, Lehmann JF, Delateur BJ, Sand PL, Trieschmann RB. Operant conditioning in the treatment of chronic pain. Arch Phys Med Rehabil 1973;54:399-408.

28. Lorig K, Lubeck D, Kraines RG, Seleznick M, Holman HR. Outcomes of self help education for patients with arthritis. Arthritis Rheum 1985;28:680-85.

29. Taal E, Rasker JJ, Wiegman O. Patient education and self-management in the rheumatic diseases: A self-efficacy approach. Arthritis Care Res 1996;9:229-38. 
30. Bijlsma JW, Oude Heuvel CH, Zaalberg A. Development and validation of the Dutch questionnaire capacities of daily life (VDF) for patients with rheumatoid arthritis. J Rehab Sci 1990;3:71-4.

31. Walker DJ, Heslop PS, Chandler C, Cleary R. Extraction and validation of a lower limb HAQ by comparison with objective measurement of ambulatory activity. Scand J Rheumatol 2001;30:154-8.

32. Kosinki M, Zhao SZ, Dedhiya S, Osterhaus JT, Ware JE jr.. Determining minimally important changes in generic and disease-specific health-related quality of life questionnaires in clinical trials of rheumatoid arthritis. Arthritis \& Rheumatism 2000;43:1478-87.

33. Tugwell P, Bombardier C, Buchanan WW, Goldsmith CH, Grace E, Hanna B. The MACTAR patient preference disability questionnaire - an individualized functional priority approach for assessing improvement in physical disability in clinical trials in rheumatoid arthritis. J Rheumatol 1987;14:446-51.

34. Verhoeven AC, Boers M, van der Linden S. Validity of the MACTAR questionnaire as a functional index in a rheumatoid arthritis clinical trial. J Rheumatol 2000; 27:2801-9.

35. Van der Hout WB, de Jong Z, Munneke M, Hazes JMW, Breedveld FC, Vliet Vlieland TPM. Cost-Utility and cost-effectiveness analyses of a long-term, high-intensity exercise program compared with conventional physical therapy in patients with rheumatoid arthritis. Arthritis Care Res 2005;53:39-47.

36. Vliet Vlieland TPM, van den Ende CHM, Breedveld FC, Hazes JMW. Evaluation of joint mobility in rheumatoid arthritis trials: The value of the EPM-range of motion scale. J Rheumatol 1993;20:2010-4.

37. Blanchard CM, Côté I, Feeny D. Comparing short form and RAND physical and mental health summary scores: Results from total hip arthroplasty and high-risk primary-care patients. Intl J of technology assessment in health care 2004;20:230-5.

38. Ware JE, Kosinski M, Keller SD. Physical and mental health summary scales - a user's manual. Boston, MA: New England Medical Center, The Health Institute; 1994.

39. Van der Zee KI, Sanderman R, Heyink J. De psychometrische kwaliteiten van de MOS 36item Short Form Health Survey (SF-36) in een Nederlandse populatie. Tijdschrift voor Sociale gezondheidszorg 1993;4:183-91.

40. Van der Zee KI, Sanderman R, Heyink JW, de Heas H. Psychometric qualities of the RAND 36-item health survey 1.0: A multidimensional measure of general health status. Int J Behav Med 1996;3:104-22.

41. Cohen, J. Statistical Power Analysis for the Behavioral Sciences 1988 published by Lawrence Erlbaum associates. 
Chapter 4: Results of the DAPPER study

42. Thorstensson CA, Roos EM, Petersson IF, Ekdahl C. Six-week high-intensity exercise program for middle-aged patients with knee osteoarthritis: a randomized controlled trial. BMC Musculoskelet Disord 2005;30:27-37.

43. De Jong Z, Munneke M, Zwinderman AH, Kroon HM, Jansen A, Ronday et al. Is a longterm high-intensity exercise program effective and safe in patients with rheumatoid arthritis? Arthritis \& Rheum 2003;48:2415-24. 


\section{Chapter 5}

Cost-effectiveness of intensive exercise therapy directly following hospital discharge in patients with arthritis: Results of a randomized controlled clinical trial

Y. Bulthuis, S. Mohammad, L.M.A. Braakman-Jansen, K.W. DrossaersBakker and M.A.F.J. van de Laar 


\section{ABSTRACT}

Objective. To estimate the cost-utility and cost-effectiveness of a 3-week intensive exercise training program (IET) directly following hospital discharge in patients with rheumatic diseases.

Methods. Patients with arthritis who were admitted to hospital because of a disease activity flare or for elective hip or knee arthroplasty, were randomly assigned to either the IET group or usual care (UC) group. Follow-up lasted 1 year. Quality-adjusted life years (QALYs) were derived from Short Form 6D scores and a visual analogue scale (VAS) rating personal health. Function-related outcome was measured using the Health Assessment Questionnaire (HAQ), the McMaster Toronto Arthritis (MACTAR) Patient Preference Disability Questionnaire, and the Escola Paulista de Medicina Range of Motion scale (EPM-ROM). Costs were reported from a societal perspective. Differences in costs and incremental cost effectiveness ratios (ICERs) were estimated.

Results. The data from 85 patients (50 IET and 35 UC) could be used for healtheconomic analysis. VAS personal health-based QALYs were in favor of IET. Function-related outcome showed statistically significant improvements in favor of IET over the first six months, according to the MACTAR $(P<0.05)$ and the EPMROM $(P<0.01)$. At 1 -year follow-up, IET was $€ 718$ less per patient. The ICER showed a reduction in mean total costs per QALY. In 70\% of the cases the intervention is cost-saving.

Conclusion. IET results in better quality of life at lower costs after one year. Thus, IET is the dominant strategy compared to UC. This highlights the need for implementation of IET after hospital discharge in patients with arthritis. 


\section{INTRODUCTION}

Rheumatoid arthritis (RA) and osteoarthritis (OA) have a different pathophysiologic basis. However, patients who have either form of arthritis experience pain and a gradual decline in muscle strength, eventually resulting in loss of function and quality of life. Hospitalization is indicated in patients with arthritis who experience disease activity flare or who require elective joint replacement. During hospitalization, an increased decline of function is observed. ${ }^{1}$ Recently, in the Disabled Arthritis Patients Post-hospitalization Intensive Exercise Rehabilitation (DAPPER) study, ${ }^{2}$ we have shown the beneficial effects of intensive exercise training (IET) directly following hospital discharge of arthritis patients with disease flare or after elective joint replacement. This finding is in line with earlier studies in patients with arthritis that evaluated IET on an inpatients basis and on an ambulatory basis. ${ }^{3-5}$

Usual care for patients with arthritis following hospitalization due to a flare of disease activity or for joint replacement is not standardized and depends upon custom, healthcare system and preferences of the patient, among other things. Nowadays, health care policy is based on evidence of effectiveness and, conversely, on health economic considerations. Thus, the implementation of novel treatment strategies should be based on evidence of effectiveness as well as on an acceptable balance between costs and effectiveness. Up to now, only a limited number of studies have reported the cost-effectiveness of exercise in patients with arthritis. ${ }^{6-10}$ However, patients with active disease were excluded.

This report addresses the health economic aspects of an IET program compared with usual care (UC) for patients with arthritis following hospitalization due to a flare in disease activity or for elective knee or hip replacement. The costeffectiveness analysis was performed alongside the randomized controlled clinical trial.

\section{PATIENTS AND METHODS}

\section{Patients}

Subjects were recruited from four Dutch hospitals (Medisch Spectrum Twente, Enschede; Twenteborg ziekenhuis, Almelo; Sint Maartenskliniek, Nijmegen and Isala klinieken, Zwolle). Patients were eligible when they were admitted either due 
to a flare in disease activity or for elective knee or hip replacement. Additional inclusion criteria were age $>18$ years and either RA according to the American College of Rheumatology (formerly the American Rheumatism Association) 1987 criteria $^{11}$ or polyarticular OA. Exclusion criteria were presence of serious cardiac disease (New York Heart Association criteria class III and IV),12 incapacitating pulmonary disease (Gold stage IV), ${ }^{13}$ serious hypertension (diastolic blood pressure $>110 \mathrm{~mm} \mathrm{Hg}$ ), pregnancy, insufficient understanding of the Dutch language, and functional incapacity (Steinbrocker functional class 4). ${ }^{14}$ A signed consent form was obtained from all participants.

\section{Design}

The DAPPER study is a randomized controlled clinical trial. In summary, consecutive eligible patients who gave informed consent were included and randomized block-wise to either the intervention group (IET) or the control group (UC). Directly following discharge, patients in the IET group were referred to a dedicated convalescent resort to receive three weeks of intensive exercise training. Thereafter, the IET group received regular care only.

In contrast, after discharge the patients in the UC group received usual care at the discretion of their attending physician only. Standard usual care after an elective joint replacement often consists of physical therapy once or twice weekly at a home-based setting. In case of comorbidity or polyarticular OA complication, rehabilitation referral to a nursing home is customary. Usual care after a disease flare is diverse, ranging from no additional therapy to physical therapy and ergotherapy at home. Outcome assessments were preformed at baseline and after 3, 13, 26 and 52 weeks. Costs were measured prospectively by monthly questionnaires.

\section{Intervention}

Directly following discharge, the IET group received a 3-week intensive exercise program at the European Care Residence and Resort "Groot Stokkert", which offers hotel facilities and professional care for disabled persons. During their 3-week stay, patients from the IET group were trained twice a day by physical therapists, for 75 minutes per session. The goals of the training were improvement of range of 
motion, muscle strength, aerobic capacity, physical function, and daily activities. The therapy sessions were administered individually and in groups. In the first two weeks, treatment focused on individual limitations (range of motion, strength, balance, aerobic capacity and simple functionality). Aerobic capacity training occurred daily on a submaximal level. Hydrotherapy was applied after sufficient wound healing. During the third week, the training focused on the functional capacities as prioritized by the patient. A group education program was administered twice per week. This program was based on the self-management training for patients with arthritis developed by Lorig et $\mathrm{al}^{15}$ and modified for The Netherlands by Taal et al. ${ }^{16}$

\section{Health outcome}

Utilities. Utilities refer to the preferences individuals or society may have for any particular health state ${ }^{17}$ and a valuation of the health of the patient ranging from 0 (equivalent to death) to 1 (full health). Utilities are used to calculate qualityadjusted life years (QALYs). A QALY is a composite index that includes effects in terms of both quality of life (utility) and the duration of time in such a health state. ${ }^{17}$ QALYs are an accepted measure for resource allocation decisions involving diverse treatments and patient populations. ${ }^{18}$

For the present study, utilities were assessed using the Short Form 6D (SF-6D) and a $100-\mathrm{mm}$ visual analogue scale (VAS). The SF-6D utility index was calculated from the RAND-36 -item health survey 1.0 (RAND-36) questionnaire. ${ }^{19}$ The RAND-36 includes the same items as those in the Short 36 (SF-36) and measures general health status. The RAND-36 comprises 36 items on physical and social functioning, role limitations, mental health, vitality, pain, and general health perception. ${ }^{20}$ The VAS score ranges from 0 (worst imaginable health) to 100 (best imaginable health). Functional ability. Outcome expressed as functional ability was calculated according to the Health Assessment Questionnaire (HAQ), ${ }^{21,22}$ the McMaster Toronto Arthritis (MACTAR) Patient Preference Disability Questionnaire ${ }^{23,24}$ and the Escola Paulista de Medicina Range of Motion scale (EPM-ROM). ${ }^{25}$ The HAQ score ranges from 0 (no disability) to 3 (severe disability); the MACTAR follow-up score ranges from 21 to 77 points (lower scores reflect better functional ability). The follow-up assessments focus on change in ability to perform impaired activities and evaluate the patient's health status by asking questions on general health; 
quality of life; and physical, social and emotional well-being. The EPM-ROM evaluates 10 distinct movements of joints on both sides of the body, and the score varies from 0 (no limitation) to 30 (severe limitation).

\section{Costs}

Costs were assessed using the societal perspective and valued in accordance to the Dutch guidelines for pharmacoeconomic research ${ }^{26}$ including direct and indirect medical costs and indirect nonmedical costs. All unit cost prices were based on the year 2003 and were expressed in Euros (€).

To estimate the costs of the convalescence program (IET), College Tarieven Gezondheidszorg/ Zorgautoriteit in oprichting (CTG/ZAio) charges were used (www.ctg-zaio.nl). The cost per day of the IET program was composed as follows: 1) accommodation €90; 2) nursing care €10.50; 3) individual physical therapy $€ 21.50$ and 4) group therapy €37.25. During the weekend no therapy was administered. The cost per weekday per IET patient were valued at $€ 159.25$. The cost per weekend day per IET patient was $€ 100.50$. The total costs of the intervention were estimated at $€ 2,991$ per patient.

Medical costs were based on the Dutch governmental charges 2003 (CTG/ZAio) or, whenever applicable, on the market prices. The general practitioner was valued at $€ 20.20$ per visit. Medical specialist visits were valued at an average charge of $€ 57.65$. The physical therapist was valued at $€ 21.50$ per visit. All other paramedical and alternative therapists (such as occupational therapists and social workers) were separately valued according to average prices of the professions in The Netherlands. The average price was $€ 32.60$ per visit. Medication was valued according to the Dutch Pharmacotherapeutic Compass ${ }^{27}$ including the $6 \%$ price per prescription to cover pharmacist fees.

For hospital admissions, the number of days spent in the hospital and the type of hospital were recorded. Hospitalization days were valued according to the prices declared by the financial administration of the hospitals. The aids used for physical restrictions were recorded as were the actual costs incurred by the patients.

Nonmedical costs were based on Dutch standard prices reflecting societal costs for economic evaluations. ${ }^{28}$ These costs included travel costs required to obtain health care, the costs of absenteeism from work, professional domestic care, paid domestic help and informal care (the number of hours per week patients received help from 
family or friends). Absenteeism was valued using the human-capital method in which productivity costs are calculated for the entire absent period. Absenteeism from paid work was recorded on a per-day basis. Monthly income and regular working hours were recalculated to value a day's income. 28,29

Professional domestic care was valued at $€ 30.70$ per hour. The costs of paid domestic help and informal care were valued as reported by the patients with a maximum of 28 hours per week in order to prevent overreporting. When actual costs were unavailable, an average cost per hour of $€ 8.00$ was imputed.

\section{Statistical analysis}

Results were analyzed for patients who completed at least 6 of the 12 monthly questionnaires on costs. Results are expressed as QALYs and measures of physical function. The time-integrated summary score (the area under the curve [AUC]) of the utilities was calculated to define the quality of life per time period (0-6 months and $0-1$ year).

The scores of the HAQ, MACTAR and EPM-ROM were presented as change scores from baseline. Between-group differences in outcome measurements were analyzed per period by Student's $t$-test for unpaired observations.

The costs are presented as arithmetic means \pm SD per patient per group. The between-group differences in resource use were analyzed per period by MannWhitney U test. Mean incremental costs per patient and study period were calculated and 95\% confidence intervals (95\% CIs) were calculated using doublesided bootstrapping.

The incremental cost-utility ratio (ICER) was calculated by dividing the incremental costs for the IET group by the gained QALYs derived from IET. The ICER is expressed as costs per QALY gained. The incremental cost-effectiveness ratio (ICER) for function measures was calculated by dividing the extra costs for the IET group by the gained units of effectiveness. These ICERs are expressed as costs per score points. The $95 \%$ CIs of the ratios were estimated with bootstrapping. ICERs were only calculated when group differences were significantly different. Costs and health outcome were not discounted because the time horizon of this study was less than one year and no modeling beyond the observed period was performed. 


\section{RESULTS}

\section{Study participants}

The DAPPER trial included 114 patients with arthritis who all were admitted to hospital because of a flare in disease activity or for elective joint replacement of the hip or knee. Cost questionnaires were completed by 85 of the patients (75\%; 50 IET and 35 UC). Twenty-nine of the patients (10 IET and 19 UC) did not complete the questionnaires, but they did not differ from the other patients in the DAPPER trial with respect to sex, age, work, or education.

The demographic and baseline disease characteristics of the patients in this health economical analysis are presented in Table 1. Differences between groups were not statistically significant.

\section{Health outcome results}

SF-6D based QALYs were similar in both groups. VAS-based QALYs were in favor of IET $(P<0.05)$ for both periods (Table 2). Function-related outcome was similar according to the HAQ. However, the MACTAR $(P<0.05)$ and the EPM-ROM $(P<0.01)$ showed statistically significant improvements in favor of IET during the first six months (Table 2).

\section{Costs results}

The amount of medical and nonmedical resource use during the follow-up is presented in Table 3. For both periods, a difference in favor of the IET-group was observed in the number of visits for paramedical treatments $(P<0.01)$. Patients from the UC group visited the physical therapists 1.8 times more frequently compared with the IET group. For the other variables, including hospitalization, no significant differences in the amount of resource use were found. 


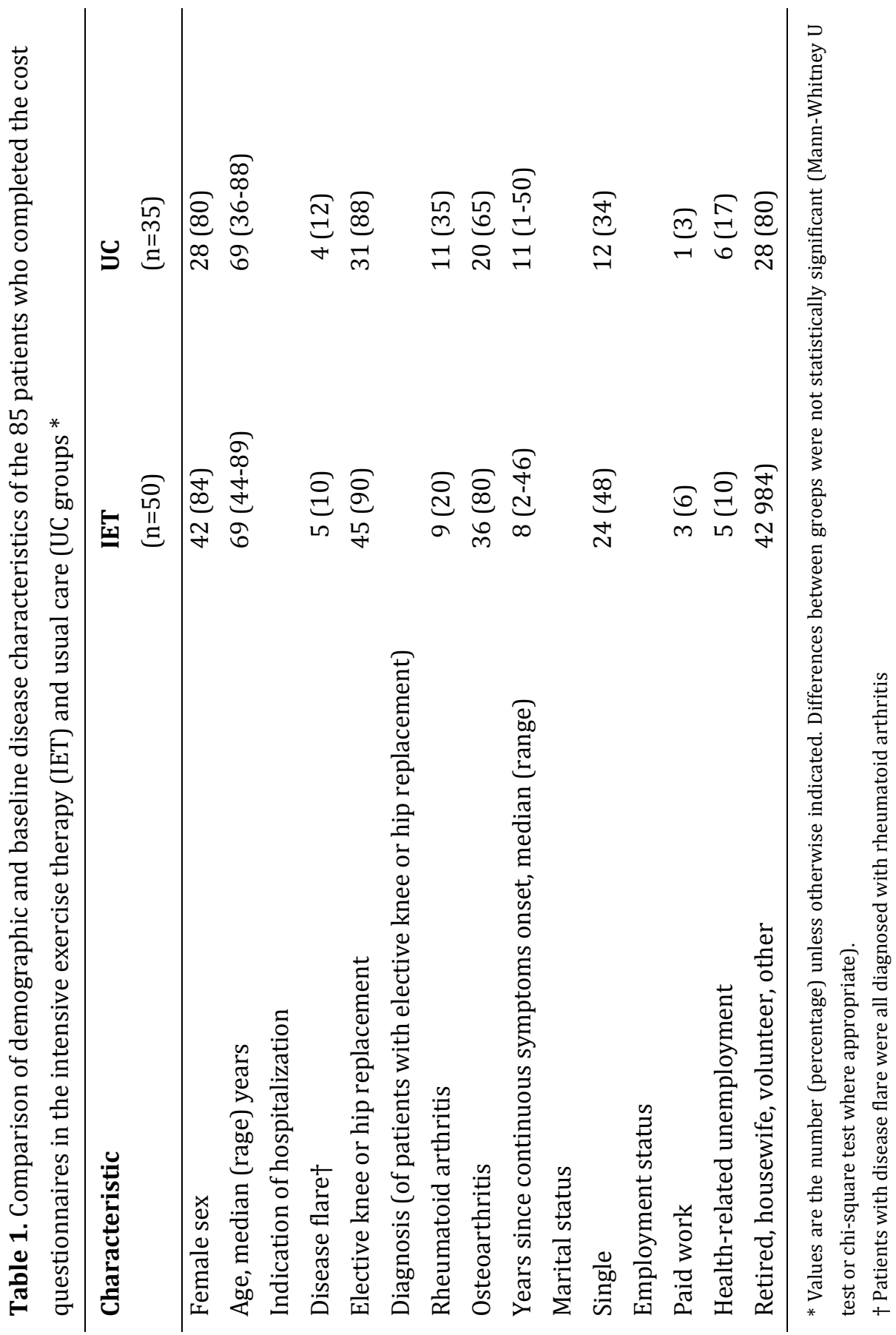




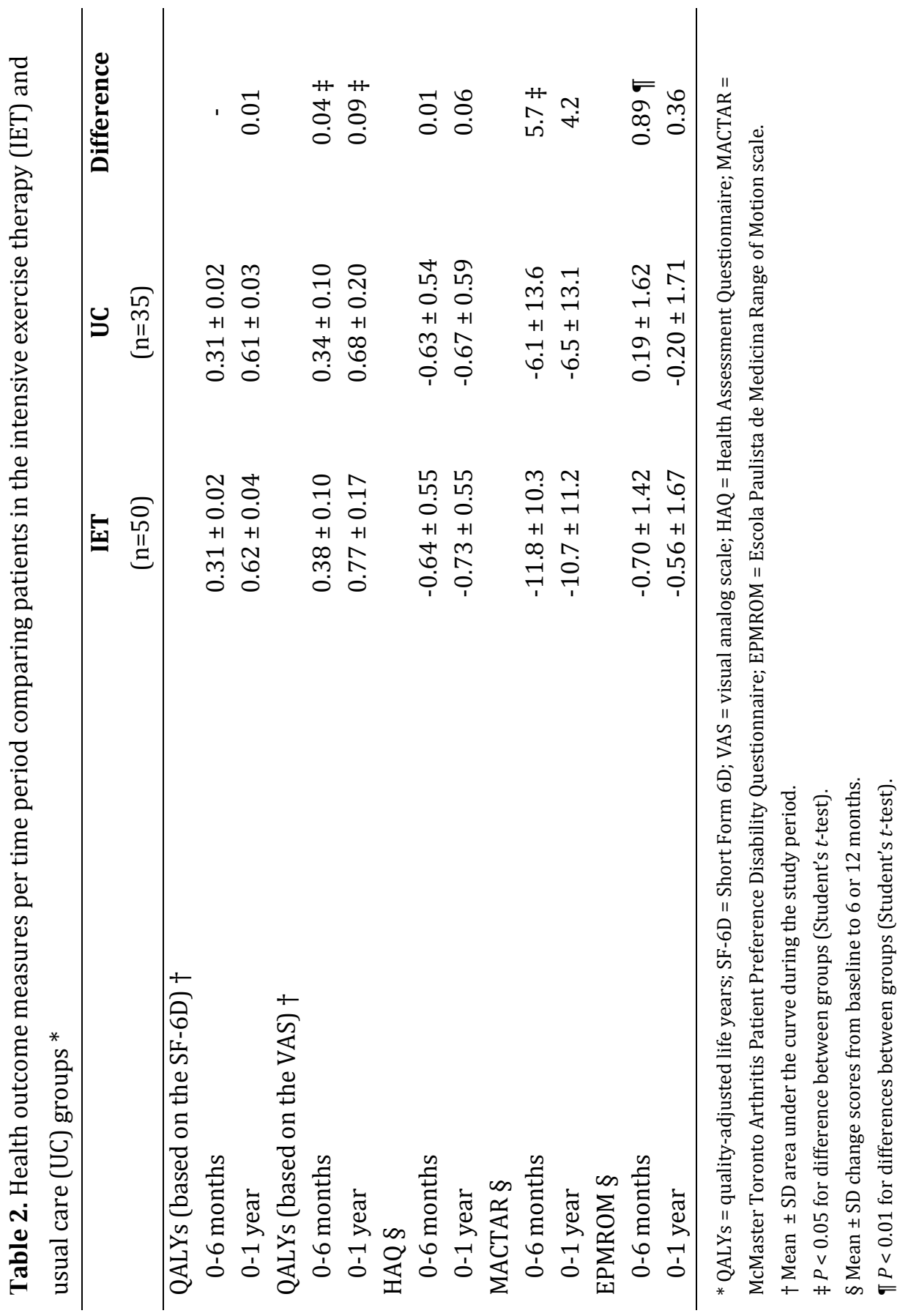




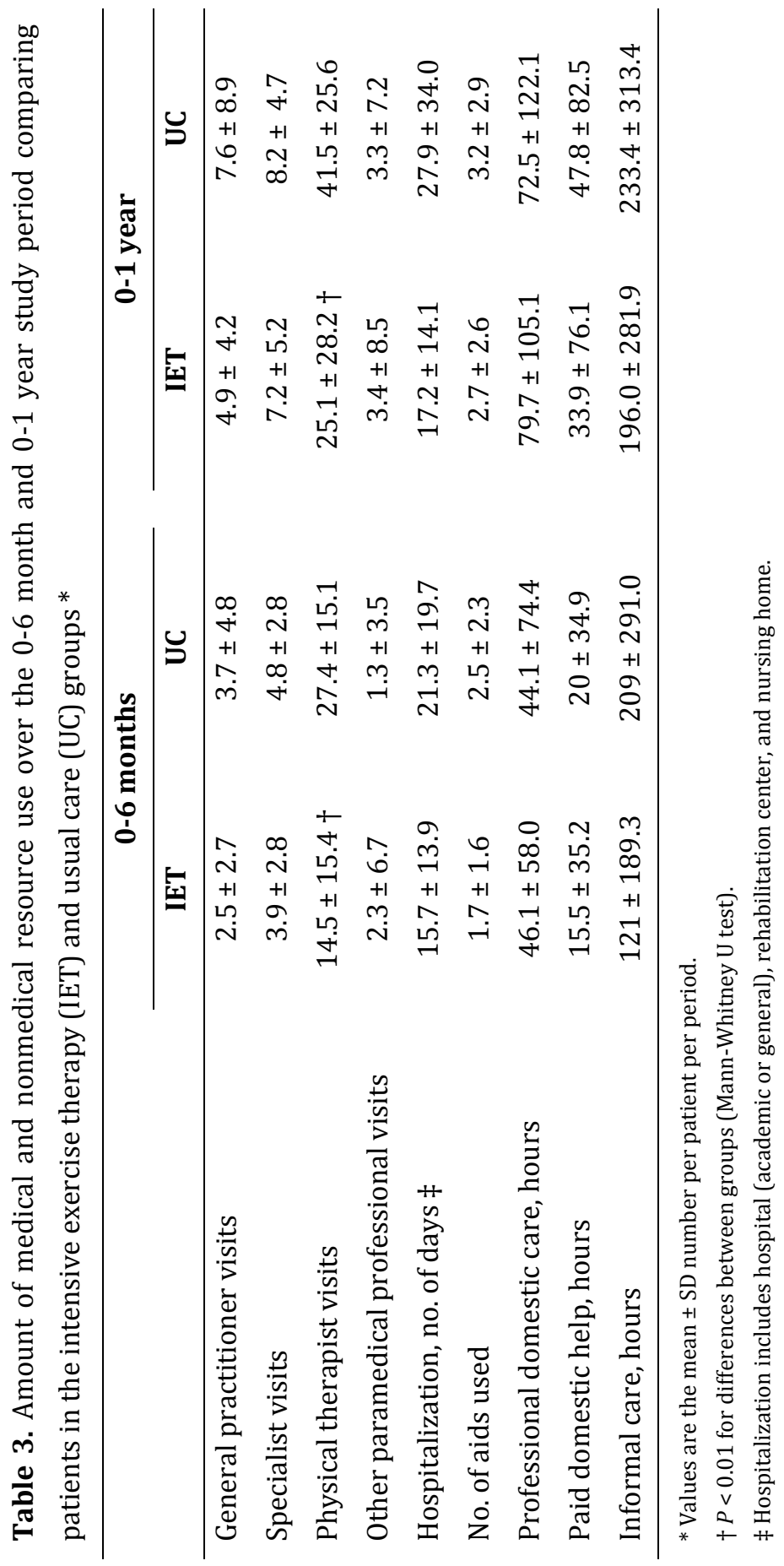




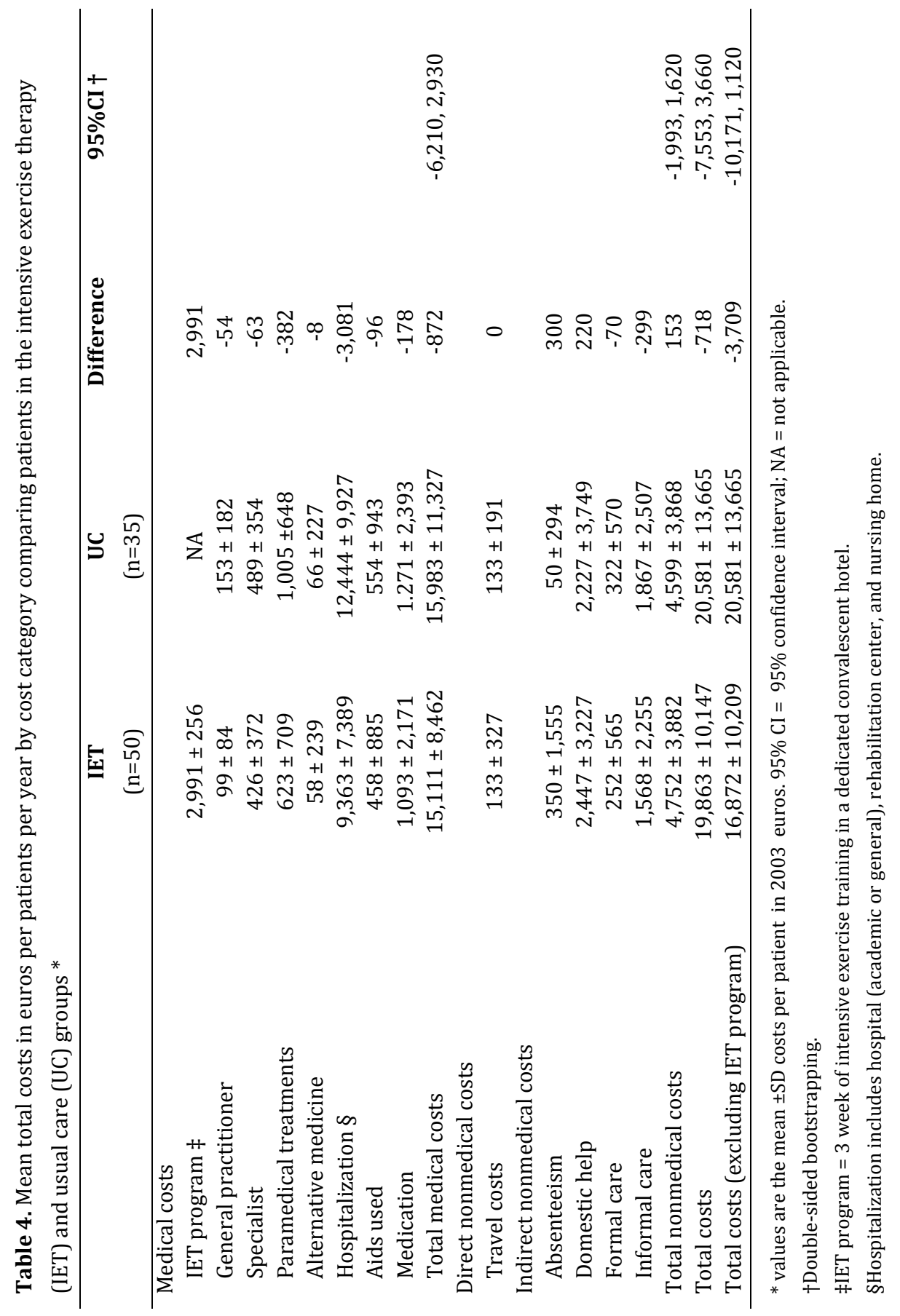


Mean costs per patient per year by cost category and treatment group are listed in Table 4. Mean total costs from a societal perspective were €718 lower per patient per year $(95 \%$ CI $-€ 7,553, € 3,660)$ for the IET compared with the UC group. When excluding the price of the IET program, mean incremental costs per patient were $€ 3,709$ lower for IET. After 6 months of follow-up, the mean incremental costs per patient was €804 higher for IET $(95 \%$ CI $-€ 2,595, € 3,996)$. When excluding the price of the IET program, mean incremental costs per patient were €2,068 lower for IET (data not shown).

The observed difference in costs between groups was mainly generated by the cost of hospitalization. Therefore, further specification of these costs was explored. The main difference in hospitalization costs could be explained by a small group of patients from the UC group. Immediately after initial discharge from the hospital, these patients (mainly diagnosed with $\mathrm{OA}$ ) were referred to a nursing home for an average of 47 days. This resulted in $€ 31,000$ extra costs for the UC group. In addition, during follow-up patients from the UC-group who were hospitalized because of a second elective hip or knee arthroplasty stayed in the hospital longer on average compared with patients from the IET group, which explains a difference in total costs of $€ 21,000$ between groups (results not shown).

\section{Cost-utility}

The incremental cost-utility ratio (based on the AUC of the VAS personal health) after 6 months of follow-up was € 20,100 (€804/0.04) per QALY gained (95\% CI$€ 235,000, € 293,000)$. In $49 \%$ of the cases the intervention was cost-saving. After 1 year of follow-up, the intervention was cost-saving and IET was the dominant strategy. The uncertainty around the ratio was estimated with bootstrapping and is presented graphically by the cost-utility plane (Figure 1). This plane shows in which quadrant the population ratio can be expected. In Figure 1, 70\% of the bootstrapped ratios were situated in the lower-right quadrant (signifying lower costs and better quality of life) whereas 30\% were situated in the upper-right quadrant (signifying a gain in QALYs against higher costs). Because the SF-6D did not show differences in QALYs between groups, the ICER was not calculated based on this instrument. 


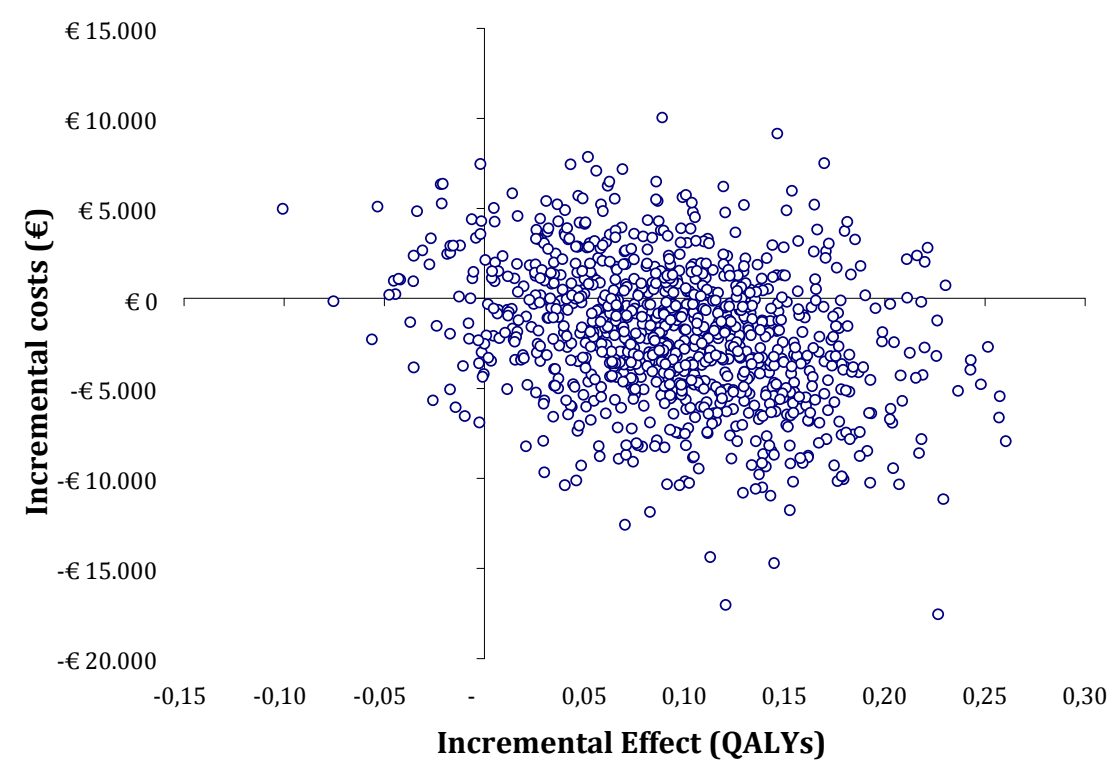

Figure 1. Cost-utility plane: bootstrap replicates of costs per QALY gained estimated using the VAS general health after one year of follow-up $†$ † QALYs indicate quality-adjusted life years

\section{Cost-effectiveness}

The ICER was calculated based on the MACTAR and EPM-ROM score over the first six months because significant differences between groups in terms of effectiveness were found with these instruments. The ICER (based on the MACTAR over the first six months) was €142 (€804/5.7) per score point (95\% CI -€2,328, €2,829): in $38 \%$ of the cases the intervention was cost-saving. The ICER based on the EPM ROM over the first six months was €903 (€804/0.89) per score point (95\% CI $€ 16,741, € 5,621)$ : in $32 \%$ of the cases IET is cost-saving. 


\section{DISCUSSION}

This health-economic analysis demonstrates that after one year of follow-up, the IET program for patients with arthritis immediately after hospital discharge is the dominant strategy. It is associated with lower costs and better effectiveness expressed as VAS personal health-based QALYs gained compared to UC. After six months of follow-up, IET is associated with slightly higher costs but a better quality of life and improved gain of function, compared to UC.

The two QALY measures used in this study led to different conclusions on the effectiveness of the intervention. This can be explained by the fact that conceptual differences exist between the measurement of utilities using the VAS and SF-6D because they are based on different elicitation methods. The VAS general health is a direct measure of utility representing the individual valuation of a single health state on a rating scale, whereas the SF-6D is a preference-based indirect utility measure in which the general public is the source of values, representing a summary score of six health states. ${ }^{19}$ The VAS is preferable to the SF-6D as a measure of patient-reported outcomes because the SF-6D uses preferences from the general public. In health-economic evaluation, however, the SF-6D is preferable as a standardized measure of QALYS representing the societal perspective. Both instruments have some disadvantages. Rating scales such as the VAS have been found to be subject to measurement bias $^{30}$ and should not be used alone in a study. ${ }^{31}$ The SF-6D, however, might not be sensitive to changes in the current study population. According to Stucki et al, ${ }^{32}$ the responsiveness of the SF-36 for patients undergoing total hip arthroplasty is rather moderate, because many items from the physical ability scale of the SF-36 reflect intermediate rather than extremes of level of difficulty. This floor effect was also demonstrated for the SF-6D: although the SF$6 \mathrm{D}$ has been shown to be a responsive measure in diseases of mild to moderate severity, it struggles to distinguish between states of severe health. ${ }^{33}$

Although the MACTAR measures primary functional ability, it combines information on functional limitations with information on health related quality of life (HRQoL). A key advantage of using the MACTAR is the ability to detect the impact of treatment on functional outcomes that are of most importance to the patient. A limitation of this instrument is that it is not widely used; little information on other patients is available for comparison. ${ }^{34}$ Therefore, the interpretation of the MACTAR results is rather difficult. 
An improvement of 3 points on the MACTAR can be interpreted to represent one less functional problem. ${ }^{7}$ In the current study, patients in the IET group showed improved functional ability as measured with the MACTAR. The estimated score difference of 4.2 after one year in the DAPPER study can be interpreted to indicate that patients receiving IET had at least one less relevant individual activity problem after one year of follow-up, at $€ 718$ less costs.

The DAPPER study demonstrates that IET reduces the mean total health care costs of patients with arthritis from a societal perspective in the first year after hospitalization. The main difference was caused by the costs of hospitalization. However, no statistically significant difference between groups was found in amount expressed as total days of hospitalization. Nevertheless, a trend showed that patients from the UC group stayed in the hospital longer immediately after study start as well as during follow-up because of (another) hospital admission. Essentially, high hospitalization costs in the UC group in the first months were caused by a small group of patients who were referred to a nursing home for a long period. During follow-up differences in costs between groups were mainly caused by another small group of patients with extremely long periods of hospitalization. In other words, it is noteworthy that patients from the IET group did not need nursing home care and were able to return home. Moreover, these patients needed less hospitalization in the year of follow-up, which could be due to a higher level of physical fitness. Because the UC group had initially more patients with RA and less with OA compared with the IET-group, one should consider selection bias. However, this is unlikely as all patients sent to a nursing home were diagnosed with OA.

Although not of great impact for the cost difference between groups, a significant difference in favor of the IET-group was observed in the number of visits for physical therapy. Obviously, the IET program included physical therapy, which influenced the difference in the first six months of follow-up. Nevertheless, the number of visits to the physical therapist continued to be lower in the IET group during the entire year. A possible explanation might be the instant favorable recovery.

This is the first study that addresses the difference in total costs between usual care and an intensive convalescence treatment program in patients with arthritis who were hospitalized because of a flare of disease activity or for elective joint 
replacement. The results of the DAPPER study are of great interest because the population is ageing and resources are limited. There are only a few studies on cost-effectiveness of exercise in patients with arthritis. ${ }^{6-10}$ However, except for the study by Mitchell et al, ${ }^{8}$ patients scheduled for joint replacement surgery or patients with total knee or hip replacements were excluded in these studies. Moreover, the definition of exercise differed greatly among the studies. Most authors concluded that exercise therapy provided insufficient improvement in health to justify the additional costs. ${ }^{6-8}$ Only Richardson et al ${ }^{10}$ found that group based exercise is likely to be cost-effective compared to home-based exercise. However, this 8-week, twice weekly, group-based program was only suitable for patients with knee $\mathrm{OA}$.

This economic evaluation was conducted alongside a randomized clinical trial. Therefore, all resource use and health outcomes data were fully stochastic and collected prospectively over the 1-year study period. This is an important strength of the current study because many economic evaluations use modeling techniques that are often based on indirect data and best guesses. Furthermore, the analysis was conducted from a societal perspective, which implies that all relevant costs (including the indirect costs) were taken into account.

There are some limitations of the current study. First, as described before, VAS personal health-based preferences are not preferable as a standardized measure of QALYs for use in societal perspective economic evaluation; therefore, caution should be taken with the interpretation of the ICER. Furthermore, the number of patients lost to follow-up was quite high: only $75 \%$ of the eligible patients could be included in the analysis. Nevertheless, there were no significant differences in baseline characteristics between the evaluable and non-evaluable patients. Finally, when considering the human-capital method, there is a possibility of overestimating the true societal costs. However, because only four patients reported absenteeism from work, it probably had limited effect on the results.

The results from this study demonstrate that IET therapy is designated for all patients with arthritis (with the emphasis on those with polyarticular arthritic symptoms complaints) after hospital discharge. Implementing of IET therapy should include the combination of intensive exercise and group-based patient education in arthritis-dedicated facilities in the presence of experienced care givers. 
In conclusion, IET after hospitalization for patients with arthritis due to a flare of disease activity or for elective joint replacement results in better quality of life at lower costs after one year compared to UC. This highlights the need for implementation of IET after hospital discharge in patients with arthritis. 


\section{REFERENCES}

1. Convertino VA, Bloomfield SA, Greenleaf JE. An overview of the issues: physiological effects of bed rest and restricted physical activity. Med Sci Sports Exerc 1997;29:187-90.

2. Bulthuis Y, Drossaers-Bakker KW, Taal E, Rasker JJ, Oostveen J, van 't Pad Bosch PJ, Oosterveld FGJ, van de Laar MAFJ. Arthritis patients show long-term benefits from three weeks intensive exercise training directly following hospital discharge; Results of the DAPPER (Disabled Arthritis Patients Post-hospitalisation intensive Exercise Rehabilitation) study. Rheumatology (oxford) 2007;46:1712-7.

3. Vliet Vlieland TP, Zwinderman AH, Vandenbroucke JP, Breeveld FC, Hazes JM. A randomized clinical trial of in-patient multidisciplinary treatment versus routine outpatient care in active rheumatoid arthritis. Br J Rheumatol 1996;35:475-82.

4. Van den Ende CHM, Breedveld FC, le Cessie S, Dijkmans BAC, de Mug AW, Hazes JMW. Effect of intensive exercise on patients with active rheumatoid arthritis: a randomised clinical trial. Ann Rheum Dis 2000;59:615-21.

5. de Jong Z, Vliet Vlieland TPM. Safety of exercise in patients with rheumatoid arthritis. Curr Opin Rheumatol 2005;17:177-82.

6. Patrick DL, Ramsey SD, Spencer AC, Kinne S, Belza B, Topolski TD. Economic evaluation of aquatic exercise for persons with osteoarthritis. Med Care 2001;39:413-24.

7. Van den Hout WB, De Jong Z, Munneke M, Hazes JMW, Breedveld FC, Vliet Vlieland TP. Cost-utility and cost-effectiveness analyses of a long-term, high-intensity exercise program compared with conventional physical therapy in patients with rheumatoid arthritis. Arthritis Rheum 2005;53:39-47.

8. Mitchell C, Walker J, Walters S, Morgan AB, Binns T, Mathers N. Costs and effectiveness of pre-and post-operative home physiotherapy for total knee replacement: randomized controlled trial. J Eval Clin Pract 2005;11:283-92.

9. Thomas KS, Miller P, Doherty M, Muir KR, Jones AC, O’Reilly SC. Cost effectiveness of a two-year home exercise program for the treatment of knee pain. Arthritis Rheum 2005;53:388-94.

10. Richardson G, Hawkins N, McCarthy CJ, Mills PM, Pullen R, Roberts C, Silman A, Oldham JA. Cost-effectiveness of a supplementary class-based exercise program in the treatment of knee osteoarthritis. Int J Technol Assess Health Care. 2006;22:84-9.

11. Arnett FC, Edworthy SM, Bloch DA, McShane DJ, Fries JF, Cooper NS et al. The American Rheumatism Association 1987 revised criteria for the classification of rheumatoid arthritis. Arthritis Rheum 1988;31:315-24.

12. The Criteria Committee of the New York Heart Association. Nomenclature and criteria for diagnosis of diseases of the heart and great vessels, 9th ed. New York: Little, Brown and Company; 1994:253-6. 
13. Rabe KF, Hurd S, Anzueto A, Barnes PJ, Buist SA, Calverley P, et al. Global strategy for the diagnosis, management and prevention of chronic obstructive pulmonary disease GOLD Executive Summery. Am J Respir Crit Care Med 2007;176:532-5.

14. Steinbrocker 0 , Traeger $\mathrm{CH}$, Batterman RC. Therapeutic criteria in rheumatoid arthritis. JAMA 1949;140:659-62.

15. Lorig K, Lubeck D, Kraines RG, Seleznick M, Holman HR. Outcomes of self-help education for patients with arthritis. Arthritis Rheum 1985;28:680-85.

16. Taal E, Rasker JJ, Wiegman O. Patient education and self-management in the rheumatic diseases: A self-efficacy approach [review]. Arthritis Care Res 1996;9:229-38.

17. Drummond MF, O'Brien B, Stoddart GL, Torrance GW. Methods for the Economic Evaluation of Health Care Programmes. Oxford: Oxford Medical Publications, 1997.

18. Hjelmgren J, Berggren F, Andersson F. Health economic guidelines - similarities, differences and some implications. Value in Health 2001;4:225-50.

19. Brazier J, Roberts J, Deverill M. The estimation of a preference-based measure of health from the SF-36. J Health Econ 2002;21:271-92.

20. Van der Zee KI, Sanderman R, Heyink JW, de Heas H. Psychometric qualities of the RAND 36-item health survey 1.0: A multidimensional measure of general health status. Int J Behav Med 1996;3:104-22.

21. Fries JF, Spitz P, Kraines RG, Holman HR. Measurement of patient outcome in arthritis. Arthritis Rheum 1980;23:137-45.

22. Siegert CEH, Vleming LJ, van den Broucke JP, Cats A. Measurement of disability in Dutch rheumatoid arthritis patients. Clin Rheumatol 1984;3:305-9.

23. Tugwell P, Bombardier C, Buchanan WW, Goldsmith CH, Grace E, Hanna B. The MACTAR Patient Preference Disability Questionnaire: an individualized functional priority approach for assessing improvement in physical disability in clinical trials in rheumatoid arthritis. J Rheumatol 1987;14:446-51.

24. Verhoeven AC, Boers M, van der Linden S. Validity of the MACTAR questionnaire as a functional index in a rheumatoid arthritis clinical trial. J Rheumatol 2000;27:2801-9.

25. Vliet Vlieland TPM, van den Ende CHM, Breedveld FC, Hazes JMW. Evaluation of joint mobility in rheumatoid arthritis trials: The value of the EPM-range of motion scale. J Rheumatol 1993;20:2010-4.

26. College voor zorgverzekeringen (CVZ). Dutch guidelines for pharmacoeconomic research. Amstelveen (The Netherlands): CVZ, 1999. In Dutch

27. College voor zorgverzekeringen (CVZ). Pharmacotherapeutisch Kompas 2003. Diemen (The Netherlands): CVZ, 2003.

28. Oostenbrink JB, Koopmanschap MA, Rutten FF. Handleiding voor kosten onderzoek: methoden en richtprijzen voor economische evaluaties in de gezondheidszorg. Diemen: CVZ, 2004. 
29. Koopmanschap MA, Rutten FFH. A practical guide for calculating the indirect costs of disease. Pharmacoeconomics 1996;10:460-66.

30. Torrance GW, Feeny DH, Furlong WJ, Barr RD, Zhang Y, Wang Q. Multi-attribute preference functions for a comprehensive health status classification system: Health Utilities Index Mark 2. Med Care 1996;24:702-22.

31. Torrance GW, Feeny D, Furlong W. Visual analog scales: do they have a role in the measurement of preferences for health states? Med Decis Making 2001;21:329-34.

32. Stucki G, Daltroy L, Katz JN, Johannesson M, Liang MH. Interpretation of change scores in ordinal clinical scales and health status measures: the whole may not equal the sum of the parts. J Clin Epidemiol 1996;49:711-17.

33. Brazier J, Roberts J, Tsuchiya A, Busschbach J. A comparison of the EQ-5D and SF-6D across seven patient groups. Health Econ 2004;13:873-84.

34. Lubeck DP. Patient-reported outcomes and their role in the assessment of rheumatoid arthritis. Pharmacoeconomics 2004;22:27-38. 



\section{Chapter 6}

Patients with impairment of multiple joints after a total joint replacement benefit from three weeks' intensive exercise training directly following hospital discharge.

Y. Bulthuis, A.V.C.M. Zeegers, D. ter Keurs, M.A.F.J. van de Laar 


\begin{abstract}
Purpose. The goal of this study was to examine the efficacy of a three weeks' intensive exercise training directly following hospital discharge for total hip or knee arthroplasty in patients with multiple joints disease.

Method. This is a prospective randomized controlled trial with 100 patients with elective hip or knee arthroplasty. The intervention group $(n=53)$ received intensive exercise training (IET) for three weeks in a dedicated resort; the control group $(n=47)$ was treated with usual care (UC). Outcomes were assessed at baseline and after 3, 13, 26, and 52 weeks. Repeated measurement analyses were performed.

Results. The intensive training did not increase pain scores. After three weeks and continuing over one year, the patients in the IET group benefited from the program significantly with respect to physical function (HAQ), quality of life (SF36), functional ability and general health (MACTAR) as compared with the control group.
\end{abstract}

Conclusions. Intensive exercise training immediately after hospital discharge has short and long-term benefits for patients with multiple joints disease after total joint replacement surgery of hip and knee. 


\section{INTRODUCTION}

Due to the senescence of the population there is an increasing need for total joint replacement surgery i.e. for knee and hip joints. In order to limit time spent during hospitalisation and to restore functional ability rapidly, several peri-operative training programmes and clinical pathways were designed.1-6 These training programmes were designed to improve physical condition and well-being in relatively young and healthy patients. ${ }^{7-10}$ Presently, in the Netherlands, the majority of hospitals have introduced such a training programme for their patients after total hip and knee surgery. Although there are no standard inclusion criteria for these programmes, they are all focused on fit and strong patients who generally rehabilitate more quickly and easily after surgery. Therefore healthy patients and patients with light systemic disease according to the American Society of Anaesthesiology classification system I or II (ASA class I or II) are entered in these adjuvant training programmes. ${ }^{1,11,12}$ In case of disabled patients or in case of comorbidity these patients can not fulfil the exercise programmes. Therefore in these patients hospitalisation is considerably longer and restoring functional status is prolonged. ${ }^{13}$ To the best of our knowledge the effect of intensive training in patients with multiple joint disease has never been studied. Major surgery and inactivity during hospitalisation for total joint arthroplasty exacerbates the decline of physical fitness and functionality. Since intensive exercise in relatively healthy patients has been demonstrated to benefit patients, ${ }^{14-16}$ we formulated the hypothesis that patients with multiple joint disease will benefit from a dedicated rehabilitation and exercise programme in a resort supplementary to their hospital stay for joint arthroplasty.

Therefore, the purpose of the present randomised controlled study is to investigate whether these patients will benefit from an adjusted intensive training programme after a total hip or knee replacement directly following discharge.

\section{PATIENTS AND METHODS}

\section{Patients}

For this study, a subgroup of patients was used from the randomised controlled clinical trial called the DAPPER study (Disabled Arthritis Patients Posthospitalisation intensive Exercise Rehabilitation). ${ }^{17}$ The DAPPER study is a 
multicentre trial which examined the efficacy of short-term intensive exercise training directly following hospital discharge in patients with rheumatoid arthritis (RA) or osteoarthritis (OA). For details we refer to the principal publication mentioned above. For this sub study, patients were eligible when they were admitted for elective total hip or knee replacement. Additional inclusion criteria were: (a) age over 18, and (b) OA of multiple joints (polyarticular OA) or RA (according to American College of Rheumatology criteria 1987). ${ }^{18}$ Exclusion criteria were; (i) presence of serious cardiac disease (New York Heart Association criteria class III and IV), ${ }^{19}$ (ii) incapacitating pulmonary disease (GOLD stage IV), ${ }^{20}$ (iii) serious hypertension (diastolic blood pressure $>110 \mathrm{~mm} \mathrm{Hg}$ ), (iv) pregnancy, (v) insufficient mastery of the Dutch language, (vi) functional incapacity (Steinbrocker functional class 4). ${ }^{21}$ Ethical approval was given before the start of the study by the medical ethical revision boards of the attending hospital. A signed consent form was obtained from all participants.

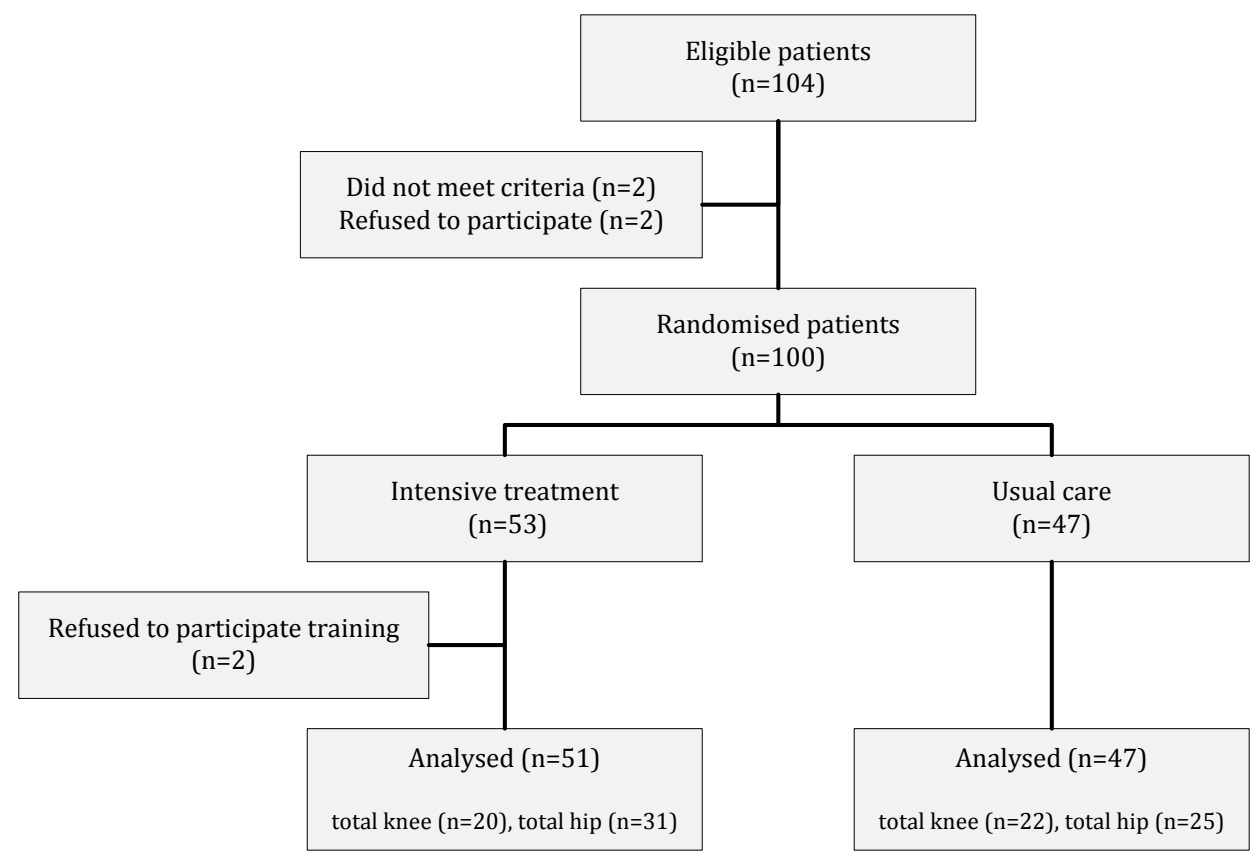

Figure 1. Flow diagram of subject progress through this study. 
Between July 2002 and January 2004, 100 patients signed informed consent and were randomised to either the intervention (IET) or the control group (UC), see Figure 1. In the UC group, one person died during the follow-up and two patients in the IET group refused to participate with all follow-up measures, due to work and mental state. From the total group (n=98), 56 patients were admitted for a total hip arthroplasty. Forty two patients were admitted for total knee arthroplasty. The demographic and baseline characteristics of the patients are presented in Table 1.

Table 1. Baseline characteristics of the two treatment groups.

\begin{tabular}{llll}
\hline Number of patients & $\begin{array}{l}\text { IET } \\
\text { (n=51) }\end{array}$ & $\begin{array}{l}\text { UC } \\
\text { (n=47) }\end{array}$ & $\begin{array}{l}\text { Total sample } \\
\text { (n=98) }\end{array}$ \\
\hline Age in years, mean (SD) & $70.4(10.8)$ & $67.3(11.2)$ & $69.0(11.0)$ \\
Female, \% [n] & $82[42]$ & $83[39]$ & $83[81]$ \\
Living alone, \% [n] & $49[25]$ & $38[18]$ & $44[43]$ \\
\% with one of more comorbidity & $88[44]$ & $81[38]$ & $84[82]$ \\
beside arthritis [n] & & & \\
Rheumatoid arthritis, \% [n] & $20[10]$ & $32[15]$ & $26[25]$ \\
Total hip, \% [n] & $61[31]$ & $53[25]$ & $57[56]$ \\
Total knee, \% [n] & $39[20]$ & $47[22]$ & $43[42]$ \\
\hline
\end{tabular}

NOTE: Between IET and UC no significant differences were found at baseline.

The mean age of the patients was 69 years ( $S D=11)$. Comorbidities besides poliarticular OA or RA were present in $84 \%(n=82)$ of the patients. The most frequent comorbidities were hypertension (45\%) and heart failure (30\%). Of all patients, 33\% (n=32) have had a joint replacement in the past. No significant differences were found at baseline between the IET and UC.

\section{Design}

This study is a post hoc analysis of subgroups in a prospective randomised controlled clinical trial. In all participating centres, consecutive eligible patients were informed of the study. Those who agreed to participate were randomised to either the IET or the UC group. We performed a blocked stratified randomisation including stratification on centre. During hospitalisation all patients were treated at the discretion of the attending physician. Directly following hospital discharge patients in the IET group were sent to a resort to receive three weeks' intensive 
exercise training (see below). After this, the IET group received regular care only. In contrast, after discharge the patients in the UC group received only usual care at the discretion of their attending physician. In general, usual care consists of either physical therapy by a local physical therapist or temporary admission to a nursing home, when applicable. Outcome assessments were performed at baseline (the moment the patient was considered well enough to be discharged from the hospital) and after 3, 13, 26 and 52 weeks, all by the same experienced physiotherapist.

\section{Intervention}

As soon as wound healing and the general medical condition of the patient made discharge from the hospital safe, the IET patients went to a dedicated 'resort' directly following hospital discharge: European Care Residence \& Resort 'Groot Stokkert'. This resort offers hotel facilities and professional care for disabled people. These include exercise facilities and physical therapy dedicated to patients with impairment of the musculoskeletal system. During their three week stay patients were trained twice a day by physical therapists, for $\sim 75$ minutes per session, depending on the capabilities of the individual patient. The goals of the training were improvement of range of motion, muscle strength, balance, aerobic capacity, physical function and activities of daily life. The therapy sessions were given individually as well as in groups. In the first two weeks, treatment focused on experienced individual limitations, appropriate to joint replacement (range of motion of affected joints, strength, aerobic capacity and simple functionality such as walking, climbing stairs, and getting up from a chair). Moreover, hydrotherapy was applied after sufficient wound healing. During the third week, the training also focused on the functional capacities in their daily lives in and around their home environment, as prioritised by the patient. A group education programme was given twice weekly. This programme was based on the self management training for arthritis patients by Kate Lorig, modified for the Netherlands by Taal.22,23 


\section{Assessments / Measures}

The Health Assessment Questionnaire (HAQ) is a patient reported outcome questionnaire developed to assess functional limitations in patients with rheumatic diseases. $^{24,25}$ The instrument contains 20 items on eight domains of life (arising, walking, dressing, eating, reach, grip, hygiene and common activities). The Dutch version of the HAQ has been validated. ${ }^{26}$ The subscales walking and arising were used to assess functional disability of the lower extremities. ${ }^{27}$ The scores range from 0 (no disability) to 3 (severe disability). Clinically relevant improvements for the HAQ vary between 0.22 and $0.26 .28,29$

The MacMaster Toronto Arthritis (MACTAR) Patient Preference Disability Questionnaire is a disease-specific questionnaire. ${ }^{30}$ An interviewer assesses at baseline which activities are most impaired and considered most important by the individual patient (maximum 5). The follow-up assessments focus on change in ability to perform these activities. The second part of the MACTAR evaluates the patient's health status by asking questions on general health, quality of life, and physical and emotional function. The baseline scores range from 39-59. The weighted MACTAR at follow-up assessments ranges from 21 to 77 points. Lower scores reflect better functional ability. The MACTAR has been validated in Dutch patients. $^{31}$ An improvement of three points can be argued to be clinically significant. $^{32}$

The EPM-ROM (Escola Paulista de Medicina - Range of Motion scale) is a diseasespecific questionnaire, which measured the range of motion. This scale evaluates 10 joint movements that are important in the performance of basic activities of daily living (ADL). The score for each joint movement can vary from zero (no limitation) to three (severe limitation). The sum of the left and right side is divided by two. The total score varies from 0 to 30.33

Health related Quality of Life (HrQoL) was measured using the short form 36 (SF36). The mental and physical component summery scales (SF36-MCS \& SF36PCS) were used, ${ }^{34}$ as were the subscales bodily pain (SF36-BP), physical function (SF36-PF) and mental health (SF36-MH). The SF36-BP is mostly used to assess pain and limitations due to daily activities. This generic instrument has been translated and validated for use in Dutch patients. ${ }^{35} \mathrm{~A}$ variety of analyses have indicated that improvements of 5-10 points in subscales and 2,5-5 points in summery scales score represent minimal clinical important difference in arthritis patients. ${ }^{28}$ 
Besides the SF36-BP, pain was also measured by the visual analog scale (VAS) for pain. The VAS is a 100 -mm one-dimensional scale from no pain (0) to extreme pain (100). The minimum clinically significant difference in VAS pain scores was found to be $9 \mathrm{~mm} .{ }^{36}$

\section{Statistical analysis}

Comparisons of the baseline scores were made using either the Mann-Whitney test or the independent Student's T-test, where appropriate. For categorical variables, analyses were performed using Chi-square and Fisher Exact test statistics. All analyses were performed on an intention-to-treat principle. Between-group differences in continuous variables over time were assessed by analysis of repeated measurements using the SPSS procedure for mixed models. This method takes into account all measurements including those between baseline and endpoint. Correction for baseline differences was performed. All statistical analyses were performed using the statistical package SPSS 16.0 and utilizing 2-tailed tests with a significance level of alpha $=.05$.

\section{RESULTS}

\section{Short-term effect of 3 weeks intensive training}

After three weeks of intensive training, the IET group improved relevantly more compared with the UC group although not all differences reached statistical significance. The results of the repeated measurements analysis are presented in Table 2 .

The IET group showed a significant improvement compared with the UC group for the subscale HAQ walking and HAQ rising. After three weeks, 79\% of the IET group $(n=38)$ showed a clinically relevant improvement with the subscale HAQ walking compared with $45 \%(\mathrm{n}=13)$ in the UC group $(\mathrm{p}=.002)$. With the subscale HAQ rising, $63 \%$ of the IET group $(n=30)$ showed a clinically relevant improvement of more than 0.22 against $37 \%(n=11)$ in the UC group $(p=.026)$. The MACTAR score for the IET group compared with the UC group improved considerably. After three weeks, $94 \%$ of the IET group $(n=48)$ showed a clinically relevant improvement on the MACTAR of more than three points compared with $73 \%$ in the UC group $(n=27)$, $\mathrm{p}=.006$. Also, with the separate questions of the MACTAR, the IET group was 
significantly more satisfied about their emotional and physical functioning, quality of life and general health after three weeks. Although the mobility (EPM-ROM) improved in the IET group compared with the UC group, this difference did not reach statistical significance.

The score on the subscale SF36-PF improved considerably for the IET group compared with the UC group. $75 \%$ of the IET group $(n=36)$ showed a clinically relevant improvement on the SF36-PF after three weeks against $43 \%$ in the UC group ( $\mathrm{n}=13), \mathrm{p}=.005$. As a practical example, stair climbing was much easier for the IET group after three weeks.

Based on the summary scales of the SF-36, physical component summary scale (SF36-PCS) and mental component summary scale (SF36-MCS), the general mental and physical health improved in the IET group. However, no significant differences were found between both groups. In the subscales SF36-MH and SF36-BP, no differences were found between both groups. However, both groups did show a relevant pain reduction in the first three weeks (SF36-BP). Measured with the VAS pain, the IET group experienced less pain after three weeks compared with the UC group, which is clinically relevant. $62 \%$ of the IET group $(n=31)$ showed a clinically relevant improvement on the VAS pain against $35 \%(n=13)$ in the UC group $(\mathrm{p}=.013)$.

\section{Long-term effects of intensive training}

Also over a period of three months and one year, the IET group improved relevantly more as compared with the UC group although not all differences reached statistical significance. A significant between-group difference was found for the MACTAR, EPM-ROM and SF36-PF for the periods, three months and one year. At three months, the subscale HAQ rising also demonstrated a statistical difference. The results of the repeated measurements analysis are presented in Table 3 en 4. 


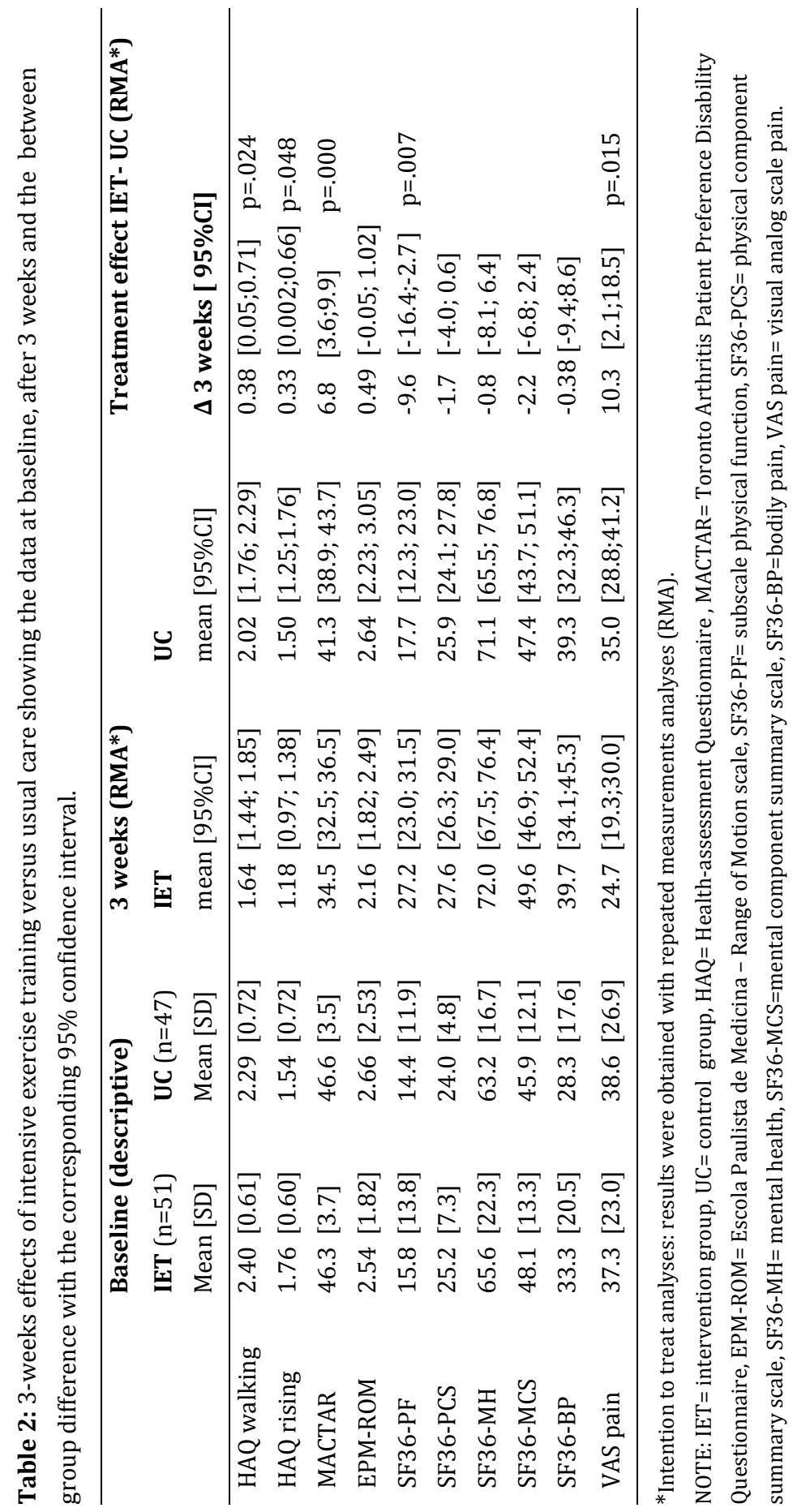




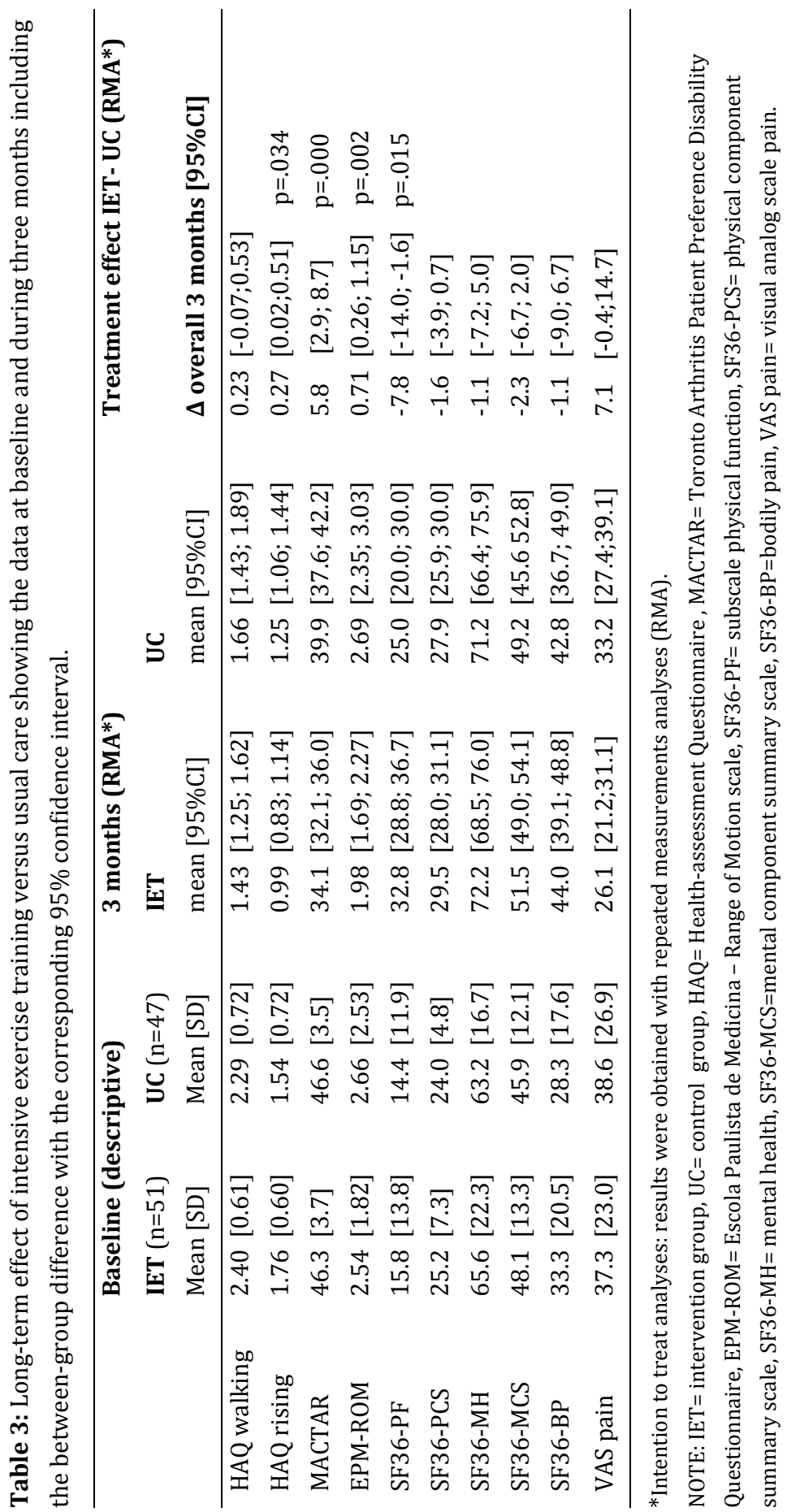




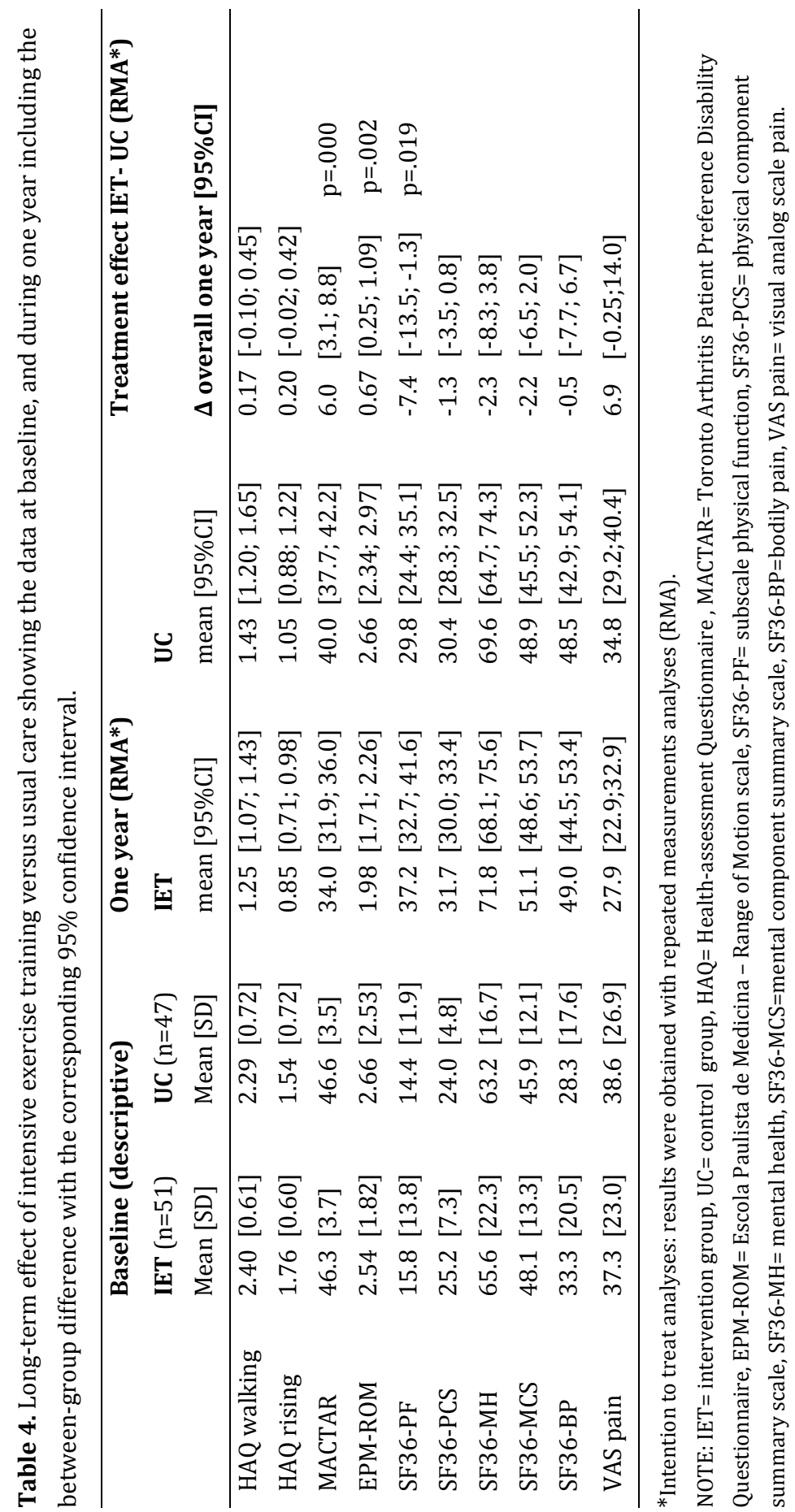


For several outcome questionnaires such as the HAQ, MACTAR and SF36 the treatment effect can be defined as a clinically relevant improvement for the IET group. To get an impression how many individuals in the IET and UC group reported a clinically relevant improvement, we presented the percentages of relevant improvements over a period of three months. On the subscale HAQ walking, $86 \%(n=44)$ of the IET group showed a relevant improvement of at least 0.22 points against $61 \%(\mathrm{n}=22)$ in the UC group ( $\mathrm{p}=.007)$. Of the IET group, $80 \%$ $(\mathrm{n}=40)$ showed a clinical relevant improvement on the subscale HAQ against 53\% $(\mathrm{n}=17)$ in the UC group ( $\mathrm{p}=.010)$. With the MACTAR, 90\% $(\mathrm{n}=46)$ of the IET group showed a relevant improvement of at least 3.0 points against $74 \%(n=28)$ in the UC group $(\mathrm{p}=.040)$. With the subscale SF36-PF $78 \%$ of the IET group $(n=39)$ demonstrated a relevant improvement of 5.0 points and more compared with $60 \%$ $(n=18)$ of the UC group ( $p=.085, n s)$.

Over a period of one year, a clinical relevant between-group difference was found for the IET group in the MACTAR and SF36-PF. Of the IET group, 90\% $(n=46)$ showed a clinical relevant improvement on the MACTAR against $77 \%(n=33)$ in the UC group ( $p=.076, n s)$. With the subscale SF36-PF, $80 \%$ of the IET group $(n=40)$ improved more than 5 points compared with $71 \%$ in the UC group (ns).

To the best of our knowledge, the EPM-ROM has no minimal important clinical difference. However, we noticed that during the first year after surgery $95 \%$ of the IET group improved their mobility as measured with the EPM-ROM. In the UC group several patients experienced a decrease of mobility according to baseline, where in the IET group none experienced a decline of mobility when compared with baseline scores.

With respect to baseline, both groups reported a clinically relevant improvement after one year. Practically, after one year a higher percentage of the IET patients were able to climb stairs and come out of bed without any problems or devices. These patients also experienced fewer disabilities, especially for walking a distance of 100 metres. Also, with the separate question of the MACTAR about the patients' general physical functioning, 84\% of the IET group experienced a reasonable to good physical functioning compared with $63 \%$ of the UC group after one year $(p=.021)$. On the summary scale mental health, $61 \%$ of the IET group against $42 \%$ of the UC group $(n=10)$ experienced an improvement of more than 2.5 points after one year $(\mathrm{p}=.132)$. 


\section{DISCUSSION}

This study demonstrates beyond doubt the beneficial effects (short-term as well as long-term) of a three week intensive exercise programme for patients with impairment of multiple joints and comorbidity directly following a hospital stay after total joint replacement. After three weeks the patients in the IET group were more satisfied about their emotional and physical functioning, quality of life, functional ability and general health. After one year, the patients in the IET group experienced a significantly improved physical function, an improved functional ability and an improved mobility. Based on the results of pain measures we can conclude that the intensive training did not cause more pain.

Increasing numbers of patients are in need of a total hip or knee arthroplasty. In ASA I and II patients, intensive training programmes have shown to be beneficial and are implemented widely. Based on the age and the percentage of comorbidities, as presented in Table 1, we conclude that the participants in this study mainly consists of ASA II and III patients. ${ }^{37}$ Furthermore, it appeared that the participating hospitals, also ran standard programs for arthroplasty patients, in which prior to the hospitalization mainly ASA I and II patients were selected. This made participation in this sub study of the DAPPER trial impossible for those generally fit and strong patients. Our study showed that an intensive exercise programme adapted for patients with impairment of multiple joints and comorbidity is beneficial. The programme is a good alternative for persons who can not meet the criteria of such existing training programmes because of substantial functional disabilities or comorbidity. Besides beneficial effects on patient-reported outcome measures, we are also interested in the cost-effectiveness of the intensive exercise therapy. The results of the DAPPER study have already shown that the treatment is cost-effective. ${ }^{38}$

Our programme was not limited to intensive exercise only. For obvious reasons, the programme was provided in a dedicated hotel facility. In this resort, people could fully focus on their training and rehabilitation, without worrying about everyday life such as cleaning, cooking or shopping.

As every study, our study has its strengths and limitations. Strong points of this study are the randomised controlled design with a considerable number of patients. Moreover, the intention to treat analysis meaning that all patients who were assigned to the study at baseline were included in the analysis underscores the 
strengths of the study. A limitation of our study was that the assessments were not blinded. Obviously, taking the informed consent obligation seriously, blinding is nearly impossible in clinical trials other than drug trials. Therefore, in this type of study, assessor bias is almost impossible to prevent.

The results of this study should have implications for the care of patients after total joint replacement. This study indicates that intensive training in a dedicated resort is effective for patients with impairment of multiple joints. In conclusion, this study shows that physical recovery as well as (physical) functioning benefits for patients after a total hip or knee arthroplasty with impairment of multiple joints and comorbidity.

\section{ACKNOWLEDGMENT}

The authors wish to express their appreciation for the collaboration of all participating patients, nurses, physiotherapists and physicians. Moreover, we are very grateful for the fruitful collaboration with European Care Residence \& Resort 'Groot Stokkert' and the Dutch Arthritis Foundation. 


\section{REFERENCES}

1. Stevens M, van den Akker-Scheek I, Spriensma A, Boss NAD, Diercks RL, van Horn JR. The Groningen Orthopedic Exit Strategy (GOES):a home-based support program for total hip and knee arthroplasty patients after shortened hospital stay. Patient Education and Counseling 2004;54:95-9.

2. van der Aast M, van Haastregt J. "Operatie heup"- een inventariserend onderzoek naar de mogelijkheden en onmogelijkheden van opnameduurverkorting bij mensen die een heupoperatie hebben ondergaan. Leiden: TNO, 1994.

3. Lin CC, March L, Crosbie J, Crawford R, Graves S, Naylor J, Harmer A, Jan S, Bennell K, Harris I, Parker D, Moffet H, Fransen M. Maximum recovery after knee replacement - the MARKER study rationale and protocol. BMC Musculoskeletal Disorders 2009;10:69-76.

4. Peerbhoy D, Keane P, Maciver K, Shenkin A, Hall GM, Salmon P. The systematic assessment of short-term functional recovery after major joint arthroplasty. J Qual Clin Pract 1999;19:165-71.

5. Pilot P, Engelen M, Dreessen F, van Os JJ, Kuipers H. Critical pathway for hip and knee arthroplasty: faster home due to multidisciplinairy cooperation. Journal of Integrated care pathways 2006;9:1-4.

6. Lenssen AF, Crijns YHF, Waltjé EMH, van Steyn MJA, Geesink RJT, van den Brandt PA, de Bie RA. Efficiency of immediate postoperative inpatient physical therapy following total knee arthroplasty: an RCT. BMC Musculoskeletal Disorders 2006;7:71-9.

7. Ostendorf M, Johnell O, Malchau H, Dhert WJ, Schrijvers AJ, Verbout AJ. The Epidemiology of total hip replacement in The Netherlands and Sweden, present status and future needs. Acta Orthop Scand 2002;73:282-86.

8. Trudelle-Jackson E, Smith SS. Effects of a late-phase exercise program after total hip arthroplasty: A randomized controlled trial. Arch Phys Med Rehabil 2004;85:1056-62.

9. Wang AW, Gilbey HJ, Ackland TR. Perioperative exercise programs improve early return of ambulatory function after total hip arthroplasty: A Randomized, controlled trial. Am J Phys Med Rehabil 2002;81:801-6.

10. Berend KR, Lombardi AV Jr., Mallory TH. Rapid recovery protocol for peri-operative care of total hip and total knee arthroplasty patients. Surg Technol Int 2004;13:239-47.

11. Bogie R. Goede resultaten heup-knieprogramma. Medisch Contact 2005;60:496-98.

12. van den Akker-Scheek I. Recovery after short-stay total hip and knee arthroplasty. Evaluation of a support program and outcome determination [dissertation]. Groningen: St. Drukkerij C.Regenboog; 2007. 97-108 p. ISBN: 9789077113608.

13. Greenfield S, Apolone G, McNeil BJ, Cleary PD. The importance of co-existent disease in the occurrence of postoperative complications and one-year recovery in patients undergoing total hip replacement. Comorbidity and outcomes after hip replacement. Med Care 1993;31:141. 
14. Roos EM. Effectiveness and practice variation of rehabilitation after joint replacement. Curr Opin Rheumatol 2003;15:160-2.

15. Munin MC, Rudy TE, Glynn NW, Crossett LS, Rubash HE. Early inpatient rehabilitation after elective hip and knee arthroplasty. Jama 1998;279:847-52.

16. Gilbey HJ, Ackland TR, Wang AW, Morton AR, Trouchet T, Tapper J. Exercise Improves Early Functional Recovery after total hip arthroplasty. Clinical orthopaedics and related research 2003;408:193-220.

17. Bulthuis Y, Dorssaers-Bakker KW, Taal E, Rasker J, Oostveen J, van't Pad Bosch P, Oosterveld F, van de Laar M. Arthritis patients show long-term benefits from 3 weeks intensive exercise training directly following hospital discharge. Rheumatology 2007;46:1712-17.

18. Arnett FC, Edworthy SM, Bloch DA, McShane DJ, Fries JF, Cooper NS et al. The American Rheumatism Association 1987 revised criteria for the classification of rheumatoid arthritis. Arthritis Rheum 1988;31:315-24.

19. Ament R. Origin of the ASA classification. Anesthesiology 1977;51:179.

20. The Criteria Committee of the New York Heart Association. Nomenclature and Criteria for Diagnosis of Diseases of the Heart and Great Vessels, 9th ed. New York: NY: Little, Brown and Company; 1994. p253-56.

21. Rabe KF, Hurd S, Anzueto A, Barnes PJ, Buist SA, Calverley P, et al. Global Strategy for the Diagnosis, Management, and Prevention of Chronic Obstructive Pulmonary Disease GOLD Executive Summary. Am J Respir Crit Care Med 2007;176:532-55.

22. Steinbrocker 0 , Traeger $\mathrm{CH}$, Batterman RC. Therapeutic criteria in rheumatoid arthritis. J Am Med Ass 1949;140:659-62.

23. Lorig K, Lubeck D, Kraines RG, Seleznick M, Holman HR. Outcomes of self help education for patients with arthritis. Arthritis Rheum 1985;28:680-85.

24. Taal E, Rasker JJ, Wiegman O. Patient education and self-management in the rheumatic diseases: A self-efficacy approach. Arthritis Care Res 1996;9:229-38.

25. Bruce B, Fries JF. Review article. The Stanford Health Assessment Questionnaire: A review of its history, issues, progress and documentation. J Rheumatol 2003;30:167-78.

26. Bruce B, Fries JF. The Stanford Health Assessment Questionnaire: dimensions and practical applications. Health Qual Life Outcomes 2003;1:20.

27. Siegert CE, Vleming LJ, Van denbroucke JP, Cats A. Measurements of disability in Dutch rheumatoid arthritis patients. Clin Rheumatol 1984;3:305-9.

28. Walker DJ, Heslop PS, Chandler C, Cleary R. Extraction and validation of a lower limb HAQ by comparison with objective measurement of ambulatory activity. Scand J Rheumatol 2001;30:154-8. 
29. Wolfe F, Michaud K, Strand V. Expanding the definition of clinical differences: From minimally clinically important differences to really important differences. Analyses in 8931 patients with rheumatoid arthritis. J of Rheum 2005;32:583-89.

30. Kosinki M, Zhao SZ, Dedhiya S, Osterhaus JT, Ware JE jr. Determining minimally important changes in generic and disease-specific health-related quality of life questionnaires in clinical trials of rheumatoid arthritis. Arthritis \& Rheumatism 2000;43:1478-87.

31. Tugwell P, Bombardier C, Buchanan WW, Goldsmith CH, Grace E, Hanna B. The MACTAR patient preference disability questionnaire - an individualized functional priority approach for assessing improvement in physical disability in clinical trials in rheumatoid arthritis. J Rheumatol 1987;14:446-51.

32. Verhoeven AC, Boers M, van der Linden S. Validity of the MACTAR questionnaire as a functional index in a rheumatoid arthritis clinical trial. J Rheumatol 2000; 27:2801-9.

33. Van der Hout WB, de Jong Z, Munneke M, Hazes JMW, Breedveld FC, Vliet Vlieland TPM. Cost-Utility and cost-effectiveness analyses of a long-term, high-intensity exercise program compared with conventional physical therapy in patients with rheumatoid arthritis. Arthritis Care Res 2005;53:39-47.

34. Vliet Vlieland TPM, van den Ende CHM, Breedveld FC, Hazes JMW. Evaluation of joint mobility in rheumatoid arthritis trials: The value of the EPM-range of motion scale. J Rheumatol 1993;20:2010-4.

35. Ware JE, Kosinski M, Keller SD. Physical and mental health summary scales- a user's manual. Boston, MA: New England Medical Center, The Health Institute; 1994.

36. van der Zee KI, Sanderman R, Heyink J. De psychometrische kwaliteiten van de MOS 36item Short Form Health Survey (SF-36) in een Nederlandse populatie. Tijdschrift voor Sociale gezondheidszorg 1993;4:183-91.

37. Kelly AM. Does the clinically significant difference in visual analog scale pain scores vary with gender, age or cause of pain? Acad Emerg Med 1998;5:1086-90.

38. Bulthuis Y, Mohammad S, Braakman-Jansen LMA, Drossaers-Bakker KW, van de Laar MAFJ. Cost-effectiveness of Intensive exercise therapy directly following hospital discharge in patients with arthritis: results of a randomized controlled clinical trial. Arthritis \& Rheumatism (Arthritis Care \& Research) 2008;59:247-54. 


\section{Chapter 7}

Summary and general conclusion 


\section{SUMMARY}

Hospitalization in arthritis patients is indicated when the disease flares or when joint replacements are to be placed. Conservative treatment aims to control disease activity and to reduce pain. Joint replacement is indicated when pain or functional limitations due to a destroyed joint impair the activities of daily living. Immobility, preceding and during hospitalization, leads to a deterioration of muscle strength and mobility of joints, resulting in limited physical functioning, which can end up in a vicious circle. Restoring function by improving the physical fitness immediately after hospitalization is a major challenge. The physical improvement should ultimately lead to an improved quality of life.

Some patients will have a severe decrease in functional capacity during hospitalization and as a consequence they will not be able to be discharged to go home when their medical condition is stable again. In those cases, a rapid recovery of function and physical condition is warranted. We hypothesized that a dedicated and short training, immediately after hospitalization, in an extramural inpatient setting like a resort or hotel could lead to a faster and better functionality for those patients. In this thesis we report on our studies on this hypothesis. We studied the effects and the cost-effectiveness of such a training program in RA and OA patients hospitalized for a RA flare or for elective TKA or THA.

Chapter 2 provides an overview of the existing knowledge and theories on the treatment of arthritis patients from the perspective of physical therapy. There is strong evidence that exercise therapy for patients with arthritis should at least consist of dynamic strength training and aerobic exercise. In which, the muscular strength training program is at least two sessions per week (involve 8-10 exercises for different muscle groups, 10-15 repetitions per exercise). The load for strengthening exercises should be moderate to hard (i.e. $50-80 \%$ of a maximal voluntary contraction). Aerobic exercise should be performed three times weekly for a duration of 30-60 minutes, with a moderate to hard intensity level (i.e. 60$85 \%$ of the maximum heart rate). Moreover, exercise therapy can be extended with range of motion, balance or co-ordination exercises. Although physical exercises are elementary for a fit body, it is important to involve the patient in the construction of the therapy to achieve a maximal result. The preferences and goals, but also the problems and fears of the patient, are important for the content of physical therapy. 
If the patient is motivated, he or she will continue to exercise and will understand the relevance of exercises. It is also important to involve the patient in finding solutions for his everyday problems, in collaboration with his or her therapist.

In Chapter $\mathbf{3}$ we describe the validation and reliability of a submaximal test using an arm ergometer. Until present a reliable way to measure the physical condition of a patient with impairments of the lower extremities is lacking. We therefore developed a submaximal test to measure the condition with an arm crack ergometer. To test the reliability and external validity of this test we used a crossover design. The measurements were randomly distributed over 30 healthy volunteers. Based on the Intraclass Correlation Coefficient (ICC) and the magnitude of within-person differences, we revealed a good reliability of the submaximal test. For the test-retest reliability the ICC was 0.76 , the interobserver reliability was 0.82 and the interergometer reliability 0.63. It appears that the arm ergometer has a good internal validation. In addition, the criterion validity was tested also by comparing the calculated $\mathrm{VO}_{2}$ max during the submaximal test on the arm crank ergometer and on a bicycle ergometer. Between the $\mathrm{VO}_{2}$ max on the arm crank- and bicycle ergometer an ICC of 0.64 was found. The results of the sub-maximal test on the arm crank ergometer are reliable and valid as compared with the bicycle crank ergometer. We showed that the sub-maximal test on the arm crank ergometer is suitable for measuring physical fitness in healthy people. We expect that disabled people can also use this submaximal test on the arm crank ergometer for measuring their physical fitness.

Chapter 4 describes a randomized controlled trial of the DAPPER study (Disabled Arthritis Patients Post-hospitalization intensive Exercise Rehabilitation). The participants were patients with RA or OA who needed hospitalization for either a flare-up in disease or for an elective arthroplasty of hip or knee. Patients were recruited from four Dutch hospitals. The intervention group received intensive exercise therapy (IET) for three weeks immediately after hospital discharge in a dedicated resort $(n=58)$; the control group (usual care: UC) was treated at the discretion of their attending physician $(n=40)$. The IET group was trained twice daily by physiotherapists, for approximately 75 minutes per session, depending on the capabilities of the individual patient. The goals of the training were improvement of range of motion, muscle strength, aerobic capacity and activities of daily living. The therapy sessions were given individually as well as in groups. An 
additional group-based patient educational program was given twice a week. This program was based on the self-management training for arthritis patients. The primary outcome was recovery of function as measured by the HAQ. Secondary outcome measures included the Escola Paulista de Medicina-Range of Motion scales (EPM-ROM), the McMaster Toronto Arthritis Patient Preference Disability Questionnaire (MACTAR) and the Research and Development 36-item Health Survey (RAND-36). The IET showed better and faster improvement compared with UC on all outcome measures except for Health Related Quality of Life (HRQoL). At three weeks, the IET had improved significantly more on the HAQ walking and rising subscales. Up to 52 weeks after baseline, the EPM-ROM and the MACTAR remained favorable in IET compared with UC. At three weeks the MACTAR improved significantly more in the IET compared with the UC: mean difference -5.5 (95\% CI -8.4 to -2.2). At 26 weeks, the mean difference remained significant (-5.2; $95 \%$ CI -10.0 to -0.34 ). At 52 weeks, the difference was no longer significant, but the mean difference in improvement between the groups could be considered clinically relevant. In conclusion, the DAPPER study shows improved and lasting recovery of function in arthritis patients due to a three-week intensive exercise training program directly following hospital discharge.

In Chapter 5 we describe the cost-effectiveness analysis which was performed alongside the randomized controlled trial presented in chapter 4. Cost-related data were prospectively collected for one year through monthly questionnaires, including direct and indirect medical costs and indirect nonmedical costs. Costs were analyzed and reported from the societal perspective and were valued in accordance with the Dutch guidelines for pharmacoeconomic research. All cost prices were based on the year 2003 and expressed in Euro's. Utilities were assessed using the Short From 6D (SF-6D) as well as a 100-mm visual analogue scale (VAS). These were used to calculate quality-adjusted life years (QALYs). Utilities refer to the preferences individuals or society may have for any particular health state and a valuation of the health of the patient ranging from 0 (equivalent to death) to 1 (full health). In addition, a QALY is a composite index that includes effects in terms of both quality of life (utility) and the duration of time in such a health state. Outcome expressed as functional ability was calculated according to the HAQ, MACTAR and EPM-ROM. Mean incremental costs per patient and study period were calculated. The incremental cost-utility ratio (ICER) was calculated by dividing the 
incremental costs for the IET group by the gained QALYs derived from IET. The ICER was expressed as costs per QALY gained. The incremental cost-effectiveness ratio (ICER) for function measures was calculated by dividing the extra costs for the IET group by the gained units of effectiveness. These ICERs were expressed as costs per score points. All 95\% confidence intervals (95\% CIs) were estimated with double-sided bootstrapping. ICERs were only calculated when group differences were significantly different. Costs and health outcome were not discounted because the time horizon of this study was less than one year and no modeling beyond the observed period was performed. Cost questionnaires were completed by 85 patients (75\%; 50 IET and 35 UC). Twenty-nine of the patients (10 IET and 19 UC) did not complete the questionnaires, but they did not differ from the other patients with respect to sex, age, work, or education. VAS personal health based QALYs were in favor of IET. Function related outcome showed statistically significant improvements in favor of IET over the first six months according to the MACTAR $(\mathrm{p}<0.05)$ as well as the EPM-ROM $(\mathrm{p}<0.01)$. At one year follow-up, IET was $€ 718$ less per patient. The ICER showed a reduction in mean total costs per QALY: in $70 \%$ of the cases the intervention is cost-saving. In conclusion, IET results in better quality of life at lower costs after one year. In other words, IET is the dominant strategy compared to usual care. This highlights the need for implementation of IET after hospital discharge in patients with arthritis.

Chapter 6 describes a sub study of the DAPPER trial (see chapter 4). Due to the senescence of the population, there is an increasing need for total joint replacement surgery, i.e. for knee and hip arthroplasty. In order to limit time spent during hospitalization and to restore functional ability rapidly, several peri-operative training programs and clinical pathways have been designed. Disabled patients or patients with severe comorbidity cannot fulfill these exercise programs. Therefore, in these patients hospitalization is considerably longer and restoration of functional status is delayed. To the best of our knowledge, the effect of intensive training after an total joint arthroplasty in patients with multiple joint disease has never been studied before. This randomized controlled trial selected 100 patients with multiple joint disease, who had been admitted to hospital for an elective hip or knee arthroplasty. The intervention group $(n=53)$ received intensive exercise training (IET) for three weeks in a dedicated resort; the control group $(n=47)$ was treated with usual care (UC). Outcomes were assessed at baseline and after 3, 13, 26, and 
52 weeks. Repeated measurement analyses were performed. After already three weeks, and continuing over one year, the patients in the IET group significantly benefited from the program with respect to physical function (HAQ), quality of life (SF36), functional ability and general health (MACTAR) as compared to the control group. The intensive training did not increase pain scores. With respect to baseline, both groups reported a clinically relevant improvement after one year. After one year, a higher percentage of the IET patients were able to climb stairs and come out of bed without any problems or devices. These patients also experienced fewer disabilities, especially for walking a distance of 100 meters. Also, with the separate question of the MACTAR on the patients' general physical functioning, after one year $84 \%$ of the IET group experienced a reasonable to good physical functioning compared to $63 \%$ of the UC group ( $\mathrm{p}=.021)$. This study demonstrates the beneficial effects (short-term as well as long-term) of a three week intensive exercise program for patients with impairments of multiple joints and with comorbidity, directly following a hospital stay after total joint replacement.

\section{GENERAL CONCLUSION}

This thesis reports on multidisciplinary care for arthritis patients immediately following their discharge from hospital. The perspective from the physical therapist is predominantly used. From the literature we concluded that intensive exercise therapy is effective and safe in arthritis patients independently of their disease activity. The hypothesis that the recovery of arthritis patients might benefit from a dedicated intensive training program in a safe and comfortable setting outside the hospital was the major goal of these studies. Therefore, we had to develop a training program as well as the necessary setting. In order to measure effects on physical condition we had to develop and validate a measurement instrument for patients with impairment of the lower extremities, since the majority of our patients would be physically impaired after discharge. We have shown that physical condition can also be measured in people with impairment of their lower extremities. Especially for patients with a THA or TKA, the arm crank ergometer is a good method to measure the physical condition directly after surgery. For this group, it is recommended to measure the physical condition also prior to surgery. 
Our randomized controlled trial, designed to study our major study question, showed that despite the difficulties related to this study, complex interventions are feasible. We showed that an intensive exercise program helped arthritis patients to regain physical fitness, function and quality of life faster than usual care. Unlike other literature, we found long-term effects (up to one year) after intensive training. Moreover, we showed that this intensive training program is costeffective. Since the majority of hospitalizations of arthritis patients is due to arthroplasty of the hip or knee, we performed a sub study on the prevalent elective invasive procedure. In these patients, repeated measurement analysis clearly revealed that intensive exercise following discharge benefits these patients by helping them to regain function rapidly.

Our studies clearly show that after hospitalization, arthritis patients may benefit lastingly from an intensive exercise program. This information broadens the increasing evidence that rest has no place in the treatment of arthritis patients. Moreover, our data suggest that not exercise alone but a broader therapeutic approach including principles from the field of patient education are necessary to obtain optimal results. Even more, our data show that the extra efforts and resources necessary for an intensive exercise program are compensated by subsequent savings, making the DAPPER exercise therapy (cost-)effective. 



\section{Chapter 8}

Samenvatting en algemene conclusie 


\section{SAMENVATTING}

Opname in het ziekenhuis is noodzakelijk bij een totale vervanging van een gewricht en bij een exacerbatie van reumatoïde artritis. Conservatieve behandelingen zijn gericht op het beheersen van de ziekteactiviteit en het verminderen van de pijn. Een gewrichtsvervangende operatie is noodzakelijk wanneer pijn of functionele beperkingen als gevolg van een beschadigd gewricht de activiteiten van het dagelijks leven ernstig beperken. Immobiliteit, voorafgaand aan en tijdens de ziekenhuisopname, leidt onherroepelijk tot een verslechtering van de spierkracht en de mobiliteit van de gewrichten, wat resulteert in een beperkt fysiek functioneren en kan eindigen in een vicieuze cirkel. Het verbeteren van het fysiek functioneren direct na een ziekenhuisopname is een grote uitdaging. De fysieke verbetering moet uiteindelijk leiden tot een betere kwaliteit van leven.

Sommige patiënten hebben een ernstige beperkte functionele capaciteit tijdens de ziekenhuisopname. Zodra ze medisch gezien uitbehandeld zijn, zijn ze niet in staat om direct naar huis te gaan. In deze gevallen is een snel herstel van functie en fysieke conditie nodig. Wij veronderstelden dat een toegewijde en korte training, onmiddellijk na de ziekenhuisopname, in een extramurale ambulante setting zoals een resort of hotel kan zorgen voor een snellere en betere functionaliteit van deze patiënten. We hebben de effecten en de kosten-effectiviteit bestudeerd van een trainingsprogramma voor patiënten met reumatoïde artritis en artrose, die opgenomen waren in het ziekenhuis wegens het opvlammen van de ontsteking in hun gewrichten of een gewrichtsvervangende heup of knie operatie.

In Hoofdstuk 2 wordt een overzicht gegeven van de bestaande kennis en theorieën met betrekking tot de behandeling van patiënten met reumatoïde artritis en artrose, vanuit het perspectief van de fysiotherapie. Er is sterk bewijs dat oefentherapie voor patiënten met reumatoïde artritis en artrose ten minste moet bestaan uit dynamische krachttraining en aerobe conditie training. Het trainen van de spierkracht moet minimaal twee keer per week gebeuren (bestaande uit 8-10 oefeningen waarbij verschillende spiergroepen worden gebruikt). De belasting van de spierkrachttraining is hierbij matig tot zwaar (d.w.z. 50-80\% van de maximale vrijwillige kracht). Aerobe conditietraining moet drie keer per week worden uitgevoerd voor een duur van 30-60 minuten per keer, met een matige tot zware intensiteit (d.w.z. 60-85\% van de maximale hartslag). Bovendien kan de 
oefentherapie worden uitgebreid met mobiliteit, balans of coördinatie oefeningen. Hoewel fysieke oefentherapie noodzakelijk is voor een fit lichaam, is het belangrijk om de patiënt bij de opbouw van de therapie te betrekken om zo het maximaal haalbare resultaat te bereiken. De voorkeuren en doelen, maar ook de problemen en angsten van de patiënt, zijn belangrijke uitgangspunten voor de samenstelling van de therapie. Als de patiënt gemotiveerd is, zal hij of zij de oefeningen blijven uitvoeren omdat hij of zij de relevantie van de oefeningen zal begrijpen. Het is ook belangrijk om de patiënt te betrekken bij het vinden van oplossingen voor zijn of haar alledaagse problemen, in samenwerking met de therapeut.

In Hoofdstuk 3 beschrijven we de validatie en betrouwbaarheid van een submaximale test op de armergometer. Tot op heden is het onvoldoende mogelijk om de fysieke conditie van een patiënt met een beperking aan de onderste ledematen te meten met een submaximale test. Daarom hebben we een submaximale test ontwikkeld om de conditie met een arm crack ergometer te meten. Er zijn tot op heden beperkte submaximale testen om de conditie te meten van de bovenste extremiteiten. De metingen werden proportioneel verdeeld over 30 gezonde vrijwilligers. Op basis van de intraclass correlatiecoëfficiënt (ICC) en de omvang van de verschillen tussen en binnen de personen, bleek dat er sprake is van een goede betrouwbaarheid van de submaximale test. Voor de test-hertest betrouwbaarheid was de ICC 0,76, de inter-observer betrouwbaarheid was 0,82 en de betrouwbaarheid tussen twee ergometers bedroeg 0,63. Gebleken is dat de armergometer een goed interne validatie heeft. Bovendien is de criterium validiteit ook getest, hierbij werd de berekende $\mathrm{VO}_{2}$ max tijdens de submaximale test op de armergometer vergeleken met fietsergometer. Tussen $\mathrm{VO}_{2}$ max op de arm -en fietsergometer werd een ICC van 0,64 gevonden. De resultaten van de submaximale test op de armergometer zijn betrouwbaar en valide ten opzichte van de fietsergometer. We hebben aangetoond dat de submaximale test op de armergometer geschikt is voor het meten van de fysieke fitheid bij gezonde mensen. We verwachten dat mensen met een beperking aan de onderste extremiteiten deze submaximale test op de armergometer ook kunnen gebruiken voor het meten van hun lichamelijke conditie.

Hoofdstuk 4 beschrijft de effecten van een trainingsprogramma bij artritis patiënten middels een gerandomiseerde gecontroleerde trial van de DAPPER studie (Disabled Arthritis Patients Post-hospitalization intensive Exercise Rehabilitation). 
De deelnemers waren patiënten met reumatoïde artritis of polyarticulaire artrose, die in het ziekenhuis zijn opgenomen in verband met een opvlamming van de reumatoïde artritis of een geplande heup-of knie-artroplastiek. Patiënten werden geselecteerd in vier Nederlandse ziekenhuizen. De interventie groep (IET) ontving direct na het ontslag uit het ziekenhuis drie weken intensieve oefentherapie in een hersteloord $(n=58)$, de controle groep (UC) werd behandeld met standaard beschikbare zorg volgens hun behandelend arts $(n=40)$. De mensen in de IET groep trainden twee keer per dag en circa 75 minuten per sessie onder begeleiding van een fysiotherapeut. De intensiteit was afhankelijk van de individuele mogelijkheden. De doelstellingen van de trainingssessies waren het verbeteren van de mobiliteit, spierkracht, balans, coördinatie, aerobe capaciteit en de activiteiten van het dagelijks leven. De therapie sessies werden zowel individueel als in groepsverband gegeven. Aanvullende voorlichting werd tweemaal per week gegeven, gebaseerd op zelfmanagement training voor artritis patiënten. De primaire uitkomstmaat was de Health Assessment Questionnaire (HAQ) die het herstel van de functie meet. Secundaire uitkomstmaten bestonden uit de Escola Paulista de Medicina-Range of Motion scales (EPM-ROM), de McMaster Toronto Artritis Patiënten Preferente Disability Questionnaire (MACTAR) en het Onderzoeks-en Developmet 36-item Health Survey (RAND-36). De IET groep verbeterde op alle uitkomstmaten sneller en beter ten opzichte van UC groep, behalve voor HRQoL (Health Related Quality of Life). Na drie weken was de IET groep significant meer verbeterd op de subschalen HAQ lopen en HAQ opstaan. Tot 52 weken na baseline, was de uitkomst voor de IET groep op de uitkomstmaten EPM-ROM en de MACTAR gunstiger vergeleken met de UC groep. Na drie weken was de IET groep aanzienlijk meer verbeterd op de MACTAR vergeleken met het UC groep: het gemiddelde verschil bedraagt $-5,5$ (95\% BI -8,4 tot -2,2). Na 26 weken, bleef het gemiddelde verschil bleef significant $(-5,2 ; 95 \% \mathrm{BI}-10,0$ tot $-0,34)$. Na 52 weken was het effect niet meer significant, echter, het gemiddelde verschil tussen beide groepen kan beschouwd worden als klinisch relevant in het voordeel van de interventie groep. Kortom, de DAPPER studie toont een verbeterd herstel van functie bij artritis patiënten als gevolg van een drie weken durende intensief trainingsprogramma direct na ontslag uit het ziekenhuis.

In Hoofdstuk 5 wordt de kosten-effectiviteitsanalyse beschreven, welke parallel is uitgevoerd aan het in hoofdstuk 4 beschreven onderzoek. De gegevens van de 
diverse kosten werden gedurende een jaar verzameld met behulp van maandelijkse vragenlijsten. Zowel de directe als indirecte medische kosten als niet-medische kosten werden meegenomen. De kosten en analyses werden daarbij beschreven vanuit het maatschappelijk perspectief en werden gewaardeerd in overeenstemming met de Nederlandse richtlijnen voor kostenonderzoek. De kosten zijn gebaseerd op het jaar 2003 en werden uitgedrukt in Euro's. Utiliteiten werden afgeleid van de Short Form 6D (SF-6D) en van de visueel analoge schaal (VAS) voor algemene gezondheid. Ze werden uitgedrukt in 'quality-adjusted life years' (QALYs). Utiliteiten verwijzen naar de voorkeuren die individuen of de samenleving kunnen hebben voor een bepaalde gezondheidstoestand en een waardering van de gezondheid van de patiënt, varieert van 0 (gelijk aan de dood) tot 1 (volledige gezondheid). Een QALY is een samengestelde index die zowel de effecten in termen van kwaliteit van leven omvat (utility) als de duur van de tijd in een dergelijke gezondheidstoestand. Resultaten uitgedrukt als functionele capaciteit werden berekend met behulp van HAQ MACTAR en EPM-ROM. De gemiddelde incrementele kosten per patiënt en studie periode werden berekend. De incrementele kosten-utility-ratio (ICER) werd berekend door de incrementele kosten van de IET-groep te delen door verkregen QALY's afkomstig van IET groep. De ICER wordt uitgedrukt in kosten per gewonnen QALY. De incrementele kosteneffectiviteitsverhouding (ICER) voor de metingen naar de functionele mogelijkheden werd berekend door de extra kosten voor de IET-groep te delen door de opgedane eenheden van de effectiviteit. Deze ICERs worden uitgedrukt als kosten per score punt. Alle 95\% betrouwbaarheidsintervallen (95\% CI) werden geschat door middel van dubbelzijdige bootstrapping. ICERs werden alleen berekend wanneer de verschillen tussen de groepen significant verschillend waren. Aangezien de tijdshorizon van deze studie een jaar was en er geen schattingsmodellen werden gebruikt, werden de resultaten van de kosten en de gezondheid niet verdisconteerd. De maandelijkse kostenvragenlijsten werden ingevuld door 85 patiënten (75\%, 50 IET en 35 UC). Negenentwintig patiënten (10 IET en 19 UC) hebben de vragenlijsten niet ingevuld. Echter, deze patiënten verschilden niet van de andere patiënten met betrekking tot geslacht, leeftijd, werk of opleidingsniveau. De VAS score persoonlijke gezondheid op basis van QALY's zijn in het voordeel van IET groep. Functie gerelateerde uitkomsten, zoals de MACTAR $(p<0,05)$ en de EPM-ROM $(p<0,01)$ laten statistische significante verschillen zien, 
gedurende de eerste zes maanden in het voordeel van de IET groep. Na een jaar follow-up zijn de kosten voor de intensieve oefentherapie $€ 718$ minder per patiënt. De ICER laat een daling zien in de gemiddelde totale kosten per QALY: in $70 \%$ van de gevallen is de interventie kostenbesparend. De kosten voor de interventie zijn laag en de controle groep heeft vooral in de eerste drie maanden meer directe zorg nodig. Tot slot, IET resulteert in een betere kwaliteit van leven tegen lagere kosten na een jaar. Met andere woorden, IET is de dominante strategie ten opzichte van de gebruikelijke zorg. Dit onderstreept de noodzaak voor de uitvoering van IET na ontslag uit het ziekenhuis bij patiënten met artritis.

Hoofdstuk 6 beschrijft een deelstudie van de DAPPER studie (zie hoofdstuk 4). Door de veroudering van de bevolking is er in toenemende mate behoefte aan totale gewrichtsvervangende operaties, met name voor knie- en heupgewrichten. Om de opnameduur in het ziekenhuis te beperken en de mogelijkheid te bieden om functioneel snel te herstellen, zijn in het verleden verschillende peri-operatieve trainingsprogramma's en klinische paden ontworpen. Echter, de patiënten met meer beperkingen, al dan niet in combinatie met comobiliteiten, zijn niet instaat deel te nemen aan deze trainingsprogramma's. Daarom zal bij deze patiënten de gemiddelde ziekenhuisopname langer zijn en het herstel van de functionele status langer duren. Voor zover bekend zijn de effecten van intensieve training bij deze doelgroep niet eerder onderzocht. In deze prospectieve gerandomiseerde gecontroleerde trial werden 100 artritis patiënten geselecteerd, met problemen aan meerdere gewrichten, die werden opgenomen in het ziekenhuis vanwege een electieve heup- of knie arthroplastiek. De interventie groep $(n=53)$ kreeg een intensieve fysieke training (IET) gedurende drie weken in een speciaal resort; de controle groep $(n=47)$ werd behandeld met de gebruikelijke zorg (UC). Resultaten werden beoordeeld rondom het ontslag uit het ziekenhuis (baseline) en na 3, 13, 26 en 52 weken. Herhaalde meting analyses (repeated measurement) werden hiervoor uitgevoerd. Na drie weken en gedurende een jaar, profiteren de patiënten in de IET groep significant van het programma ten opzichte van de controle groep, met betrekking tot de fysieke functie (HAQ), kwaliteit van leven (SF36), functionele capaciteit en de algemene gezondheid (MACTAR). Het intensieve trainingsprogramma zorgde in ieder geval niet voor een toename van pijn. Ten opzichte van baseline, laten beide groepen een klinisch relevante verbetering zien na een jaar. In de praktijk blijkt dat een hoger percentage van de IET patiënten in 
staat was om trap te lopen en uit bed te komen zonder problemen of hulp(middelen). Deze patiënten ervaren ook minder problemen met het lopen van een afstand van 100 meter. Ook met de afzonderlijke vraag van de MACTAR, over de ervaren 'algemene fysieke functie' over een jaar, ervaart $84 \%$ van de IET groep een redelijke tot goede fysieke functie ten opzichte van $63 \%$ in de UC groep $(\mathrm{p}=.021)$. Deze studie laat zonder twijfel de gunstige effecten zien van drie weken intensief trainen (zowel op korte termijn als de lange termijn) bij patiënten met aantasting van meerdere gewrichten en comobiliteiten direct na het verblijf in het ziekenhuis na een totale vervanging van het gewricht.

\section{ALGEMENE CONCLUSIE}

Dit proefschrift beschrijft de multidisciplinaire zorg voor patiënten met reumatoïde artritis en artrose onmiddellijk na het ontslag uit het ziekenhuis. Er wordt hierbij vooral vanuit het perspectief van de fysiotherapie gekeken. Uit de literatuur is bekend dat intensieve oefentherapie effectief en veilig is voor onze doelgroep en niet afhankelijk is van de ziekteactiviteit. In dit proefschrift hebben we onderzocht of patiënten met reumatoïde artritis en artrose kunnen profiteren van een speciale intensieve training, uitgevoerd in een veilige en comfortabele omgeving buiten het ziekenhuis. Daarvoor moesten we een trainingsprogramma ontwikkelen alsmede een geschikte locatie bepalen. Om de fysieke conditie te bepalen, hebben we een meetinstrument ontwikkeld en gevalideerd voor patiënten met beperkingen aan de onderste ledematen. Immers, het merendeel van onze patiënten was na het ontslag uit het ziekenhuis fysiek beperkt aan de onderste ledematen. We hebben aangetoond dat de fysieke conditie kan worden gemeten bij mensen met deze beperking. Vooral voor patiënten met een gewrichtsvervangende heup of knie operatie is de armergometer een goede methode om de fysieke conditie te meten direct na de operatie. Het verdient de voorkeur om de fysieke conditie bij deze doelgroep ook voorafgaand aan de operatie te meten. Onze gecontroleerde en gerandomiseerde studie laat zien dat een complexe interventie uitvoerbaar is. We hebben aangetoond dat het intensieve trainingsprogramma patiënten met reumatoïde artritis of artrose helpt om hun lichamelijke conditie, functie en kwaliteit van leven sneller te herwinnen dan met de standaard beschikbare zorg. In tegenstelling tot wat gemeld wordt in veel andere literatuur, vonden we in onze 
studie naast korte termijn effecten ook lange termijn effecten (tot een jaar) na het intensieve training programma. Bovendien hebben we aangetoond dat deze intensieve training kosteneffectief is. Bij patiënten met gewrichtsaandoeningen is het merendeel van de ziekenhuisopnames te wijten aan een heup- of knievervangende operatie, daarom hebben we een deelstudie uitgevoerd voor geplande heup en knie operaties. Bij deze patiëntgroep hebben herhaalde meting analyses duidelijk aangetoond dat intensieve training na ontslag ervoor zorgt dat de geopereerde patiënt sneller herstelt.

Onze studie resultaten laten duidelijk zien dat patiënten langdurig baat hebben bij het intensieve trainingsprogramma direct na de ziekenhuisopname. Deze resultaten bevestigen dat het voorschrijven van rust achterhaald is bij behandeling van patiënten met gewrichtsaandoeningen. Bovendien suggereren onze gegevens dat niet alleen oefening, maar ook een bredere therapeutische aanpak met inbegrip van de beginselen van patiëntenvoorlichting nodig zijn om optimale resultaten te verkrijgen. Het blijkt dat de extra inspanningen en middelen die nodig zijn voor het uitvoeren en realiseren van het intensieve trainingsprogramma worden gecompenseerd door de latere besparingen, waardoor de DAPPER studie (kosten-) effectief is. 


\section{Dankwoord}



De afgelopen jaren heb ik zeer veel mensen ontmoet. Velen zijn, direct en indirect, in werk of privé, betrokken geweest bij het promotietraject. Graag wil ik alle mensen die op enige manier een bijdrage hebben geleverd hiervoor hartelijk danken. Zonder hen was het onmogelijk geweest om dit proefschrift te voltooien. Een aantal van hen wil ik graag bij name noemen.

Allereerst de patiënten uit de omgeving Enschede, Almelo, Nijmegen en Zwolle. Ik waardeer jullie inzet enorm. Ik besef dat het voor velen een hele opgave was alle metingen en vragenlijsten te voltooien. Ook de familieleden en vrienden die jullie op enige wijze hebben geholpen wil ik bedanken.

Mart van de Laar, Beste Mart, ik wil je bedanken voor je kennis en inzicht als promotor. Dank voor jouw kritische, maar altijd constructieve commentaar. Vooral in de laatste fase waardeer ik je betrokkenheid, geduld, vertrouwen en inzet.

Wiepke Drossaers-Bakker, Beste Wiepke, ik wil je bedanken voor je bijdrage als copromotor. Wat me bij is gebleven dat jij vooral actief was in de vroege ochtend en ik bij voorkeur laat in de avond. Bedankt dat ik je naast je werk als reumatoloog en je gezinsleven altijd om hulp mocht vragen.

De afdelingen orthopedie en reumatologie van het Medisch Spectrum Twente in Enschede, Ziekenhuisgroep Twente in Hengelo en Almelo, Isala kliniek, locatie Weezenlanden in Zwolle en de Sint Maartenskliniek in Nijmegen hebben het mogelijk gemaakt dat er patiënten konden instromen voor de DAPPER studie. De specialisten die mede hebben bijgedragen aan de implementatie op de afdeling in hun ziekenhuis zijn: Paul van 't Padbosch, Niek Tulp, Stef Zaanen, Remco Karthaus, Elgun Zeegers, Ans Oostveen, Hein Moens, Cees Haagsma, Ina Kuper en Marijn Kruijser. Het was plezierig met jullie samen te werken. Paul, Elgun en Ans bedankt voor jullie bijdrage aan de artikelen. Verder wil ik alle verpleegkundigen, artsen, afdelingssecretaresses, afdelingshoofden en fysiotherapeuten bedanken voor hun bijdrage rondom de inclusie, het ontslag en de planning rondom de onderzoeksmetingen.

Het team van 'Groot Stokkert', Cees Bol, Gert-Jan Logtenberg, Elly van der Meulen, dhr. Boelen, medewerkers van de verzorging, verpleging en het restaurant wil ik bedanken voor de goede zorgen, beschikbaarheid van kamers en fitness faciliteiten. Beste Elly, zonder jouw inzet was de opvang van patiënten nooit zo snel en soepel verlopen. Samen vormden we een fantastisch team qua logistiek. Stef Zaanen bedankt voor je beschikbaarheid bij acuut medische problemen. 
Zonder de stagiaires fysiotherapie van de Saxion Hogeschool was de intensieve oefentherapie niet mogelijk geweest. Ralph, Annemieke, Anneke, Doenja, Mariëlle, Christine, Eelco, Marlon, Allard, Femke, Dinja en Joan, ik vond het erg leuk om met jullie te werken. Ik hoop dat jullie genoten hebben van deze bijzondere stage.

Frits Oosterveld, bedankt voor de continuïteit van bekwame stagiaires fysiotherapie, alsmede de studenten voor het onderzoek van de armergometer. En voor je aanvullend commentaar en belangstelling voor mijn onderzoek.

Job van der Palen, Beste Job, het was altijd mogelijk alle epidemiologische, statistische vraagstukken en analyse technieken met je te bespreken. Je hebt mijn kennis en vaardigheden op dit gebied zeker verruimd, heerlijk! Je enthousiasme voor onderzoek en analyses waren aanstekelijk. Je zette me aan het denken en gaf me vertrouwen en kracht om verder te gaan.

Alle collega's van de polikliniek reumatologie van het Medisch Spectrum Twente en de 'reumagroep Twente', bedankt voor jullie ondersteuning, collegialiteit, gezelligheid en kennisoverdracht. Annet ter Avest en Anita Mooy, jullie ondersteuning bij de diverse metingen als researchsverpleegkundigen was zeer waardevol. Fijn dat ik altijd bij jullie terecht kon. Hans Rasker, Beste Hans ik heb je enthousiasme en interesse erg gewaardeerd.

De 'Tenderpoints', Theo Zijlstra, Ellen Dutmer, Harald Vonkeman, Monique Hoekstra, Hetty Baan, Ramon Voorneman en Erna Barendregt, ik heb genoten van de voorbereidingen voor diverse optredens. Ik ben benieuwd of jullie iets voor mij in petto hebben. Hetty, ik kom graag nog een keer voor jou in actie, zet hem op ik weet dat je het kunt! Theo, Ellen, Monique en Harald, ik vond het fijn dat ik als kamergenoot zowel wetenschappelijk als persoonlijk lief en leed met jullie heb mogen delen. Harald, bedankt voor je enorm motiverende rol, Engelstalige deskundigheid en het feit dat je mijn paranimf wil zijn!

De collega's van de Universiteit Twente, faculteit gedragswetenschappen van de vakgroep PCGR, bedankt voor jullie collegialiteit, ondersteuning en gezelligheid. Erik Taal, bedankt voor je kritische blik, je deskundigheid op het gebied van psychosociale factoren en je gezelschap tijdens congressen. Annemarie BraakmanJanssen, Beste Annemarie, ik vond het bijzonder fijn en gezellig om samen met jou te brainstormen en discussiëren over de opzet van het artikel. Bedankt voor de kennis en ervaring op het gebied van kosten onderzoek. Somaya Ben Allouch, je gezelligheid en steun in de laatste fase waren waardevol! 
De 'refereergroep Twente', ondanks dat de onderwerpen over epidemiologie en statistiek soms pittig waren, denk ik terug aan interessante en leerzame bijkomsten, mede door de plezierige samenstelling van de groep.

Sabrina Mohammed, het was prettig om samen de kostendata te bewerken. Het was een tijdrovende en nauwkeurige klus.

Sanne Leerling, bedankt voor het scannen en digitaliseren van de vele vragenlijsten. Daan ter Keurs, bedankt voor je inzet.

Paul van der Valk, Betty Rinsma en de 'dames van het kippenhok' wil ik in het bijzonder bedanken voor de gezellige en ontspannen werksfeer tijdens het ontwerpen, controleren en scannen van de vragenlijsten op de poli longfunctie.

Het 'promovendi clubje', Beste Lieke, Tanja, Marjolein, Martine, Evelien, Astrid, zowel jullie persoonlijke als wetenschappelijke ondersteuning is van onschatbare waarde! Ik hoop dat we in de toekomst nog veel voor elkaar kunnen betekenen. Beste Martine, je hebt vanaf de zijlijn het gehele onderzoekstraject van begin tot eind meegemaakt, fijn dat je mijn paranimf wil zijn! Beste Tanja, jammer dat je niet bij de plechtigheid kan zijn. Ik wens je veel sterkte toe!!

Nicole Herink, lieve nicht, zonder jouw hulp was de omslag van dit boekje niet zo mooi geworden.

Lieve vrienden, jullie medeleven, belangstelling, humor, gezelligheid en steun gaven mij kracht en energie. Ik heb genoten van de allerlei momenten zoals feestjes, uitjes, sporten (turnen, fitness, tennis), boswandelingen, carnavalsbijeenkomsten en vakanties. Laten we vooral doorgaan met genieten van de kleine simpele dingen in het leven.

Lieve pap en mam, jullie zijn van onschatbare waarde, jullie gaven mij onvoorwaardelijke liefde en steun. Vanaf nu gelukkig weer meer tijd voor elkaar! Daniel, zonder jouw liefde en steun was het niet gelukt! $\odot$ 



\section{Curriculum Vitae}



Yvette Bulthuis werd op 11 mei 1974 geboren te Losser. Zij behaalde in 1991 haar HAVO diploma aan het Twents Carmellyceum te Oldenzaal. In 1995 voltooide zij haar studie Fysiotherapie aan de Hogeschool Enschede, met een extra aantekening op het gebied van hydrotherapie bij reumapatiënten en sensomotorische tests. In hetzelfde jaar begon ze met de studie Bewegingswetenschappen aan de Faculteit Psychologie, Pedagogiek en Sociale Wetenschappen van de Rijksuniversiteit Groningen. Tijdens haar studie bewegingswetenschappen was ze mede werkzaam als fysiotherapeut bij het sportcentrum van de Universiteit Groningen en in de zomermaanden als fysiotherapeut in diverse fysiotherapie praktijken in de regio Twente. Na haar afstudeeropdracht bij Roessingh Research \& Development in Enschede behaalde ze in 1998 haar doctoraal examen Pedagodiek in de afstudeerrichting bewegingsopvoeding en- behandeling met als differentiatie revalidatie en gehandicaptenzorg.

$\mathrm{Na}$ het afronden van de studie heeft ze enige tijd een gecombineerde baan gehad als fysiotherapeut en onderzoekster. Als fysiotherapeut heeft ze eind jaren 90 ervaring en kennis op gedaan bij de Zorg- en preventie centra Twente (met name het trainingen van groepen en individuen) en bij Het Revalidatiecentrum Het Roessingh (hoofdzakelijk de behandeling van CVA patiënten). Als onderzoeker is ze bij Roessingh Research \& Development drie jaar betrokken geweest bij diverse onderzoeken op het gebied van EMG, functionele elektrostimulatie en het gebruik van virtual reality binnen revalidatie.

Van medio 2001 tot begin 2010 is ze parttime als algemeen coördinator (manager) werkzaam geweest bij het Sportmedisch Adviescentrum Oost. In 2002 is zij parttime gestart bij Reumacentrum Twente (Medisch Spectrum Twente \& Universiteit Twente te Enschede) met het onderzoek dat in dit proefschrift staat beschreven. Sinds april 2010 is zij werkzaam als adviseur bij de organisatie ROSET (Regionale Ondersteunings Structuur voor de Eerstelijnszorg in Twente). Zij is getrouwd met Daniel Roetenberg. 



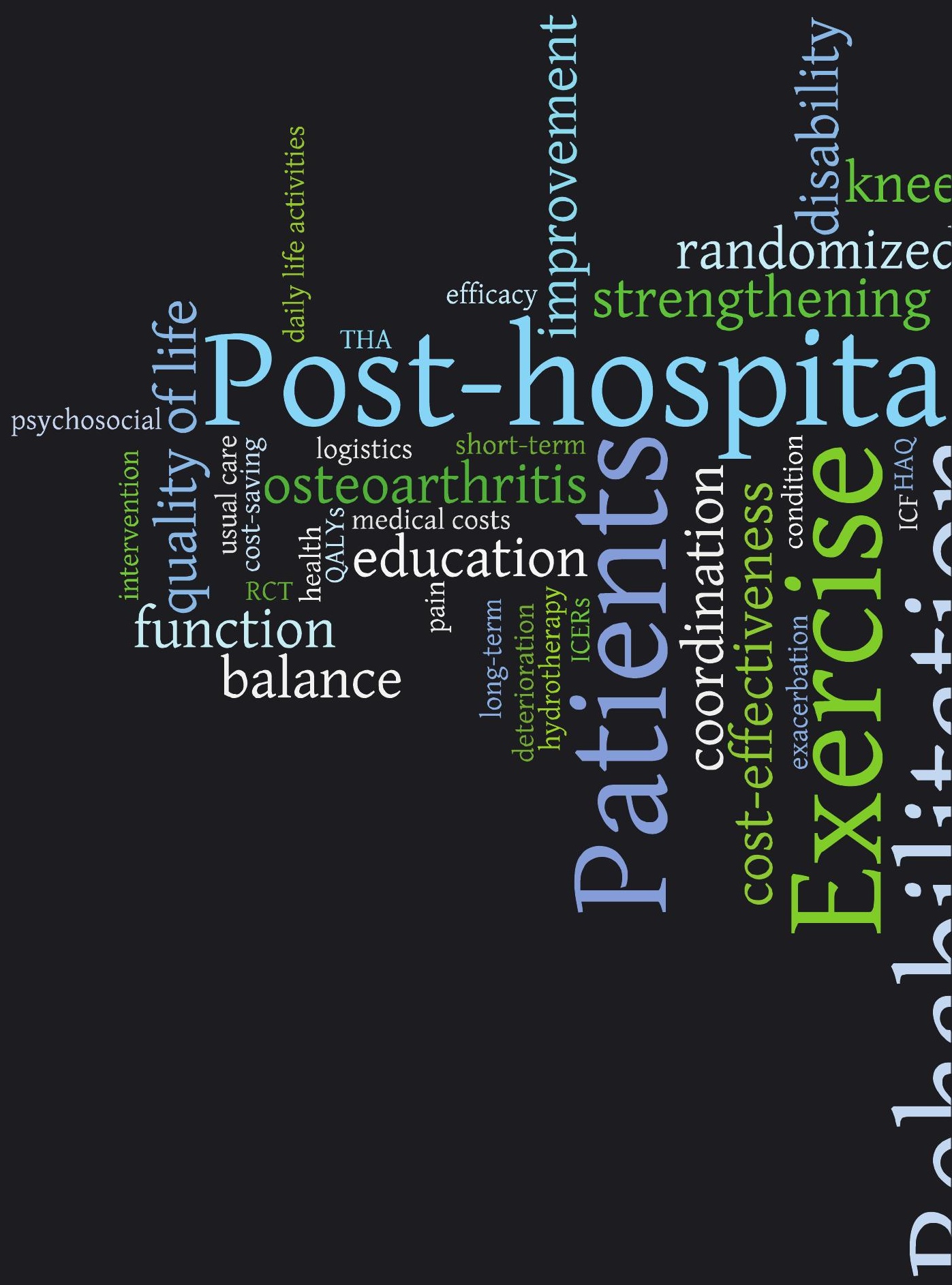

